\title{
Avaliação de Desempenho de uma Ferramenta para Simulação Distribuída Baseada no Protocolo Otimista Time Warp
}

\author{
Mara Andrea Dota
}

Orientador:

Prof Dr. Marcos José Santana

Dissertação apresentada ao Instituto de Ciências Matemáticas e de Computação ICMC-USP, como parte dos requisitos para obtenção do titulo de Mestre em Ciências de Computação e Matemática Computacional.

\section{USP - São Carlos \\ Julho/2001}

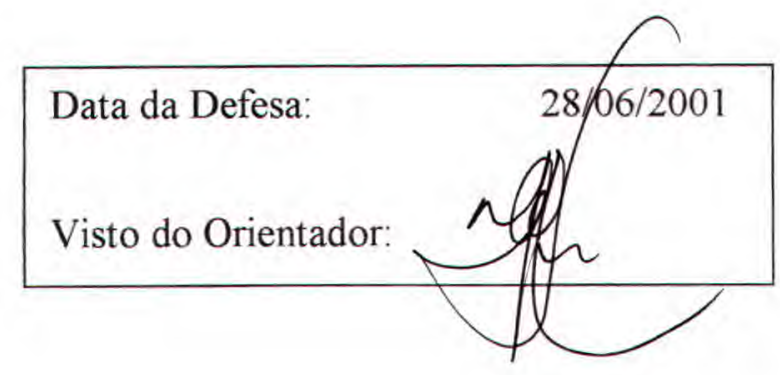


"Vá tão longe quanto possa ver. Quando chegar lá, você poderá ver ainda mais longe." 
Dedico este trabalho a meus pais, Milton e Maria, pela dedicação, apoio e incentivo para que isso fosse possivel. 


\section{Agradecimentos}

A Deus, por estar sempre ao meu lado e me guiar em todos os momentos da minha vida.

Ao Prof. Dr. Marcos José Santana, pela oportunidade, orientação e atenção dedicadas a este trabalho e a mim.

À Prof $^{a} \operatorname{Dr}^{a}$ Regina Helena C. Santana, pelas valiosas contribuições e sugestões que foram de grande importância para o fechamento do trabalho.

Aos meus pais e meus irmãos, por todo apoio e compreensão que me deram, ajudando-me sempre a superar as dificuldades que encontrei aqui em São Carlos.

A todos do LaSDPC, sem exceção, pela ajuda e atenção em todas as horas.

À Prof ${ }^{a} \operatorname{Dr}^{\mathrm{a}}$ Roberta S. Ulson, pelo seu incentivo e ajuda.

Ao Rômulo, pelo seu carinho e ajuda em todos os momentos.

A todos os meus colegas do ICMC, pela amizade e palavras de incentivo. Ao meu amigo André, pelo incentivo nas horas difíceis e por sua amizade sempre presente.

Ao LCAD, pela utilização da máquina SPP3.

Ao CNPq, pelo apoio financeiro. 


\section{Sumário}

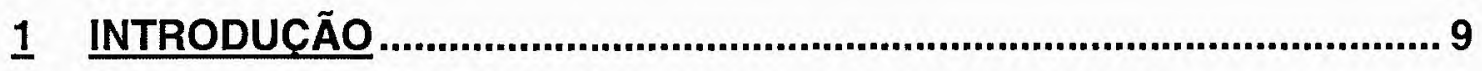

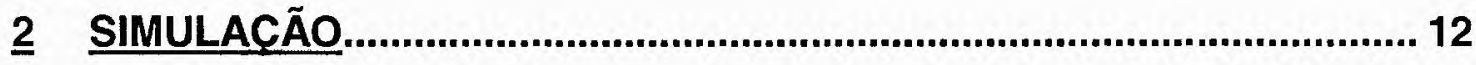

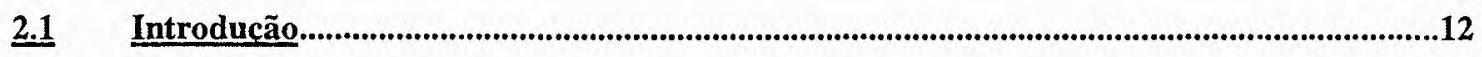

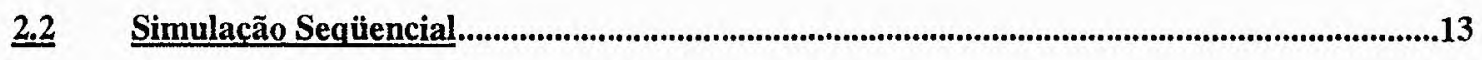

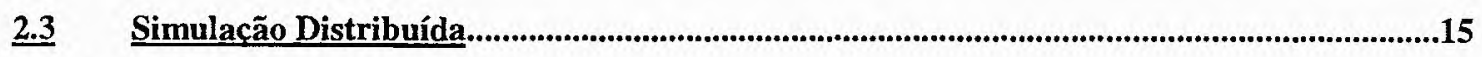

2.3.1 Decomposição da Simulação..............................................................................................19

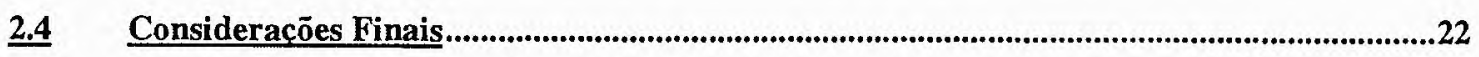

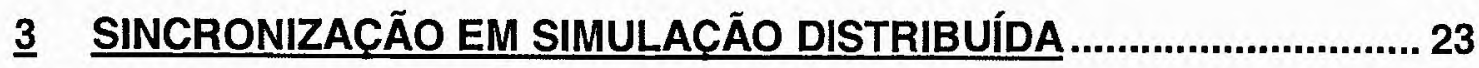

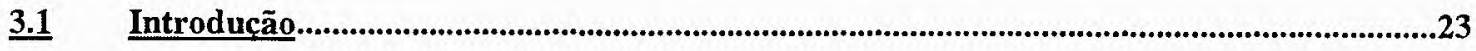

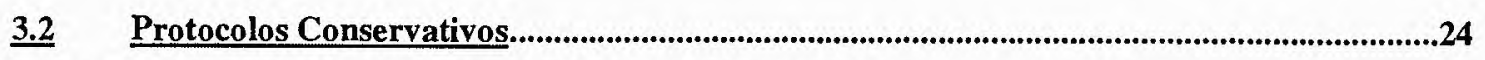

3.2.1 Protocolo CMB (Prevenção do Deadlock utilizando mensagens nulas)...................................25

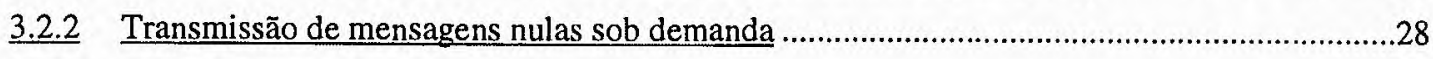

3.2.3 Detecção e recuperação do Deadlock ....................................................................................

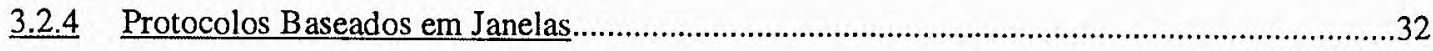

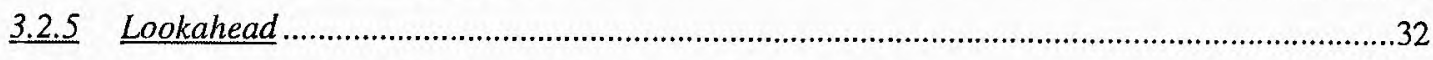

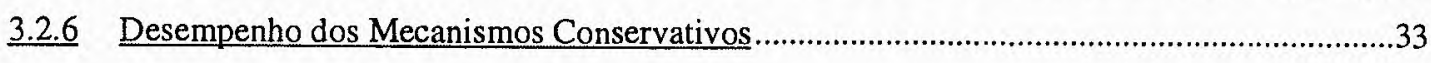

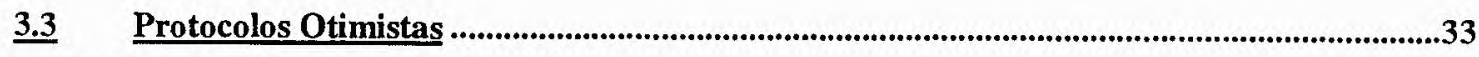

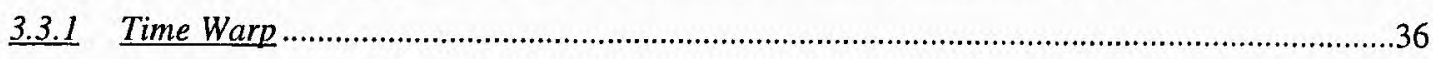

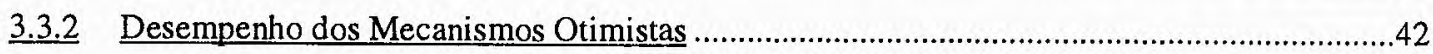

3.4 Comparacão entre os Mecanismos Conservativo e Otimista..................................................44

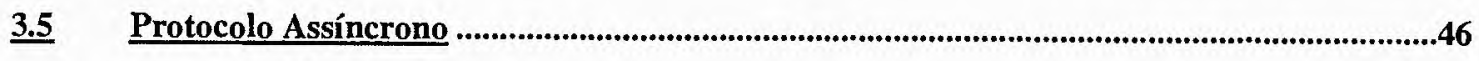

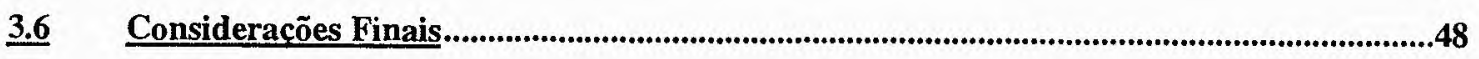

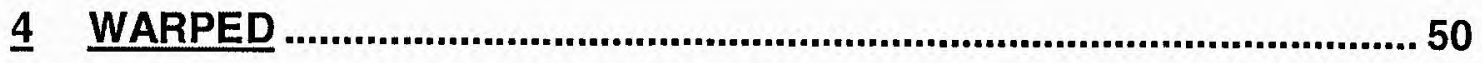




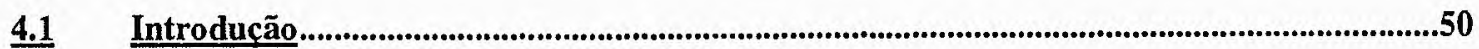

4.2 Interface de Programacão da Aplicacão (API) do WARPED ...................................................53

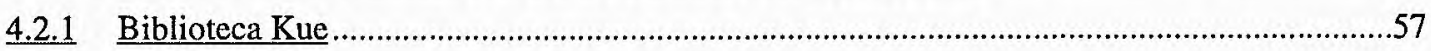

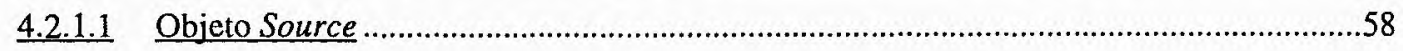

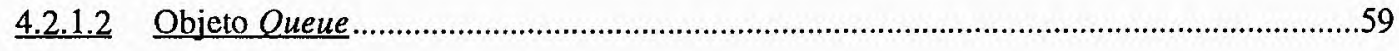

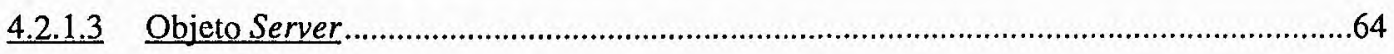

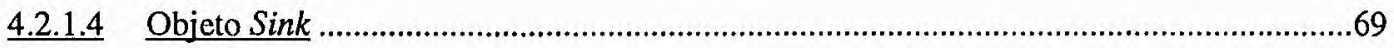

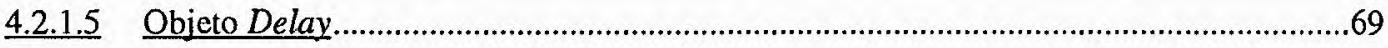

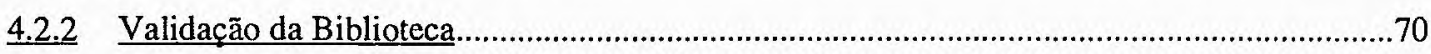

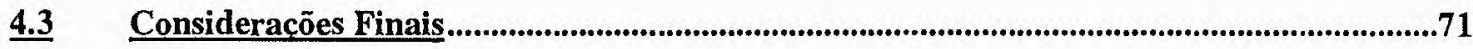

$\underline{5}$ AVALIACÃO DE DESEMPENHO DE ALGUNS MODELOS NO WARPED 73

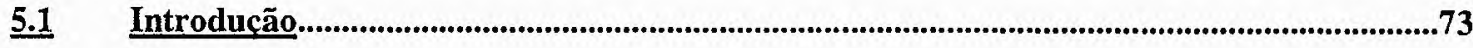

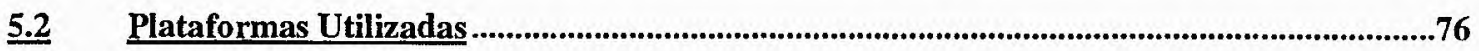

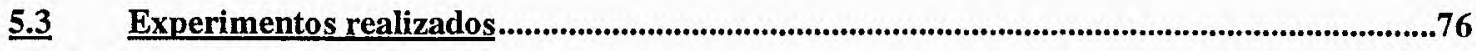

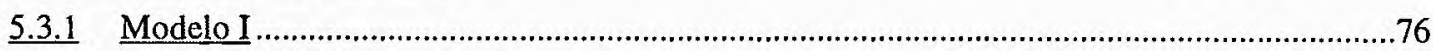

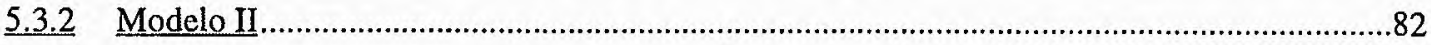

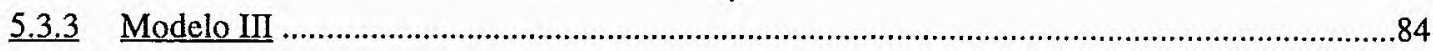

5.4 Efeitos da Granulosidade e da Comunicacão entre Processos Lógicos ..................................87

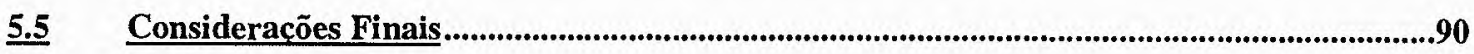

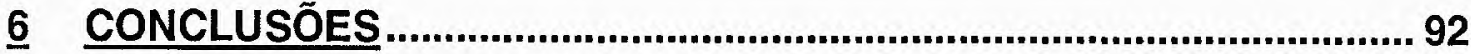

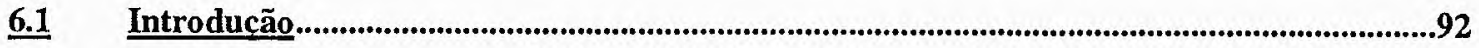

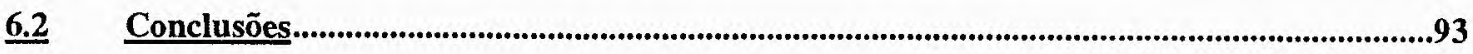

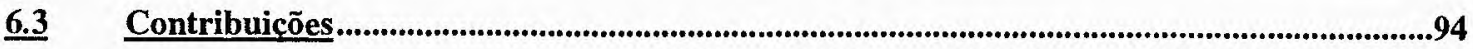

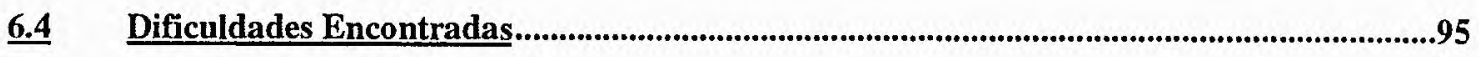

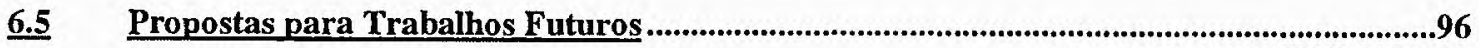




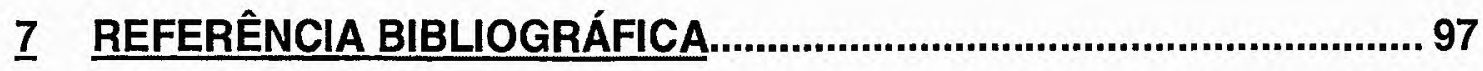




\section{Índice de Figuras}

Figura 2-1 Arquitetura de uma simulação de Processos Lógicos................................................15

Figura 2-2 Estrutura de um sistema de simulação. ........................................................................ 16

Figura 2-3 Erro de causa e efeito............................................................................................................ 17

Figura 2-4 Simulacão Distribuída de dois LPs.................................................................................19

Figura 2-5 (a) Gráfico tempo-espaç. A execucão da simulacão (tempo $=0$.. t ) é equivalente a preencher a área sombreada. (b) Decomposicão pelo tempo. (c) Decomposicão pelo espaco. ....................................................................................................................................... 21

Figura 3-1 LVT de um processo. ...........................................................................................................26

Figura 3-2 Situacão de Deadlock. .............................................................................................................. 27

Figura 3-3 Transmissão de mensagem nula sob demanda (1) ....................................................... 29

Figura 3-4 Transmissão de mensagem nula sob demanda (2) ......................................................30

Figura 3-5 Relacão entre os valores de tempo da simulacão. …………..........................................4 41

Figura 3-6 Arquitetura do NoTime, ..........................................................................................................4 48

Figura 4-1 Organizacão de um sistema modelado no WARPED. ................................................51

Figura 4-2 Processo Lógico. ..................................................................................................................52

Figura 4-3 API do WARPED......................................................................................................5

Figura 5-1 M/M/1 representando um Servidor de Arquivos.........................................................74

Figura 5-2 Modelo I : MM1 ................................................................................................................. 74

Figura 5-3 Modelo II: Servidor de Arquivos.................................................................................75

Figura 5-4 Modelo III: Servidor de Arquivos com PFE ................................................................... 75

Figura 5-5 Organizacão do Modelo I no WARPED. ...............................................................76

Figura 5-6 Estrutura de dados da multilista. ........................................................................................ 79

Figura 5-7 Organizacão do Modelo II no WARPED.............................................................. 83

Figura 5-8 Modelo II - configuracão 2 ......................................................................................... 83

Figura 5-9 Modelo II - configuracão 3 ............................................................................................ 83

Figura 5-10 Organizacão do Modelo III no WARPED................................................................. 84

Figura 5-11 Modelo III - configuracão 2................................................................................ 85

Figura 5-12 Modelo III - configuracão 3.................................................................................8

Figura 5-13 Modelo III - configuracão 4.............................................................................................. 86

Figura 5-14 Modelo III - configuracão 5...................................................................................86 


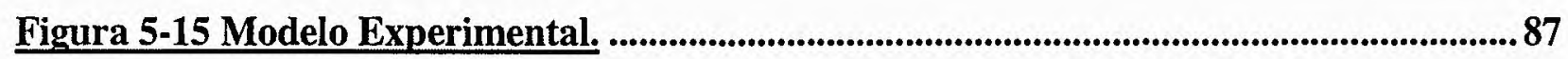

Figura 5-16 Gráfico com os valores de speedup....................................................................................89 


\section{Índice de Tabelas}

Tabela 1 Comparacão das características dos protocolos Conservativos e Otimistas. ......... 45

Tabela 2 Exemplo de um arquivo main.cc....................................................................................5 56

Tabela 3 Criacão de uma instancia do objeto source....................................................................55

Tabela 4 Código do objeto queue versão original. ..........................................................................59

Tabela 5 Código do objeto queue da biblioteca KUE versão nova..........................................60

Tabela 6 Criacão de uma instância do objeto queue. ...........................................................6 63

Tabela 7 Código do objeto server da biblioteca KUE versão original.................................... 64

Tabela 8 Código do objeto server da biblioteca KUE versão nova...........................................66

Tabela 9 Criacão de uma instância do objeto server. ..........................................................69

Tabela 10 Criação de uma instância do objeto sink ..............................................................69

Tabela 11 Criacão de uma instância do objeto delay.....................................................................70

Tabela 12 Resultados obtidos com o modelo 1.......................................................................70

Tabela 13 Resultados obtidos com o modelo 2 (a). …...................................................................71

Tabela 14 Resultados obtidos com o modelo 2 (b) ....................................................................71

Tabela 15 Modelo I: tempos de execucão. …..........................................................................77

Tabela 16 Tempos do ciclo da simulação do Modelo I - configuracão 1.................................77

Tabela 17 Tempo médio de envio de mensagens remotas - Ethernet.......................................80

Tabela 18 Tempo Médio de envio de mensagens remotas - SPP3 . ......................................80

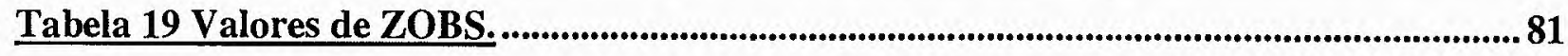

Tabela 20 Modelo II - tempos de execucão. ..............................................................................84

Tabela 21 Modelo III - tempos de execucão. .........................................................................86

Tabela 22 Modelo Experimental - Granulosidade 1 - tempos de execucão.............................88

Tabela 23 Modelo Experimental - Granulosidade 1 - Speedup. ...........................................88

Tabela 24 Modelo Experimental - Granulosidade 2 - tempo de execucão............................. 88

Tabela 25 Modelo Experimental - Granulosidade 2 - Speedup................................................88 


\section{Resumo}

A avaliação de desempenho de sistemas computacionais tem constituído uma área de grande investigação ao longo das últimas décadas. Dentre as diversas ferramentas e técnicas disponíveis para esse propósito, a simulação se destaca por ser flexível, podendo ser utilizada em várias situações e por oferecer soluções a um custo relativamente atrativo.

O objetivo deste trabalho é avaliar o desempenho da ferramenta WARPED para simulação distribuída, através de alguns modelos de Redes de Filas. O WARPED é um simulador distribuído otimista que implementa o paradigma de Virtual Time, tendo sido escolhido por permitir a execução de simulações tanto em um sistema distribuído, como em uma máquina paralela, e por ser um software livre (código aberto).

O projeto WARPED implementa um núcleo para o simulador Time Warp, livremente disponível, de fácil portabilidade, simples de se modificar e de ser estendido. O sistema foi escrito em C++ (GNU C++), orientado a objeto e utiliza o MPI (Message Passing Interface) para troca de mensagens entre os processos distribuídos.

Nos experimentos realizados neste trabalho, foi observado que aumentando-se a granulosidade dos modelos, speedup pode ser alcançado com a simulação distribuída. A comunicação entre processos fisicamente separados pode sobrecarregar a execução da simulação distribuída, podendo mesmo inviabilizar sua utilização. Por isso, a partição do modelo de simulação deve ser feita considerando-se as características do modelo e da arquitetura de hardware que será usada.

Em geral, deve-se tentar minimizar a necessidade de comunicação e submeter aos processadores uma carga de trabalho de tamanho adequado, explorando granulosidades de média a grossa. No caso estudado, o próprio sistema de passagem de mensagens (MPICH) introduz sobrecargas difíceis de serem contornadas.

Modelos simples dificilmente levarão a ganho de desempenho, sendo preferido o uso da simulação seqüencial. Modelos de complexidade média podem obter ganhos de desempenho, desde que haja um balanceamento cauteloso entre a granulosidade dos processos lógicos e a necessidade de comunicação entre processos alocados em máquinas distintas.

Apesar de nem sempre ser fácil obter-se speedup com as simulações distribuídas, adotando-se a granulosidade adequada e minimizando-se a comunicação, bons resultados podem ser sempre esperados. 


\section{Abstract}

The performance evaluation of computer systems has been an area of large investigation over the last decades. Among the several tools and techniques available for that purpose, simulation stands out for being flexible, able of being used in various situations and for offering solutions at a relatively attractive cost.

The goal of this work is to evaluate the WARPED tool performance for distributed simulation with some Queuing Networks models. WARPED is a distributed optimist simulator that implements the Virtual Time paradigm and it was chosen for allowing the execution of simulations in both distributed systems and parallel machines and also for being a free software (open code).

The WARPED project implements a kernel for the Time Warp simulator, freely available, easily portable and simple to modify and to extend. The system was written in the C++ language (GNU C++), it is object oriented and it uses the MPI (Message Passing Interface) for exchanging messages among the distributed processes.

It was experimentally observed that increasing the model granularity, speedup can be reached with the distributed simulation. The communication among physically separated processes may overload the distributed simulation execution making it unfeasible. Therefore, the simulation model partitioning must be made considering characteristics of the model and the hardware architecture being used.

In general terms, the need for communication should be minimized while submitting to the processors an appropriate size of workload, exploring medium up to coarse granularity. In the current case study, the message passing system (MPICH) also introduces high overloads. Simple models will hardly obtain good performance with distributed simulation; in this case it is generally preferred the use of sequential simulation. Models of medium complexity may obtain good performance since there is a cautious balancing between logical process granularity and communication needs among processes allocated to different machines.

Although it is not always easy to obtain speedup with distributed simulations, adopting an appropriate granularity and minimizing the communication needs, good results can always be expected. 


\section{Capítulo 1}

Introdução

A avaliação de desempenho de sistemas computacionais tem constituído uma área de grande investigação ao longo das últimas décadas. Dentre as diversas ferramentas e técnicas disponíveis para esse propósito, a simulação se destaca por ser flexível, podendo ser utilizada em várias situações e por oferecer soluções a um custo relativamente atrativo [ULS97][ULS99].

A simulação pode ser executada de maneira seqüencial ou distribuída. A simulação seqüencial tende a ser mais lenta e inadequada para modelos detalhados de grande porte. Nesse caso, a simulação distribuída poder ser utilizada, reduzindo o tempo de execução através da paralelização da simulação.

O problema fundamental da simulação distribuída é a sincronização entre os eventos paralelos que devem obedecer à restrição de causa e efeito imposta pela ordem sequiencial do sistema real. Assim, vários mecanismos de sincronização têm sido desenvolvidos para prevenir erros de causa e efeito e, basicamente, classificam-se em conservativos e otimistas.

Os protocolos conservativos evitam a possibilidade de ocorrência de erros de causa e efeito, determinando quando é seguro processar um evento. Os protocolos otimistas utilizam uma estratégia de detecção e recuperação de erros; erros de causa e efeito são detectados e um mecanismo de rollback é utilizado para a recuperação. 
A necessidade de sincronização dentro da simulação introduz sobrecargas que aumentam o tempo de execução. Uma abordagem assíncrona que tenta minimizar essas sobrecargas adota um comportamento anarquista ${ }^{1}$ [RAO98] [THO99]. Esse protocolo não trata os erros de causa e efeito que eventualmente ocorrem na execução da simulação, simplesmente ignora-os, fornecendo resultados aproximados e tempo de execução mais rápido. Porém, nem todo sistema modelado pode ser simulado com sucesso utilizando essa abordagem.

Considerando-se a variedade de mecanismos para sincronização, uma questão importante na simulação distribuída está na decisão de qual protocolo deve ser empregado para a simulação de um sistema, resultando em uma implementação eficiente.

A simulação distribuída, ou SRIP (Single Replication in Parallel) é composta por processos lógicos os quais se comunicam através de mensagens [BRU97]. Outra alternativa para diminuir o tempo de simulação é a técnica conhecida como Multiple Replications in Parallel, ou MRIP. Nesta técnica, independentes replicações do programa de simulação são executadas em paralelo. Cada replicação fornece seus resultados para um analisador global, onde as médias finais são calculadas. É importante ressaltar que cada replicação é alimentada por diferentes sementes de números aleatórios o que garante que os resultados gerados são estatisticamente independentes.

O objetivo deste trabalho é avaliar o desempenho da ferramenta WARPED para simulação distribuída, através de alguns modelos de Redes de Filas. O WARPED é um simulador distribuído otimista que implementa o paradigma do Virtual Time definido por [JEF85] e foi escolhido por permitir a execução de simulações tanto em um sistema distribuído como em uma "máquina paralela", e por ser um software livre (código aberto). O projeto WARPED é uma tentativa de se implementar um núcleo do simulador Time Warp, livremente disponível, que seja de fácil portabilidade, simples de se modificar e de ser estendido [RAD98, RAD99]. O sistema foi escrito em $\mathrm{C}++$ (GNU C++), orientado a objeto e utiliza o MPI (Message Passing Interface) [ARG98] para troca de mensagens entre os processos distribuídos.

${ }^{1}$ O termo Anarquista é uma denominação sugerida neste trabalho e está relacionada ao relaxamento da sincronização. Esse termo será utilizado nesse trabalho fazendo-se referência a simulação assíncrona. 
A monografia está organizada da seguinte forma: o Capítulo 2 apresenta as definições de simulação seqüencial e simulação distribuída, distingüindo suas características e levantando os problemas relacionados às suas aplicações. O Capítulo 3 traz a classificação dos mecanismos de sincronização na simulação distribuída, alguns protocolos já desenvolvidos baseados nessa classificação e uma comparação entre esses mecanismos.

O Capítulo 4 apresenta uma descrição geral do WARPED e as modificações realizadas na biblioteca KUE (biblioteca para a construção de modelos de Redes de Filas) para a sua utilização. No Capitulo 5, são descritos os modelos de Redes de Filas usados para os teste do simulador e os resultados obtidos. As conclusões sobre o trabalho são feitas no Capitulo 6. 


\section{Capítulo 2}

Simulação

Este capítulo apresenta as principais questões relacionadas à simulação, estando organizado nos seguintes tópicos: introdução, simulação seqüencial, simulação distribuída e considerações finais.

\subsection{Introdução}

A simulação é uma técnica de modelagem utilizada na avaliação e análise de sistemas físicos. Na área de avaliação de desempenho de sistemas computacionais, é uma ferramenta que tem se destacado pela sua flexibilidade e baixo custo. Por exemplo, a construção de protótipos de sistemas físicos consome tempo e tem custos altos; por outro lado, a modelagem de um sistema para a simulação fornece resultados próximos da realidade em um tempo menor e com custos baixos.

Tradicionalmente, os programas de simulação têm sido desenvolvidos através de técnicas seqüenciais. Porém, a complexidade de um sistema pode gerar um modelo de simulação muito grande, exigindo muita memória e tempo de processamento para que a simulação obtenha resultados confiáveis. Nesse caso, a simulação seqüencial pode levar muitas horas ou dias de processamento, tornando-se inviável. 
A simulação distribuída é empregada para diminuir o esforço computacional de simulações realísticas, fornecendo resultados confiáveis em um tempo de processamento significativamente mais rápido do que a seqüencial [ULS97]. A simulação distribuída é baseada na decomposição do modelo de simulação em processos lógicos, executados em diversos processadores e comunicando-se entre si através de ambientes de passagem de mensagens.

O problema crítico desse tipo de simulação é a sincronização dos vários processos que compõe a simulação. A execução da simulação deve obedecer à ordem seqüencial imposta pelo sistema real, a restrição de causa e efeito. Visando solucionar esse problema, vários protocolos de sincronização têm sido desenvolvidos e alguns deles serão apresentados no próximo capítulo.

A simulação distribuída oferece vantagens em relação à seqüencial, incluindo maior escalabilidade e melhor desempenho. Além do speedup, requer pouca memória adicional para a execução comparada com a seqüencial, exige pouco controle global exercido por qualquer máquina e a simulação de um sistema pode ser adaptada à estrutura do hardware disponível (com poucas máquinas, diversos processos físicos podem ser simulados em um único processador) [ULS99] [MIS86] [FUJ90] [FUJ90a].

\subsection{Simulação Seqüencial}

A simulação seqüencial de um sistema consiste na modelagem das entidades físicas ${ }^{2}$ do sistema e das interações entre elas, através de eventos que modificam os estados do sistema. Três estruturas de dados básicas são utilizadas [OVE91]:

- Variáveis de estado que descrevem o estado do sistema;

- Lista de eventos futuros que contém todos os eventos pendentes que foram escalonados para a execução;

- Relógio global que controla o progresso da simulação.

${ }^{2}$ Entidades físicas são objetos ou componentes de um sistema que necessitam ser representados explicitamente no modelo de simulação. 
Cada evento possui um timestamp e determina alguma mudança do estado do sistema que está sendo simulado. O timestamp determina quando essa mudança deve ocorrer. Os passos do programa de simulação, fundamentalmente, são os seguintes [THO98]:

1. Selecionar o evento de menor timestamp da lista de eventos futuros para ser processado.

2. Atualizar o valor do relógio global de acordo com o timestamp do evento a ser processado.

3. Processar o evento e fazer as modificações necessárias nas variáveis de estado do sistema.

4. Se o processamento do evento gerar novos eventos, esses devem ser postos na lista de eventos futuros.

5. Se a lista de eventos futuros não estiver vazia, voltar ao passo 1. Se não, terminar simulação.

A lista de eventos futuros é ordenada de modo não-decrescente pelo tempo de ocorrência dos eventos (timestamp). Essa ordenação limita a execução da simulação seqüencial restringindo a um único evento processado por ciclo da simulação. Porém, ela deve ser preservada, pois se um evento for executado fora da ordem, as variáveis de estado da simulação podem ser alteradas, afetando a execução dos eventos de tempo menor que ainda estão na lista. Essa restrição imposta pelo comportamento do sistema real é chamada de restrição de causa e efeito.

A simulação seqüencial pode ser empregada eficientemente em muitos casos, porém não fornece um bom desempenho na simulação de grandes sistemas com numerosas entidades e eventos. O tempo de processamento pode ser muito grande, tornando a simulação inviável. Além da restrição da lista de eventos única, a simulação seqüencial também fica limitada pela capacidade de memória de um único processador na qual a simulação é executada.

Solucionando os problemas citados e tornando a aplicação da simulação mais eficiente, a simulação distribuída tem se tornado uma alternativa para a aplicação da simulação. 


\subsection{Simulação Distribuída}

A simulação distribuída constitui uma solução para os problemas encontrados na simulação seqüencial. Explorando-se o paralelismo inerente no modelo de simulação de um sistema, é possível dividir a simulação seqüencial em vários processos que podem ser executados paralelamente. Esses processos, chamados de processos lógicos, podem então ser distribuídos entre vários processadores de uma máquina paralela ou de um sistema distribuído, ganhando-se em speedup ${ }^{3}$ e desempenho.

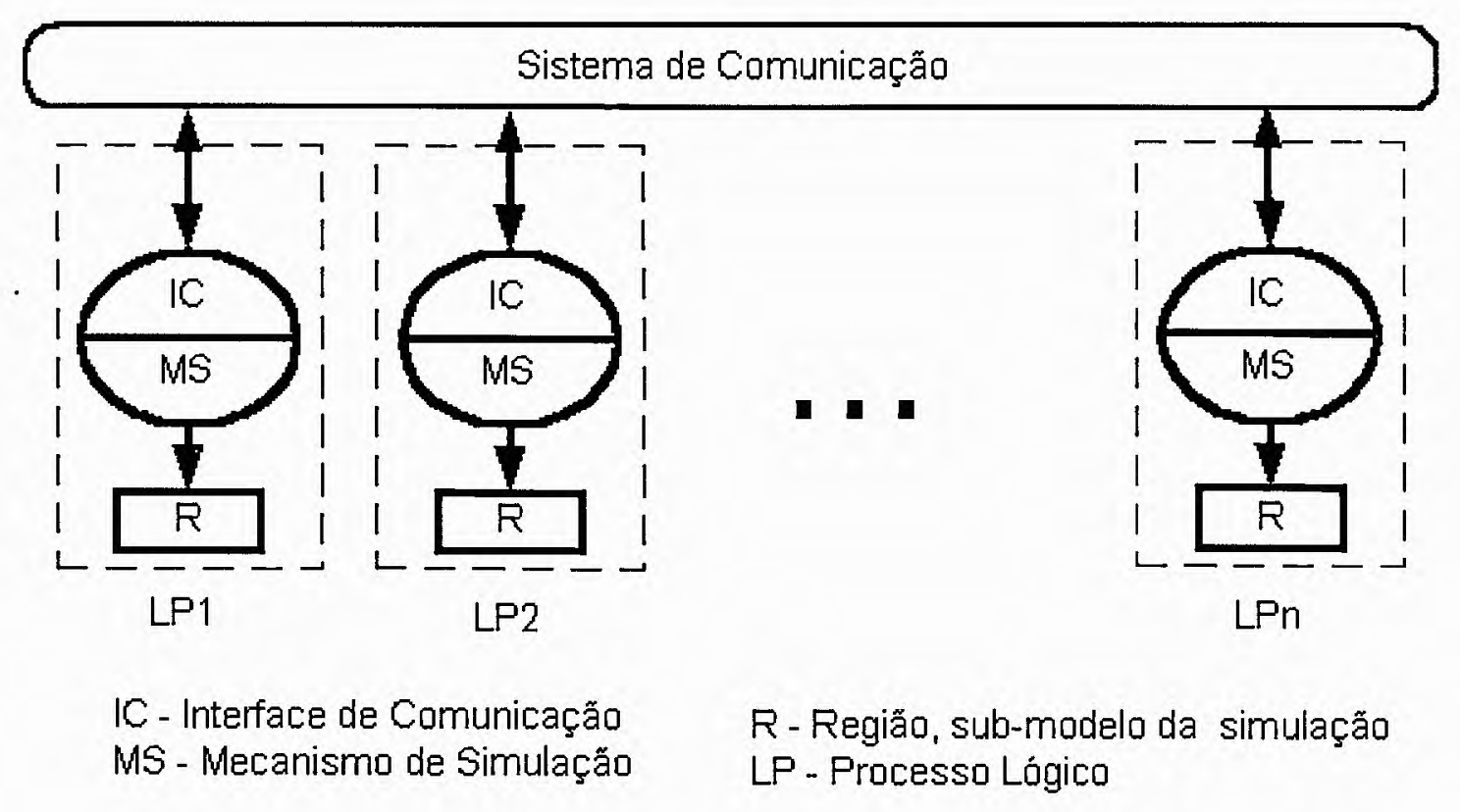

Figura 2-1 Arquitetura de uma simulação de Processos Lógicos.

${ }^{3}$ Speedup é uma medida que indica o ganho de velocidade obtido na execução de um programa utilizando vários processadores em relação a sua execução seqüencial. 
Os processos lógicos representam processos físicos do sistema real (entidades da simulação). A Figura 2-1 apresenta a arquitetura da simulação dos vários processos lógicos de um sistema modelado. Um grupo de LPs pode executar eventos paralelos de modo assíncrono ou síncrono. A Interface de Comunicação fornece ao LP mecanismos para a troca de dados com os outros LPs. Cada LP atua em uma região, uma parte do modelo da simulação, processando os seus eventos locais e gerando eventos remotos [THO99].

A Figura 2-2 apresenta os principais componentes de um sistema de simulação: as entidades da simulação, suas variáveis de estado, suas listas de eventos futuros e os canais entre as entidades para a troca de mensagens [THO99].

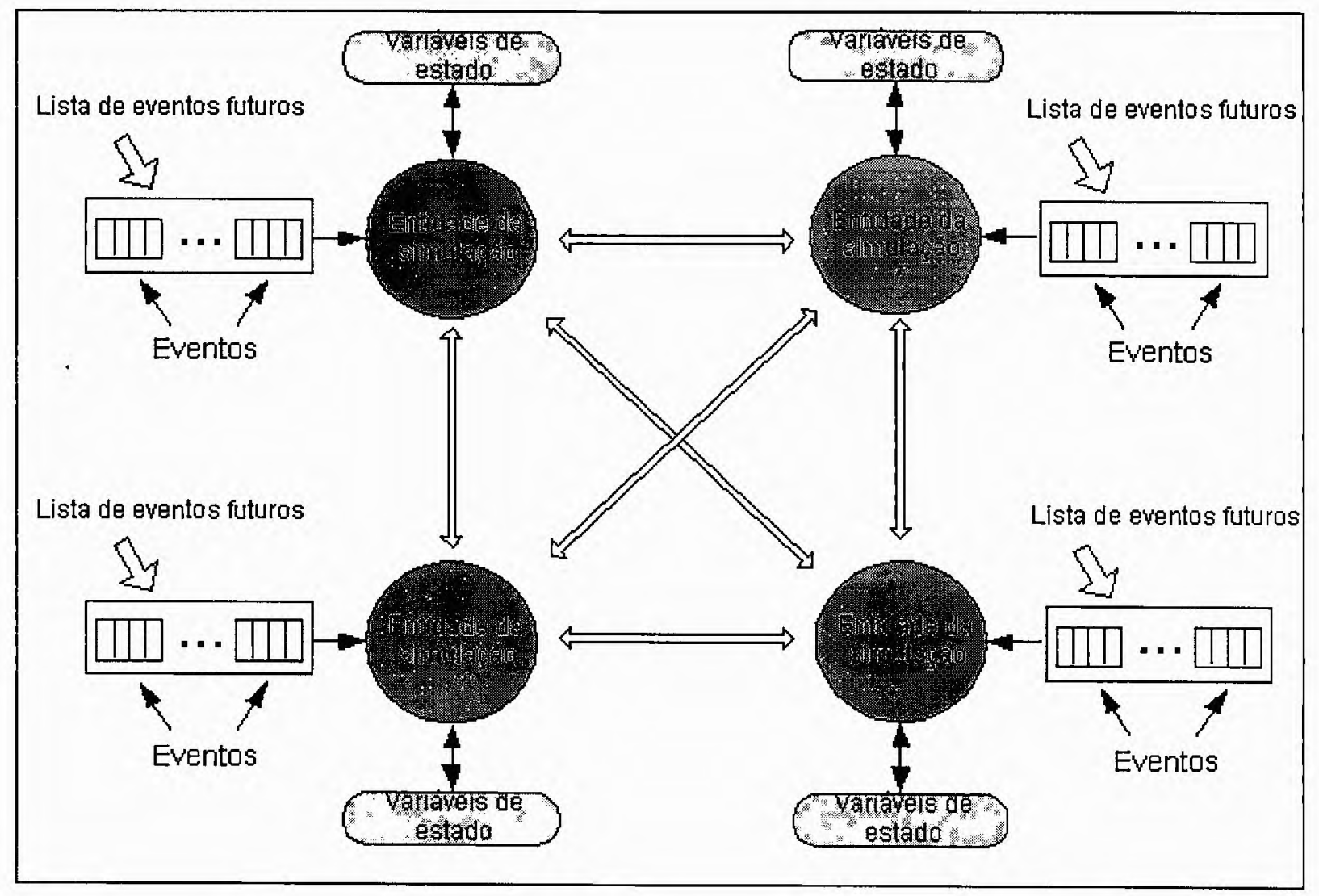

Figura 2-2 Estrutura de um sistema de simulação. 
A execução dos eventos da simulação deve ser análoga ao comportamento do sistema real e os relacionamentos de causa e efeito dos eventos nunca devem ser violados [FUJ90]. Se num 'sistema real, um evento A ocorre antes de um evento $\mathrm{B}$, o mesmo deve acontecer na simulação. Caso o evento B seja processado na simulação antes do A, tem-se uma violação da relação de causa e efeito.

Considerando-se dois eventos [OVE91]: $\mathrm{E}_{1}$ de timestamp 10 no $\mathrm{LP}_{1}$ e $\mathrm{E}_{2}$ de timestamp 20 no $\mathrm{LP}_{2}$ (Figura 2-3); se a execução do evento $\mathrm{E}_{1}$ gerar um novo evento $\mathrm{E}_{3}$ para o $\mathrm{LP}_{2}$ de timestamp menor do que 20 , então o evento $E_{3}$ poderá afetar $E_{2}$ sendo assim necessária a execução seqüencial dos três eventos.

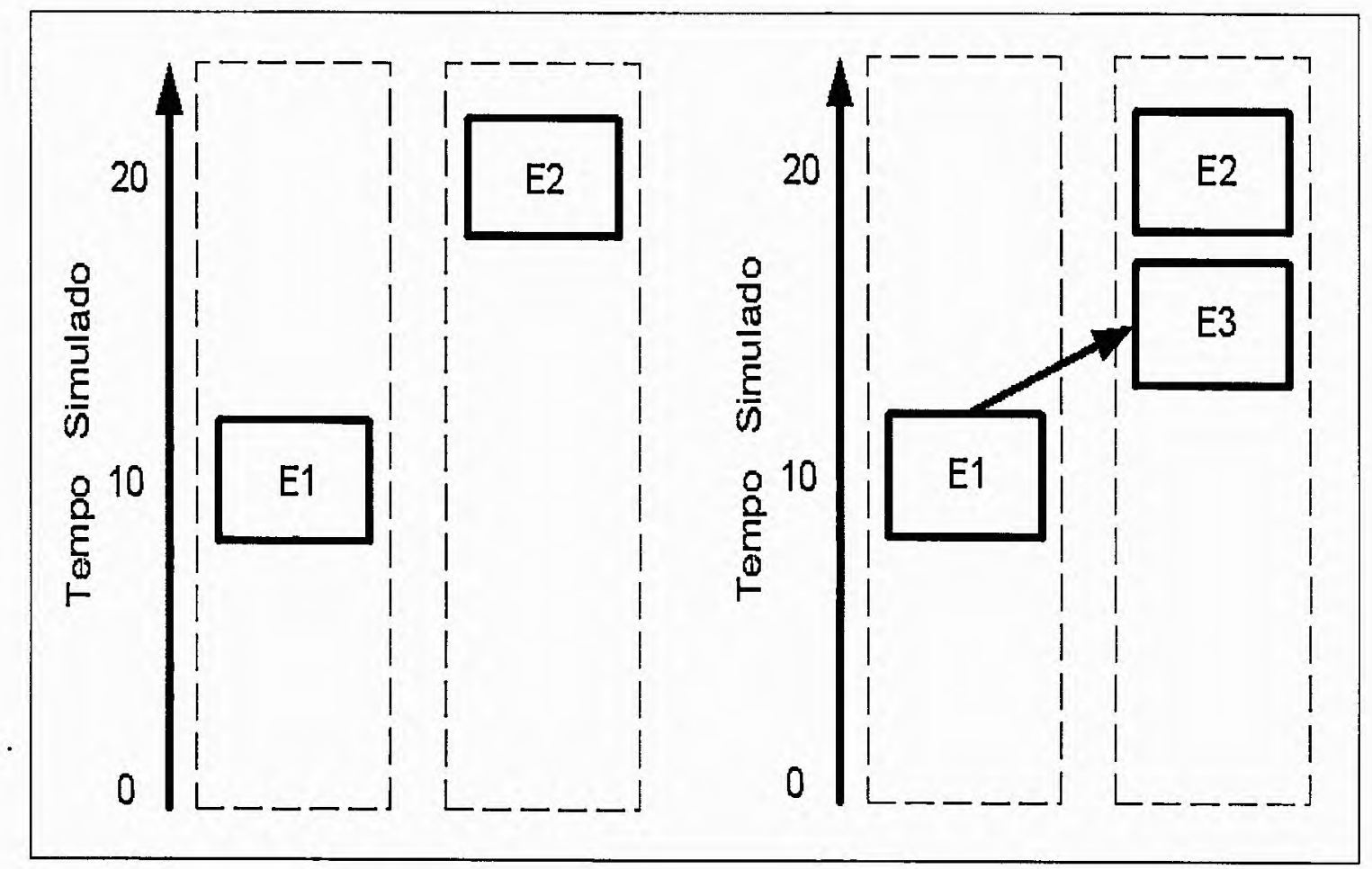

Figura 2-3 Erro de causa e efeito.

O mecanismo de implementação da lista de eventos futuros deve sempre selecionar o evento de menor timestamp para ser executado, pois, assim, a relação de causa e efeito dos eventos é preservada. A lista de eventos futuros pode ser implementada de duas formas: 
1. Lista de eventos centralizada: todos os eventos da simulação são mantidos em uma única lista de eventos central em um determinado processo. Um escalonador de eventos decide qual processo deve receber um evento para ser executado. Oferece bom desempenho apenas para um grupo limitado de aplicações, onde a natureza da lista de eventos é seqüencial.

2. Lista de eventos distribuída: cada processo mantém um relógio local virtual (LVT) e uma lista de eventos. Cada processo então executa os eventos de menor timestamp de suas listas de eventos. Um erro de causa e efeito é detectado quando o evento retirado da lista de eventos futuros possuir um timestamp menor do que o LVT do processo lógico.

A implementação distribuída da lista de eventos é a metodologia mais popular entre as duas citadas, e será considerada neste trabalho.

Se cada LP pudesse prosseguir sua execução de forma independente das demais, melhores speedups poderiam ser alcançados. Porém, os LPs interagem entre si através de troca de mensagens, e não são independentes.

Considerando-se a simulação distribuída de dois processos lógicos [THO98], como na Figura 2-4, cada processo lógico é executado em diferentes processadores; enquanto não há interação entre os LPs, a simulação prossegue normalmente, porém, uma vez que um LP interage com o outro através de envio de mensagens, deve haver um mecanismo de sincronização. Podese notar na Figura 2-4 que na fase de interação entre os LPs, existe a possibilidade do evento E5 ser executado antes do evento E4, isto porque o E5 chega no LP0 antes de E4. Quando o evento E5 chega no LP0, não há como saber que irá chegar um evento E4 com timestamp menor a não ser que o LP0 e o LP1 estejam sincronizados. A falta de sincronização nesse caso levaria à violação da causa e efeito. 


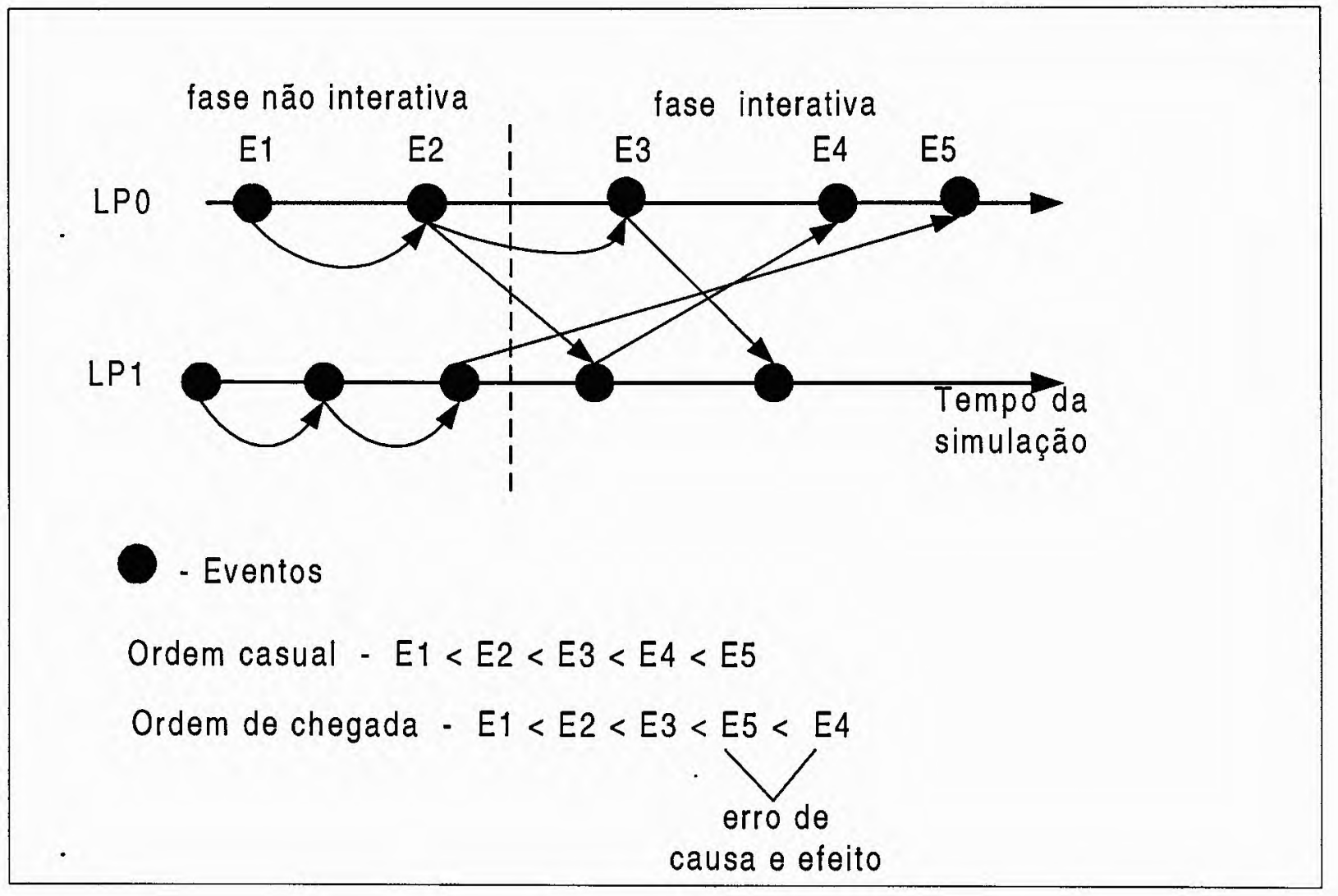

Figura 2-4 Simulação Distribuída de dois LPs.

Dessa forma, a principal preocupação da simulação distribuída está exatamente em como se manter a relação de causa e efeito dos eventos do sistema simulado. Muitos mecanismos têm sido propostos para a sincronização da simulação distribuída [JEF85] [MIS86][FUJ90a] [FUJ90] e alguns deles serão descritos no próximo capítulo.

\subsubsection{Decomposição da Simulação}

Existem várias formas propostas para a decomposição de uma simulação seqüencial para ser executada em múltiplos processadores, ou seja, como uma simulação distribuída [VEE99]:

1. Parallelizing compilers: nesta abordagem, são utilizados compiladores de paralelização que exploram o paralelismo possível em um dado programa sequiencial. Como o compilador ignora a estrutura do problema, o paralelismo explorado é muito limitado. 
2. Replicated Trials (Parallel Independent Runs, Distributed Experiments): $\mathrm{n}$ simulações seqüenciais são executadas independentemente em $\mathrm{n}$ processadores, e seus resultados são calculados pela média de todas saídas das $\mathrm{n}$ execuções no final. Nenhuma coordenação é necessária entre as replicações, por isso alta eficiência é alcançada. Porém, os parâmetros de todas as replicações da simulação devem ser decididos antes da inicialização de qualquer uma delas. $O$ espaço de memória é proporcional ao número das replicações.

3. Distributed Functions: as sub-tarefas essenciais da simulação (geração de números aleatórios, manipulação de arquivos, coleta de estatísticas) são associadas a um número de processadores. Isso requer algumas mudanças no código da simulação seqüencial e como o número de tais sub-tarefas é limitado, pouco paralelismo pode ser alcançado.

4. Distributed Events (com lista de eventos centralizada): um processador que esteja disponível processa o evento de menor timestamp da lista de eventos global. Para evitar computação errada, cada processador tem que garantir que o evento com o menor timestamp da lista não será cancelado por outros eventos que estejam sendo processados por outros processadores naquele instante. Isso requer um conhecimento do modelo de simulação, o que não é uma tarefa fácil. Além disso, a lista de eventos global pode se tornar o "bottleneck" se muitos processadores estiverem envolvidos na simulação.

5. Domain Decomposition: essa classe de decomposição está baseada na visão de que a execução da simulação é equivalente a preencher uma região bidimensional, sendo uma dimensão o tempo simulado e a outra as variáveis de estados, como na Figura 2-5 (a). De acordo com essa visão, o domínio de espaço-tempo pode ser decomposto em relação ao tempo, Figura 2-5(b), ou ao espaço, Figura 2-5(c). 
Space-Parallel Decomposition (ou Distributed Simulation): o modelo da simulação é decomposto em um número de submodelos ou componentes. Cada componente é associado a um processo, onde vários processos podem ser executados no mesmo processador. Essa decomposição é atrativa porque pode ser aplicada em qualquer modelo e pode oferecer uma grande possibilidade de desempenho para modelos grandes.

Time-Parallel Decomposition (ou Time Parallelism): o domínio é dividido em um número de intervalos $\left[\mathrm{t}_{\mathrm{i}-1}, \mathrm{t}_{\mathrm{i}}\right]$ para $0 \leq \mathrm{i} \geq \mathrm{p}$, sendo $\mathrm{p}$ o número de processadores. $\mathrm{A}$ cada processador está associado um intervalo e é responsável em computar os valores das variáveis de estado dentro daquele intervalo. Com esta abordagem, o mecanismo da simulação deve garantir que o estado do sistema no final do intervalo $\left[\mathrm{t}_{\mathrm{i}-1}\right.$, $\left.t_{i}\right]$ combine com o estado inicial do intervalo $\left[t_{i}, t_{i+1}\right]$. A reexecução de alguns intervalos é necessária caso algum erro entre as variáveis de estado seja detectado. A eficiência dessa decomposição depende de alguma forma de se prever com exatidão o estado inicial para cada intervalo.

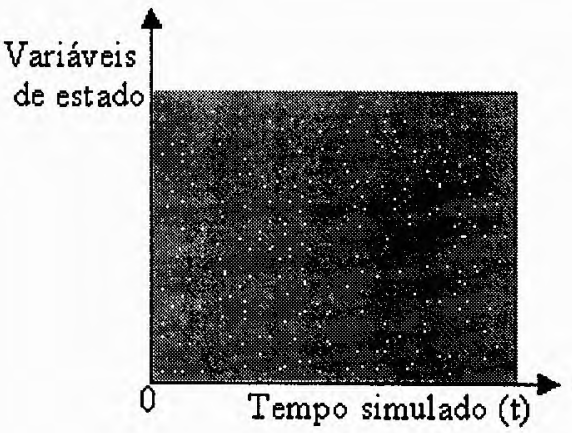

(a)

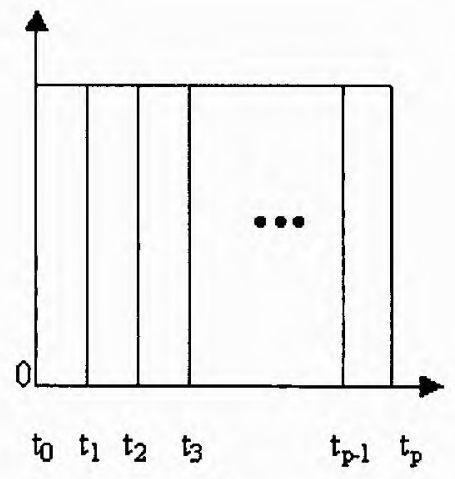

(b)

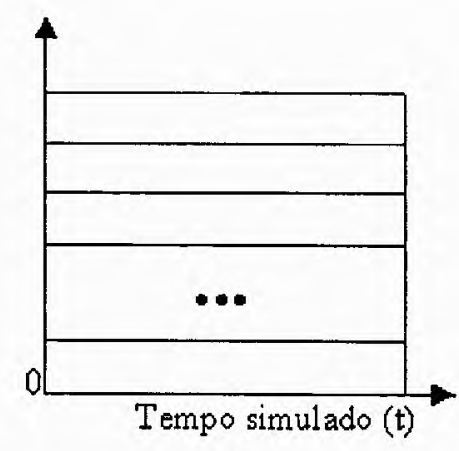

(c)

Figura 2-5 (a) Gráfico tempo-espaço. A execução da simulação (tempo= 0 .. t t) é equivalente a preencher a área sombreada. (b) Decomposição pelo tempo. (c) Decomposição pelo espaço. 


\subsection{Considerações Finais}

Entre as ferramentas disponíveis para a avaliação de desempenho de sistemas computacionais, a simulação se destaca por ser flexível, podendo ser utilizada em várias situações e por oferecer soluções a um custo relativamente atrativo.

A simulação seqüencial pode ser empregada eficientemente em muitos casos, mas em simulações de sistemas complexos que envolvem muitas entidades e eventos ela não oferece um bom desempenho. O seu tempo de processamento pode ser muito grande, tornando a simulação inviável. Além da restrição da única lista de eventos, a simulação seqüencial também fica limitada pela capacidade de memória de um único processador na qual a simulação é executada.

A simulação distribuída pode substituir a seqüencial melhorando o desempenho e o speedup do programa de simulação. O programa seqüencial pode ser dividido em vários processos lógicos que podem ser executados paralelamente. Esses processos são então distribuídos entre vários processadores de uma máquina paralela ou Sistema Distribuído.

Várias são as vantagens oferecidas pela simulação distribuída sobre a seqüencial: além do speedup, requer pouca memória adicional, exige pouco controle global exercido por qualquer máquina e a simulação de um sistema pode ser adaptada à estrutura do hardware disponível (com poucas máquinas, diversos processos físicos podem ser simulados em um único processador) [ULS97] [MIS86] [FUJ90] [FUJ90a].

Entre as abordagens mostradas de como uma simulação pode ser decomposta, a SpaceParallel Decomposition demonstra um grande potencial e é considerada a abordagem mais promissora para a execução da simulação distribuída [RIG89].

A principal preocupação da simulação distribuída está na manutenção da relação de causa e efeito dos eventos, isto é, a sincronização entre os processos que executam em paralelo. Para solucionar este problema, vários mecanismos têm sido propostos e são descritos no próximo capítulo. 


\section{Capítulo 3}

\section{Sincronização em Simulação Distribuída}

Neste capítulo são apresentados a classificação dos mecanismos de sincronização na simulação distribuída e alguns protocolos já desenvolvidos baseados nessa classificação.

\subsection{Introdução}

A sincronização é a principal preocupação da simulação distribuída e diferentes abordagens podem ser utilizadas para esse objetivo. Muitos mecanismos têm sido desenvolvidos e tradicionalmente são classificados em duas categorias clássicas:

- Conservativos: evitam a possibilidade de ocorrência de erros de causa e efeito, ou seja, determinam quando é seguro processar um evento; nessa categoria temse o CMB [BRY77][CHA79], como um exemplo de implementação bem sucedida e largamente difundida;

- Otimistas: utilizam uma estratégia de deteç̧ão e recuperação de erros, onde erros de causa e efeito são detectados e um mecanismo de rollback é utilizado para a recuperação; nessa categoria encontra-se o Time Warp [JEF85] e suas derivações [SPO99] como um exemplo. 
Ambos os tipos de mecanismos, conservativos e otimistas, introduzem sobrecargas na execução da simulação devido às suas características. Algumas sobrecargas comuns às duas abordagens são devidas à necessidade de ordenação e entrega de mensagens e do gerenciamento da lista de eventos pelo LP.

Uma outra abordagem que tenta minimizar as sobrecargas introduzidas pela necessidade de sincronização adota um comportamento de certa forma anarquista [THO98] [RA098] [THO99] [PHA00]. Esse protocolo não trata os erros de causa e efeito, simplesmente ignora-os, fornecendo resultados aproximados e execução da simulação mais rápida.

Nos próximos tópicos essas três abordagens são discutidas com mais detalhes e alguns de seus protocolos também são apresentados.

\subsection{Protocolos Conservativos}

Os protocolos conservativos permitem a execução dentro da simulação apenas de eventos seguros, eventos que respeitam a ordem de causa e efeito do sistema. Para isso utiliza a técnica de bloquear os LPs que não tenham eventos seguros a serem processados.

Quando um LP não tem nenhum evento seguro (mesmo que sua lista de eventos futuros não esteja vazia), a sua execução é bloqueada até que ele receba um evento que o desbloqueie e avance o seu tempo de simulação, para poder processar eventos de sua lista de eventos futuros.

O bloqueio de processos lógicos pode levar à situação de deadlock, onde processos bloqueados ficam à espera de mensagens de outros processos que também estão bloqueados, formando um ciclo.

Uma simulação conservativa segue basicamente duas regras [FIS95]: 
1. Input waiting rule: um LP não processa nenhuma mensagem de entrada até receber pelo menos uma mensagem de cada um de seus canais de entrada. A mensagem de entrada de menor tempo de ocorrência (menor timestamp) é selecionada para ser processada. Considerando que todas as mensagens enviadas de um LP para outro estão em ordem não-decrescente de timestamp (o que é garantido pela Output waiting rule), então essa regra garante que a mensagem selecionada de menor timestamp é um evento seguro.

2. Output waiting rule: um LP não pode mandar nenhuma mensagem de saída para outro LP até garantir que nenhuma outra mensagem com timestamp menor será escalonada para o LP no futuro. Considerando que todas as mensagens de entrada são manipuladas em uma ordem não-decrescente de timestamp (o que é garantido pela regra Input waiting rule), isso é satisfeito, se um LP apenas enviar mensagens de saida com timestamp menores ou iguais ao seu LVT.

Prevenção e recuperação de deadlock são os principais enfoques dos protocolos conservativos. Alguns protocolos evitam a ocorrência de deadlocks [CHA79] [BRY77] [MIS86] [FUJ90][FUJ90a] e outros permitem que os processos entrem em situação de deadlock e então um mecanismos de recuperação é utilizado [CHA81] [FUJ90a]. A seguir, serão apresentados alguns protocolos baseados nessa abordagem.

\subsubsection{Protocolo CMB (Prevenção do Deadlock utilizando mensagens nulas)}

O protocolo CMB [BRY77] [CHA79] exige que se especifique estaticamente ${ }^{4}$ os canais que indicam a comunicação entre os processos. A seqüência dos timestamps das mensagens enviadas por um canal deve ser não decrescente, sendo assim seguro o processamento de um evento.

\footnotetext{
${ }^{4}$ Estudos mostram que a conectividade dinâmica também é possível para os protocolos conservativos, sendo necessárias algumas modificações para suportar a plataforma paralela [JHA94].
} 
As mensagens que chegam em cada canal de entrada são armazenadas em uma fila ordenada de maneira FIFO (First-In First-Out), que também é a ordenação seguida pelos timestamps, de acordo com a restrição citada acima. Cada canal tem um relógio que assume o componente $t$ (tempo) da última mensagem recebida através daquele canal; o relógio terá valor zero se nenhuma mensagem tiver sido recebida por aquele canal.

O relógio do processo (Local Virtual Time) é sempre o menor valor entre os relógios dos seus canais de entrada. Por exemplo, (Figura 3-1), um processo chamado Proc tem canais de entrada $L 1, L 2$ e $L 3$ com relógios iguais a 11,2 e 4 respectivamente. A mensagem com menor valor de tempo (relógio do canal igual a 2) pertence ao canal $L 2$ e, portanto, o relógio do processo Proc é igual a 2. Assim, o processo Proc pode seguramente prosseguir sua execução até esse tempo [JEF85] [MIS86]. O valor do relógio da simulação (T) é o menor valor de relógio de todos os seus processos lógicos.

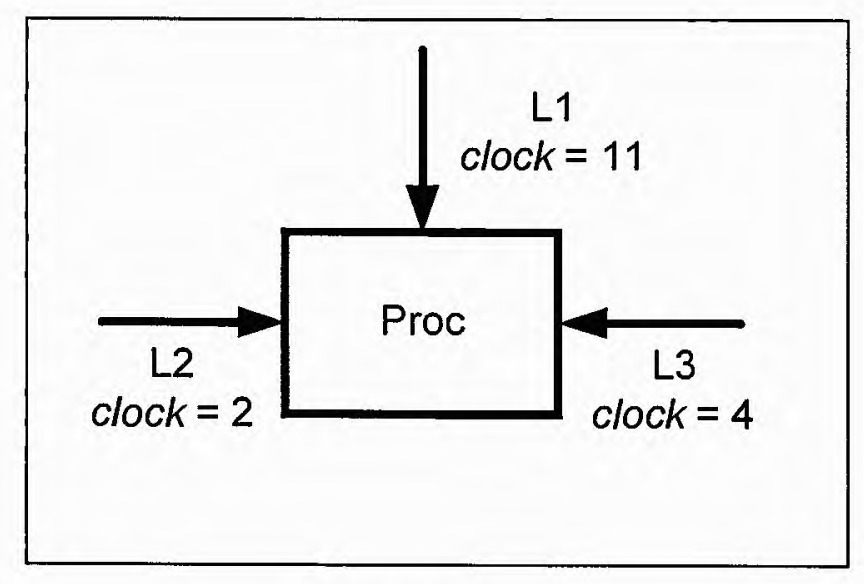

Figura 3-1 LVT de um processo.

Esse protocolo garante que cada processo tratará os eventos somente em uma ordem não decrescente dos timestamps, pois o processo repetidamente seleciona o canal com o menor valor de relógio e se houver um evento na fila este é processado.

Se a fila estiver vazia, o processo é então bloqueado. Na Figura 3-2 é demonstrado um problema crítico desse protocolo: cada processo fica indefinidamente esperando uma mensagem do canal de entrada que contém o menor valor de relógio, uma vez que a fila correspondente está vazia. Todos os três processos estão bloqueados, embora existam mensagens em outras filas de entrada de cada processo aguardando para serem processadas (situação de deadlock) [OVE91]. 


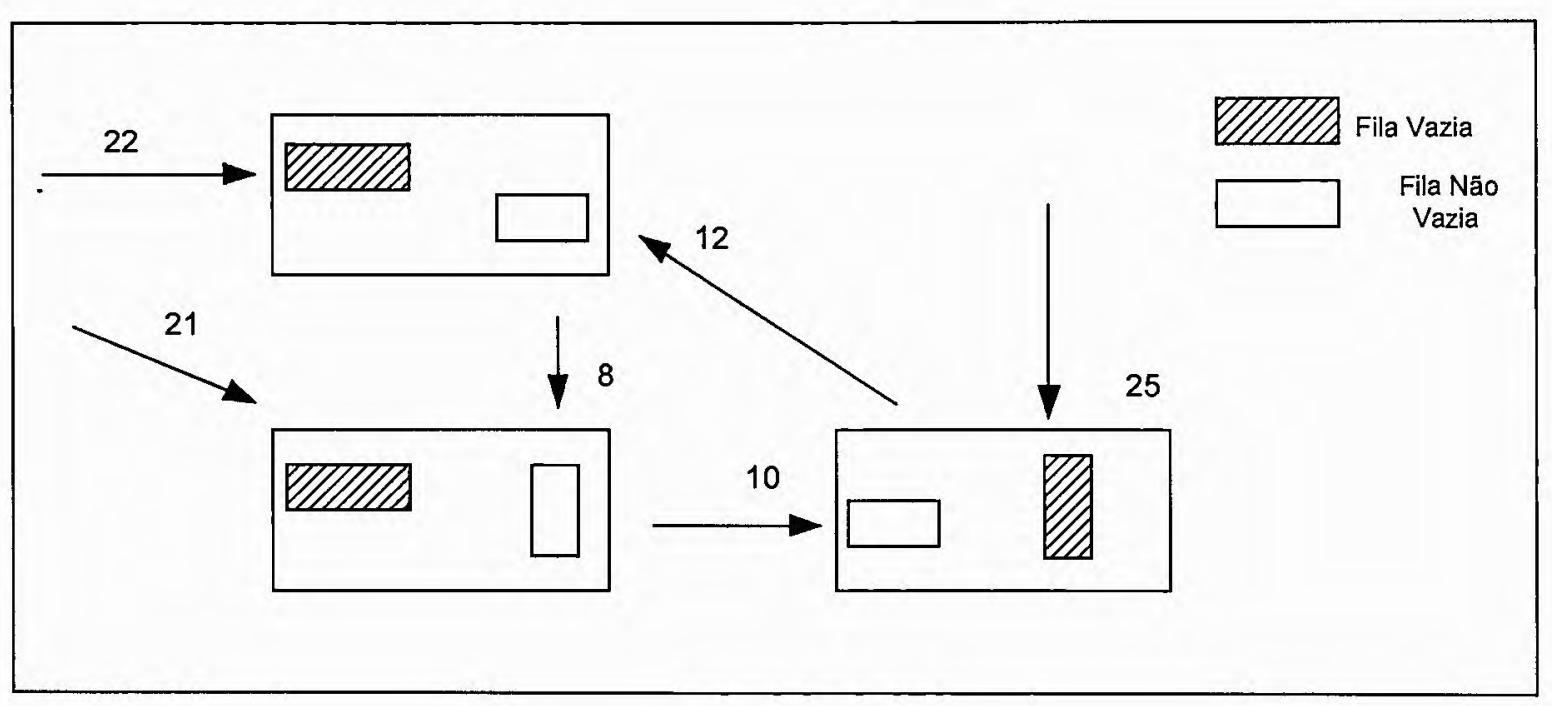

Figura 3-2 Situação de Deadlock.

Um conjunto D de processos lógicos está em deadlock em um mesmo ponto da execução se todas as seguintes condições forem satisfeitas [MIS86]:

- Todo LP, pertencente a D está esperando uma mensagem ou encerrou a sua execução;

- No mínimo um LP, pertencente a D, está esperando uma mensagem;

- Um LPi qualquer, pertencente a D, está esperando uma mensagem de algum LPj (também pertencente a $\mathrm{D}$, e não existe mensagem em trânsito de LPj para LPi) .

Para que a simulação não entre em deadlock são utilizadas mensagens nulas. Essas meṇsagens não correspondem a atividades no sistema físico, são utilizadas apenas com o propósito de sincronização. Uma mensagem nula com timestamp $t$, enviada por um LPi para um LPj indica que LPi não enviará mensagem a LPj entre o valor corrente do seu relógio e o tempo $t$. Assim, qualquer mensagem futura de LPi para LPj terá timestamp superior a $t$. 
Quando o processo LPi recebe uma mensagem, ele próprio atualiza seu LVT. Se o LVT é alterado, LPi avança a simulação do processo físico correspondente até o valor de LVT. Nesse instante, LPi prediz para cada canal de saída uma seqüência de mensagens que o processo físico possa ter enviado, gerando uma seqüência de mensagens para transmitir para LPj, para cada j no qual exista um canal de saída.

Suponha que LPi possa futuramente predizer que após a transmissão dessa seqüência de mensagens, o processo físico i não irá enviar mensagens ao processo físico $\mathrm{j}$ até o tempo tj. Nesse caso, LPi envia a mensagem ( $t j$, nula) a LPj depois de ter enviado a seqüência correta de mensagens. Uma vez que LPi conhece o estado do seu processo físico correspondente até o tempo LVTi, ele pode dizer todas as mensagens que estão sendo enviadas e detectar a ausência de mensagens, no mínimo até o tempo LVTi. Nesse caso, todo canal de saída possuirá a última mensagem com o componente tempo igual ou maior que LVTi [MIS86].

As mensagens nulas são tratadas como quaisquer outras mensagens quando recebidas por um processo. Quando um processo recebe uma mensagem nula, o seu LVT é atualizado de acordo com a mensagem. A desvantagem do protocolo $\mathrm{CMB}$ é a sobrecarga causada pelo envio de mensagens nulas.

\subsubsection{Transmissão de mensagens nulas sob demanda}

Uma variação do protocolo $\mathrm{CMB}$ é o envio de mensagem nula sob demanda e não após o processamento de cada evento, o que provoca sobrecargas [CHA81]. A freqüência dessa demanda pode ser dada por um timeout ou também quando o menor valor de relógio de todos os canais for de uma fila vazia (indicando que o processo está bloqueado).

Quando isso ocorre, uma mensagem é requisitada do processo que envia para esse canal, e a execução do processo que faz a requisição só prossegue quando uma resposta é recebida. 
Considere o seguinte exemplo [CHA81]: o processo $L_{1}$ requisita a um processo $L_{2}$ que aumente o valor do relógio do canal que conecta os dois processos. Esse avanço é possível se o valor do relógio desse canal for menor do que o valor atual do LVT de $\mathrm{LP}_{2}$ (mínimo entre os relógios dos canais de entrada de $\mathrm{LP}_{2}$ ). Nesse caso, $\mathrm{LP}_{2}$ envia uma mensagem, possivelmente nula, avançando o relógio do canal $\left(\mathrm{LP}_{2}-\mathrm{-LP} \mathrm{P}_{1}\right)$. Na Figura 3-3, $\mathrm{LP}_{2}$ pode enviar uma mensagem ao $L P_{1}$, incrementando o relógio do canal $\left(L P_{2}--L P_{1}\right)$ para 12 (Figura 3-3). Assim, $L P_{1}$ pode computar o novo valor do seu LVT (igual a 9) e prosseguir a sua execução.

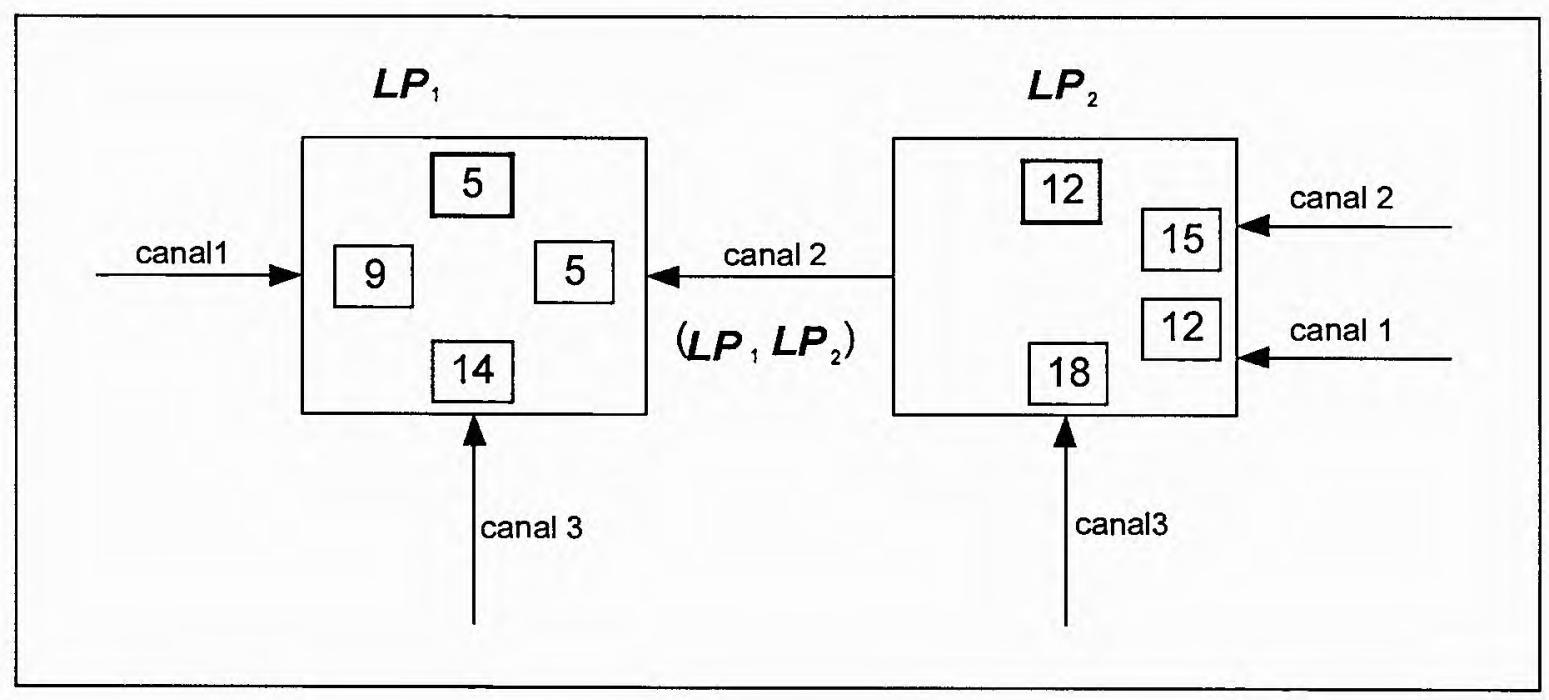

Figura 3-3 Transmissão de mensagem nula sob demanda (1).

Mas se o valor do relógio do canal $\left(\mathrm{LP}_{2}-\mathrm{LP}_{1}\right)$ for igual ao valor do $\mathrm{LVT}$ de $\mathrm{LP}_{2}$, nenhum avanço será possível (Figura 3-4). $\mathrm{LP}_{2}$ tem que avançar seu próprio LVT primeiro, fazendo o mesmo tipo de pedido a todos os processos que enviam para $\mathrm{LP}_{2}$ cujos relógios dos canais sejam iguais ao LVT de $\mathrm{LP}_{2}$. É o caso do canal de entrada 2 do processo 2 . O pedido será efetivamente propagado pelo processo 2 . 


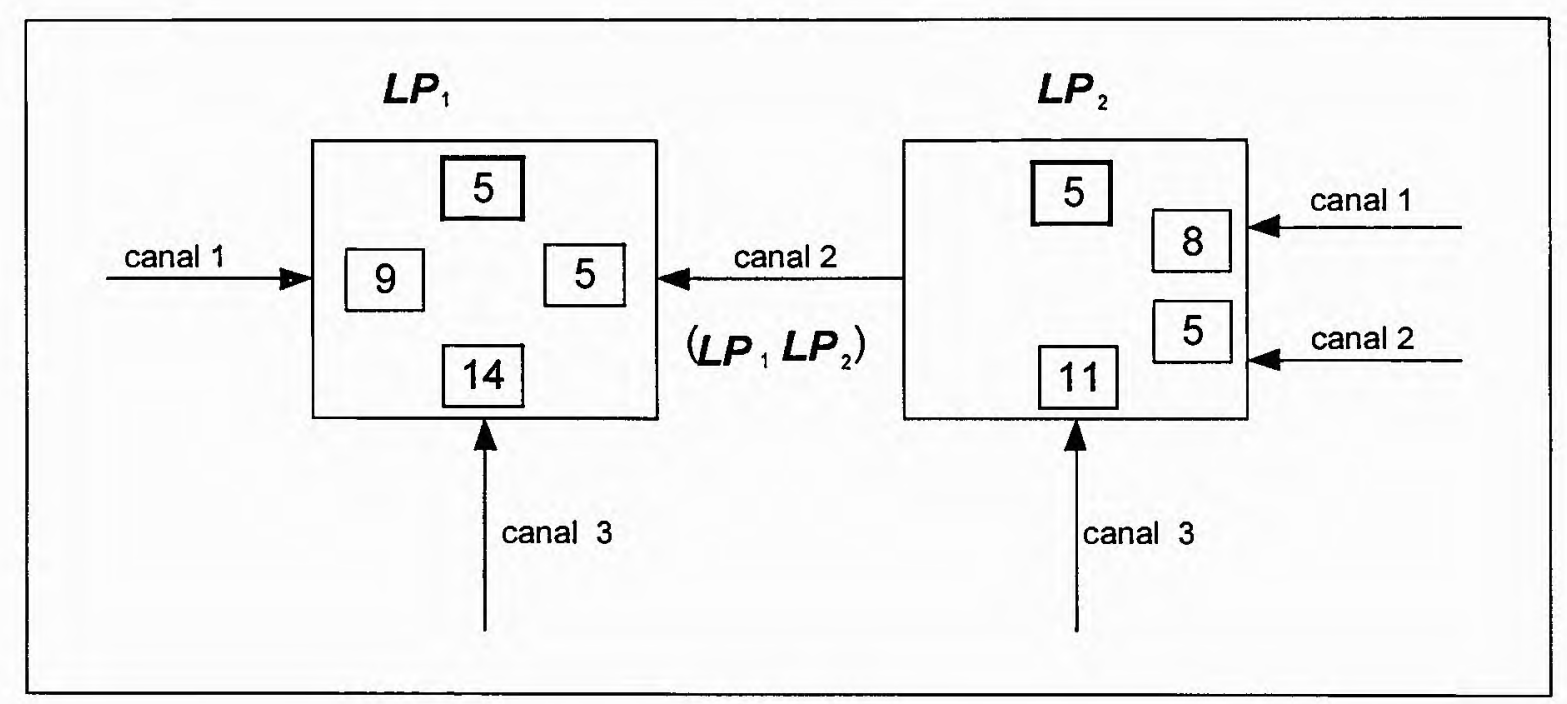

Figura 3-4 Transmissão de mensagem nula sob demanda (2).

Quando o valor do LVT do processo 2 for maior que o valor do relógio do canal $\left(\mathrm{LP}_{2}-\right.$ $\mathrm{LP}_{1}$ ), $\mathrm{LP}_{2}$ pode enviar uma mensagem para LP1, incrementando o valor do relógio do canal. As propagações dos pedidos de avanço de relógio também podem formar um ciclo, gerando uma situação de deadlock.

A resolução do deadlock é complicada, havendo vários métodos para solucioná-lo. Uma forma seria a seguinte: para cada processo no conjunto de processos em deadlock, o tempo em que uma mensagem será enviada é determinado e o valor do relógio do processo com o menor valor é avançado para esse tempo. Esse cálculo pode ser realizado de modo centralizado ou descentralizado.

A redução da quantidade de tráfego de mensagens nula é a vantagem desse protocolo. Uma desvantagem é um atraso maior para receber mensagens nulas, já que são necessárias as transmissões de duas mensagens, mensagem de avanço do relógio e a própria resposta a esse pedido. 


\subsubsection{Detecção e recuperação do Deadlock}

Nesse protocolo, a simulação é executada até que ocorra deadlock. Um mecanismo detėcta quando isso ocorre e outro mecanismo é utilizado para a recuperação e, assim, a simulação pode prosseguir a sua execução [CHA81].

Para isso, esse protocolo mantém um marcador que circula pela rede, percorrendo todos os canais da rede em algum tempo durante um ciclo. O marcador é um tipo especial de mensagem. Quando um processo recebe um marcador, deve enviá-lo para sua rota designada depois de um certo tempo em que o processo se torna ocioso (sem mensagens para enviar) [FUJ90a] [MIS86].

Cada processo tem uma variável flag de um bit que indica se o processo recebeu ou enviou uma mensagem desde a última passagem do marcador pelo processo. Um processo é branco se ele não recebeu nem enviou mensagens desde a última passagem do marcador, senão o processo é preto. Todos os processos inicialmente são pretos. Um deadlock é detectado quando os últimos $\mathrm{N}$ processos visitados pelo marcador estiverem brancos $(\mathrm{N}$ é o número de canais na rede). Mas o sucesso desse protocolo é garantido apenas quando, entre dois processos quaisquer, a ordem de recebimento das mensagens, incluindo o marcador, for à mesma ordem com que foram enviadas.

Como o marcador guarda o próximo tempo de evento e o processo em que ocorre, quando o deadlock é detectado, o marcador pode reiniciar o processo. O marcador armazena o número de processos brancos que visitou desde o último processo preto que viu.

Para aplicações onde a ocorrência de deadlocks é rara, a utilização de protocolos que fazem envio de mensagens nulas introduz sobrecarga na simulação, já que na maior parte dos casos elas são desnecessárias. A desvantagem desse protocolo é a sobrecarga de comunicação causada pela transmissão do marcador. 


\subsubsection{Protocolos Baseados em Janelas}

Uma janela de tempo simulada é utilizada para reduzir a sobrecarga que ocorre quando se determina quando é seguro processar um evento. Somente eventos não processados com timestamp "dentro" da janela podem ser processados. O propósito da janela é reduzir o espaço que deve ser percorrido para se determinar se um evento é seguro para ser processado [FUJ90a].

A questão importante nesse protocolo é a determinação do tamanho da janela de tempo. Se for muito pequena, poucos eventos ficam disponíveis para serem tratados paralelamente. Se for muito grande, o protocolo se comporta como se a janela não estivesse sendo utilizada [FUJ90a] [NIC93].

\subsubsection{Lookahead}

Lookahead é uma técnica utilizada por alguns protocolos conservativos [MIS86], podendo ser definida como a capacidade de prever o que acontecerá no futuro de uma simulação. Se um processo no tempo de simulação $\mathrm{T}$ pode prever com segurança todos os eventos que ele gerará até o tempo de simulação $\mathrm{T}+\mathrm{L}$, diz-se que o processo tem lookahead $\mathrm{L}$.

Essa técnica aumenta a capacidade de prever eventos futuros e, assim, pode ser usada para determinar quando os eventos podem ser seguramente processados. O CMB utiliza essa técnica para determinar os timestamps das mensagens nulas; o protocolo de Detecção e Recuperação de Deadlock utiliza quando um processo manda uma mensagem com um incremento de L no timestamp para outro processo, para garantir que nenhuma outra mensagem que contenha um timestamp menor que $\mathrm{T}+\mathrm{L}$ seguirá por aquele caminho. 


\subsubsection{Desempenho dos Mecanismos Conservativos}

O sucesso dos mecanismos conservativos depende, em grande parte, do grau de lookahead que pode ser computado [THO99]. Esse grau, por sua vez, depende da aplicação que está sendo simulada. No caso de aplicações como Redes de Filas, é possível pré-computar os tempos de serviço e de espera em alguns casos, dando um cálculo de lookahead melhor. Porém, este não é o caso de muitas aplicações onde explorar a técnica de lookahead é encarada como um desafio.

Nicol [NIC93] analisou alguns algoritmos conservativos baseados na pré-computação do tempo de serviço. Pôde ser concluído que esses algoritmos fornecem bom desempenho para problemas grandes de simulação quando têm lookaheads adequados. Os protocolos que utilizam mensagens nulas para evitar deadlocks sofrem com os altos custos devido ao tráfego das mensagens nulas. Por outro lado, a detecção e recuperação de deadlocks prejudicam a capacidade de computação detectando e recuperando deadlocks.

Os estudos já realizados investigando o desempenho dos mecanismos conservativos mostram que o bom desempenho depende principalmente da aplicação e do algoritmo para o cálculo do lookahead [THO99]. A desvantagem da abordagem conservativa é que não se pode explorar o total paralelismo da aplicação. Além disso, alguns protocolos só permitem a configuração estática da simulação, não sendo possível criar novos processos nem novas conexões de comunicação dinamicamente.

\subsection{Protocolos Otimistas}

Ao contrário dos protocolos conservativos, os métodos otimistas supõem que nenhum erro de causa e efeito irá ocorrer. Eles não necessitam detectar quando é seguro processar um evento, apenas seguem a execução normal da simulação e, quando um erro é detectado, um procedimento de recuperação chamado de rollback é ativado [FUJ90a] para voltar a simulação a um estado consistente. 
Para a realização do rollback é necessário manter algumas estruturas de dados tais como: lista de estados (state queue) e lista de saídas (output queue). As variáveis de estado do LP após o processamento de um evento são guardadas na fila de estados e são recuperadas no caso de rollback. Quando um LP gera mensagens para serem enviadas a outros LPs, antimensagens das mensagens correspondentes são também geradas e postas na fila de saída. Uma antimensagem de uma mensagem desfaz os efeitos da execução da mensagem correspondente. $\mathrm{Na}$ ocorrência de rollback, as antimensagens são utilizadas para cancelar as mensagens que foram enviadas pelo LP em momentos errados.

Para manter essas estruturas é necessário que o protocolo cuide do gerenciamento da memória da simulação, pois, senão, a execução da simulação ficará comprometida com a quantidade de dados que deverão ser armazenados.

As variações dos protocolos otimistas se diferenciam na forma como tratam e utilizam essas estruturas, e nos algoritmos de rollback. Três fatores caracterizam um protocolo: como os dados são gravados, gerenciamento do espaço de memória e mecanismos de cancelamento. Há três abordagens diferentes para se decidir quando e como os dados devem ser armazenados [SPO99]:

1. Copy state saving: as variáveis de estado do processo lógico são gravadas toda vez que um evento é executado;

2. Sparse state saving: as variáveis de estado são gravadas periodicamente e qualquer estado pode ser recuperado através da re-execução de eventos intermediários. Os intervalos de gravação podem ser:

- Fixo: o intervalo de gravação é constante durante toda a execução da simulação; 
- Adaptável: o intervalo é dinamicamente ajustado de acordo com o comportamento da simulação; os intervalos podem adotar dois modos de decisão: (1) sensível a evento que leva em consideração a granulosidade dos diferentes tipos de eventos da simulação e (2) baseado em rollback onde o intervalo é fixado baseado no comportamento do rollback do LP.

3. Incremental state saving: apenas parte dos estados que sofreu modificações é gravada; pode ser dividida em: não transparente (todas as variáveis de estado atualizadas devem ser identificadas e modificadas) e transparente (são automaticamente atualizadas usando-se tipos de dados especiais que encapsulam todas as variáveis de estados).

Em relação ao gerenciamento do espaço de memória, a técnica adotada é a do Tempo Global Virtual (GVT), que garantem que os estados gravados com tempo abaixo do GVT podem ser descartados. A avaliação do GVT pode ser dividido em duas abordagens [SPO99]:

1. Centralizada: a avaliação do GVT é feita por um determinado processo lógico; a manutenção do GVT é responsabilidade de um LP especificado (software) ou de um hardware especial. A vantagem do hardware especial é a pequena interferência que exerce no desempenho da simulação, porém é uma abordagem cara e complexa. A abordagem de software é mais usada e o problema está em minimizar o seu impacto no desempenho da simulação; pode ser executado em background ou inicializado periodicamente ("congelamento" dos processos).

2. Distribuída: a avaliação do GVT é distribuída entre vários LPs, diminuindo-se assim a sobrecarga em cima de um único LP. Pode ser de modo local (grupos de LPs com diferentes GVTs) ou global (único GVT para todos os LPs).

$\mathrm{Na}$ recuperação de erros de causa e efeito, quatro técnicas podem ser usadas pelo mecanismo de rollback para o cancelamento das mensagens erradas [SPO99]: 
1. Cancelamento agressivo: as antimensagens são enviadas imediatamente após a ocorrência de violações de causa/efeito. Esses envios podem ocasionar rollbacks secundários, podendo gerar cascatas de rollbacks em outros processos (e erros computacionais em outros processos).

2. Cancelamento preguiçoso: nessa estratégia as antimensagens não são enviadas imediatamente, é observado se a re-execução da computação regenera as mesmas mensagens; se as mesmas mensagens são criadas, em ordem correta de timestamp, não há necessidade de se cancelar as mensagens originais via antimensagens (o que pode reduzir a quantidade de rollbacks secundários em relação ao cancelamento agressivo).

3. Cancelamento direto: é utilizada em arquiteturas com memória compartilhada e tem como objetivo otimizar o cancelamento de computações incorretas através da utilização de ponteiros. Por exemplo, se um evento El escalona um evento E2, um ponteiro é utilizado para estabelecer a ligação entre E1 e E2. Se ocorrer algum erro no evento E2, o ponteiro é usado para cancelar o evento. Essa estratégia reduz a sobrecarga de espaço e de tempo associada ao cancelamento de mensagens e minimiza os danos causados por uma computação errada [FUJ90a].

4. Cancelamento experimental: um grupo de mensagens enviado a um LP pode ser completamente cancelado por uma anti-mensagem de cancelamento de grupo e as últimas mensagens podem ser preservadas, significando que estados podem ser recuperados sem a necessidade de se re-executar os eventos [KAL97].

O protocolo otimista mais popular é o Time Warp [JEF85] que se baseia no paradigma de Tempo Virtual para organizar e sincronizar os processos em ambientes distribuídos. $\mathrm{O}$ próximo tópico apresenta o Time Warp mais detalhadamente. 


\subsubsection{Time Warp}

Como já mencionado, o Time Warp se baseia no paradigma de Tempo Virtual. O objetivo do paradigma de tempo virtual é organizar e sincronizar os processos em um ambiente distribuído, através do uso de um sistema de coordenadas de tempo e espaços virtuais. Um sistema de tempo virtual é um sistema paralelo, executando em coordenadas de acordo com um relógio imaginário, usado para estimar o progresso computacional e definir a sincronização [JEF85].

Considere, por exemplo, um sistema com muitos processos pequenos, todos executando concorrentemente sobre um computador com vários processadores [JEF85]. Cada processo ocupa um lugar no espaço virtual, com um nome que deve ser único em todo o sistema, e que atua como sua coordenada espacial. Cada ação primitiva (mudança de variáveis, envio de mensagens etc.) possui coordenadas de tempo e espaço virtuais. Dessa forma, o conjunto de todas as ações localizadas no mesmo espaço virtual $x$ e tempo virtual $t$, refere-se a um evento em $(x, t)$.

A comunicação é feita por troca de mensagens e cada mensagem é composta por quatro valores: nome do processo transmissor, o tempo virtual de envio (tempo virtual em que a mensagem é enviada), nome do processo receptor e tempo virtual de chegada (tempo virtual em que a mensagem é recebida por um determinado processo).

Os sistemas de tempo virtual baseiam-se em duas regras fundamentais [JEF85]:

- Regra 1: o tempo virtual de envio de uma mensagem deve ser menor do que o seu tempo virtual de chegada.

- Regra 2: o tempo virtual de um evento em um processo deve ser menor que o tempo virtual do próximo evento.

O mecanismo Time Warp não foi projetado para atender a uma arquitetura específica de computadores, podendo ser implementado em sistemas com multiprocessadores [JEF85] e apresenta dois mecanismos básicos:

- mecanismo de controle local: cujo objetivo é garantir que os eventos sejam executados e as mensagens recebidas estejam em ordem correta; 
- mecanismo de controle global: destinado ao gerenciamento de memória, controle de fluxo, controle de entrada/saída, tratamento de erros etc.

O mecanismo de controle local do Time Warp se estrutura da seguinte maneira [JEF85]:

- relógio local de cada processo: determina o tempo virtual local (LVT) do processo, o seu valor não muda durante a ocorrência de um evento, mas sim entre eventos;

- lista de entrada de mensagens: armazena, em ordem crescente de timestamp (maiores ou iguais ao LVT), as mensagens recebidas; as mensagens já processadas situam-se na parte "passada" da lista e as que ainda não foram processadas situamse na parte "futura" da lista;

- lista de saída de mensagens: lista com as cópias das mensagens que já foram enviadas para outros processos (mensagens com timestamps menores ou iguais ao LVT);

- lista de estados passados: cada processo mantém uma lista de estados passados com timestamps menores que LVT.

Cada processo é responsável pela recepção de mensagens e execução de seus eventos em ordem crescente de timestamp. Se chegar uma mensagem com timestamp menor do que as mensagens já processadas (violação da relação de causa e efeito), o processo receptor deve efetuar rollback para retornar o processo a um estado anterior à violação.

O evento causador de rollback é chamado de extraviador (straggler, mensagem atrasada). No processo de rollback, são desfeitos os efeitos causados por todos os eventos que foram processados prematuramente pelo processo que recebeu o evento extraviador. $O$ cancelamento de uma mensagem previamente enviada ocorre através do envio de uma antimensagem que elimina a mensagem original. 
Um processo lógico é composto por um nome (que deve ser único no sistema), um relógio local virtual, variáveis que representem os dados do processo, uma lista de estados passados (para realizar o rollback), uma lista de mensagens de entrada e uma lista de mensagens de saída.

Para cada mensagem existe uma antimensagem que é exatamente igual em formato e conteúdo da mensagem original, exceto por um campo denominado sinal; mensagens enviadas explicitamente por processos têm sinal positivo $(+)$ e suas antimensagens têm sinal negativo $(-)$. Sempre que um processo envia uma mensagem, ela é enviada para a lista de entrada do processo receptor e uma cópia negativa é mantida na lista de saída do processo transmissor. Quando uma mensagem e antimensagem ocupam a mesma lista, elas se anulam.

Quando uma mensagem chega na lista de entrada de um processo com um timestamp (T) maior que o LVT desse processo, ela é enfileirada e a execução continua normalmente. Se o timestamp for menor significa que esse evento deveria ter sido executado antes [JEF85]. Então houve erro de causa/efeito, e todo o trabalho feito antes até o valor de timestamp dessa última mensagem que chegou deve ser desfeito através de rollback. O mecanismo rollback descarta todos os estados armazenados na lista de eventos passados após o tempo $\mathrm{T}$ e o processo receptor é réativado. Devem ser canceladas as mensagens transmitidas por esse processo com tempo maior que $\mathrm{T}$, através das antimensagens.

Três atitudes podem ser consideradas para a realização ou não de rollback [JEF85]:

1. Se a mensagem original já chegou, mas ainda não foi processada, seu timestamp deve ser maior que o LVT do processo receptor. A mensagem negativa que tem o mesmo valor de tempo virtual de chegada será colocada na mesma lista de entrada e não ocorrerá rollback.

2. Se a mensagem original tem um timestamp igual ou menor que o LVT do processo receptor. Ela pode ter sido parcialmente ou completamente processada, causando efeitos adversos no estado do processo receptor, possibilitando o envio de mais mensagens para um terceiro conjunto de processos. 
3. Se uma mensagem negativa chegar antes de uma mensagem positiva, ela é colocada na lista de entrada de mensagens até a chegada da mensagem positiva. Quando esta última chega, ela também é colocada na lista de entrada de mensagens e então elas se eliminam.

O processo de recuperação não necessita ser atômico, permitido que muitos rollbacks sejam executados simultaneamente. Não existe possibilidade de deadlock no Time Warp por ele ser não bloqueante. O Time Warp implementa três técnicas de cancelamento: agressivo, preguiçoso e direto.

Como cada processo necessita gravar seu estado para rollback, dois efeitos adversos são gerados neste momento de gravação: sobrecarga de memória consumida (pode faltar memória para realizar a simulação); tempo de processamento necessário para copiar a porção do estado no ponto de checagem.

O mecanismo de controle global trabalha para manipular e solucionar questões relacionadas ao sistema global, como assegurar o progresso global do sistema e manipular entrada/saída entre tantas atividades de rollback, já que o mecanismo de controle local não consegue resolver tais questões.

O principal conceito dentro do controle global é o do tempo virtual global (Global Virtual Time), GVT. O GVT é uma foto instantânea e global do sistema em um tempo $r$ [JEF85]. É considerado o relógio virtual do sistema e é utilizado como valor base do sistema, pois nenhum evento com tempo menor que o GVT pode sofrer rollback.

O LVT é o tempo virtual local corrente de um processo. Se a simulação fosse parada, os EVT's de todos os processos do sistema seriam verificados juntamente com os tempos virtuais de envio de todas as mensagens em trânsito para calcular o valor do GVT.

A relação entre o GVT e o LVT pode ser vista na Figura 3-5. Objetos "passados" são objetos com timestamp menores que GVT. Objetos com tempos de envio menores ou iguais ao GVT, mas com timestamp maiores ou iguais ao GVT são chamados de objetos "presentes". Todos os objetos com tempo de envio e timestamp maiores que GVT são denominados objetos "futuros". 


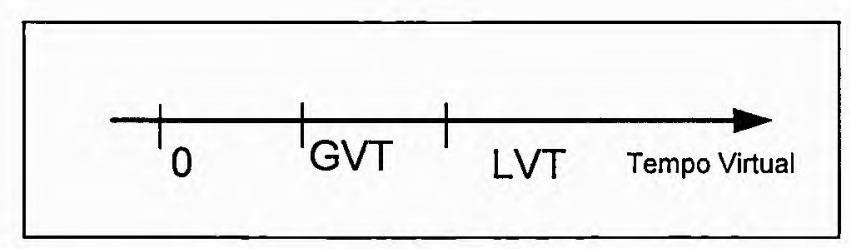

Figura 3-5 Relação entre os valores de tempo da simulação.

No Time Warp, a sobrecarga causada pelas mensagens futuras que ainda não foram processadas faz parte do problema de controle de fluxo em ambientes distribuídos. O processo receptor deve ser cuidadoso para não aceitar muitas mensagens, pois ele torna-se responsável pelo armazenamento em um buffer das mensagens recebidas até que sejam processadas.

Se a memória do processo receptor estiver cheia, o protocolo Time Warp deve ser capaz de recuperar espaço através da devolução de mensagens ainda não processadas para os seus respectivos processos transmissores [JEF85]. O processo transmissor efetua rollback para voltar ao estado em que estava antes do envio da mensagem devolvida e posteriormente ele retransmite a mensagem para que ela seja executada pelo processo destino.

Se um processo envia um comando para um dispositivo de saída, ou qualquer outro agente externo, é necessário que nenhuma atividade física de saída seja realizada imediatamente, porque o processo transmissor pode realizar rollback e cancelar a requisição de saída. A saída só pode ser fisicamente efetuada se o GVT for maior que o timestamp da mensagem que contém o comando.

O Time Warp consome memória através do armazenamento de estados, de mensagens em listas de entrada e de saída. Pode-se classificar os esquemas de gerenciamento de memória em dois tipos [JEF85]: (1) esquemas que reduzem a média de memória utilizada, mas não recuperam memória sob demanda e (2) esquemas que recuperam memória sob demanda. (sob demanda significa liberar espaço de memória através do mecanismo de rollback em um ou mais processos lógicos, para um tempo anterior ao tempo de simulação). 
Os esquemas (1) utilizam redução de estados salvos (quando o tamanho do estado é grande, apenas uma porção do estado é modificada por um evento, somente a mudança é registrada ao invés de se fazer uma cópia inteira do estado) e otimismo limitado (limitar a quantidade de processos que possam adiantar-se em relação aos outros, que possam provocar violação da causa/efeito).

Os esquemas (2) se dividem em duas subclasses: esquemas que recuperam espaços usados por objetos "passados" e por objetos "futuros". A coleta de fósseis (destruição de informações com tempos mais antigos que o GVT) recupera os espaços empregados por objetos "passados".

Esquemas de recuperação de espaços usados por objetos "futuros":

- retorno de mensagem: quando uma mensagem chega a uma lista de entrada de um processo receptor e não existe lugar na lista para armazená-la, o processo receptor devolve uma das mensagens (maior tempo de envio) para o processo que a transmitiu.

- protocolo de Gafni: é uma generalização do retorno de mensagem. Se o objeto descartado é uma mensagem em uma lista de entrada, ela é devolvida para o seu processo transmissor como o esquema anterior realiza. Se for uma mensagem da lista de saída, ela é transmitida para o processo receptor, onde cancelará a mensagem positiva correspondente e aciona o mecanismo de rollback. Se o objeto é um estado, ele é descartado e é efetuado o rollback.

- cancelback: destinado a arquiteturas com memória compartilhada. Assume a definição original do GVT: seleciona qualquer objeto "futuro" do sistema, isto é, qualquer objeto que tem seu tempo de envio maior que GVT, para então cancelá-lo.

\subsubsection{Desempenho dos Mecanismos Otimistas}

Algumas das principais sobrecargas que os simuladores Time Warp têm que lidar são [THO99]:

- Manipular as listas de eventos. 
- Custos relacionados à gravação das variáveis de estados.

- Computações do GVT.

- Exigência de muita memória comparada com as técnicas seqüenciais e conservativas.

Apesar disso, um maior paralelismo pode ser alcançado devido ao processamento otimista dos eventos, sem bloqueio da simulação. Se os custos de rollback forem minimizados, melhor será o desempenho obtido na simulação.

Porém, o desempenho da simulação otimista depende de outros fatores tais como o tamanho e o comportamento da aplicação, sendo difícil determinar em que casos executariam com melhor desempenho [THO99]. A questão crítica enfrentada pelos protocolos otimistas, como o Time Warp, é se a simulação apresentará um comportamento onde a maioria de seu tempo será gasta na ocorrência de computações erradas e execução de rollbacks.

Às vezes, eventos atrasados podem causar uma cascata de rollbacks, degradando o desempenho da simulação. Algumas experiências foram realizadas por Fujimoto [FUJ90a] usando-se cargas de trabalho sintéticas para avaliar o desempenho do Time Warp. Foi observado que o Time Warp pode alcançar speedup proporcional ao nível de paralelismo da carga de trabalho.

Mais recentemente, Spolon [SPO01] propôs uma técnica para avaliação de desempenho de implementações do protocolo otimista Time Warp, que utilizou um modelo de Redes de Petri. Nesse trabalho foi possível obter resultados de desempenho de diversas variantes do protocolo de sincronização otimista, sem a necessidade de implementá-los e dessa forma o usuário da simulação distribuída pode definir com melhor precisão qual variante trará melhor desempenho à sua aplicação: “ $O$ método de avaliação definido também é útil nas situações onde o usuário está convencido de que a simulação distribuída sincronizada por um determinado protocolo otimista é a melhor solução para resolver a sua aplicação. Nesse caso, o método permite que se faça uma avaliação do comportamento da simulação distribuida em relação à granulosidade dos eventos e à divisão da aplicação em processos lógicos, antes da implementação." 
Outro problema é o gasto de memória encontrado nos algoritmos otimistas, que tendem a utilizar espaço de memória algumas vezes maior do que a simulação conservativa correspondente a ele. Isso é devido à necessidade de se manter algumas estruturas (output queue, variáveis de estado, etc) para possibilitar o rollback.

\subsection{Comparação entre os Mecanismos Conservativo e Otimista}

A superioridade entre os protocolos otimistas e conservativos é uma questão freqüentemente levantada. Porém, regras gerais para a utilização de um ou outro protocolo na simulação distribuída não podem ser formuladas, uma vez que o desempenho não pode ser suficientemente caracterizado pelos modelos [FER94]. A Tabela 1 apresenta uma comparação entre as principais características dos protocolos CMB e Time Warp: 


\begin{tabular}{|c|c|c|}
\hline Estratégia & Protocolos Conservativos (CMB) & Protocolos Otimistas (Time Warp) \\
\hline $\begin{array}{l}\text { Princípio } \\
\text { Operacional }\end{array}$ & $\begin{array}{l}\text { Evita a violação do princípio de } \\
\text { causa e efeito; somente eventos } \\
\text { "seguros" são processados. }\end{array}$ & $\begin{array}{l}\text { Violações ao princípio de causa e efeito } \\
\text { ocorrem, mas um mecanismo de } \\
\text { recuperação é acionado quando detectado } \\
\text { (imediatamente ou no futuro); todos os } \\
\text { eventos são processados. }\end{array}$ \\
\hline Sincronização & $\begin{array}{l}\text { Mecanismo de sincronização: } \\
\text { bloquear processos; propenso a } \\
\text { situações de deadlock; protocolos } \\
\text { baseados em mensagens nulas: } \\
\text { sobrecarga de comunicação; } \\
\text { protocolos de detecção e } \\
\text { recuperação: gerenciador de } \\
\text { deadlock centralizado. }\end{array}$ & $\begin{array}{l}\text { Mecanismo de sincronização: rollback; } \\
\text { mecanismo de aniquilação: sobrecarga de } \\
\text { comunicação; cascatas de rollbacks: } \\
\text { sobrecarrega a utilização da memória e } \\
\text { degrada o desempenho. }\end{array}$ \\
\hline Para & $\begin{array}{l}\text { Paralelismo do modelo não pode ser } \\
\text { completamenter } \\
\text { comportamentor explorado; } \\
\text { pessimista se a ocorrência de erros } \\
\text { de causa e efeito for rara. }\end{array}$ & $\begin{array}{l}\text { Paralelismo do modelo é totalmente } \\
\text { explorado; se a ocorrência de erros de } \\
\text { causa e efeito for provável, mas não } \\
\text { freqüente, o desempenho do protocolo } \\
\text { aumenta. }\end{array}$ \\
\hline Lookahead & $\begin{array}{l}\text { Necessário para tornar o protocolo } \\
\text { operável, essencial para seu } \\
\text { desempenho. }\end{array}$ & $\begin{array}{l}\text { Não trabalha com Lookahead, porém } \\
\text { pode ser utilizado para sua otimização. }\end{array}$ \\
\hline Bala & $\begin{array}{l}\text { Melhor desempenho quando todos } \\
\text { os canais são igualmente utilizados. }\end{array}$ & $\begin{array}{l}\text { Melhor desempenho quando a diferença } \\
\text { entre os LVTs é pequena. }\end{array}$ \\
\hline $\begin{array}{l}\text { Global Virtual } \\
\text { Time }\end{array}$ & Não requer cálculo de GVT. & $\begin{array}{l}\text { GVT difícil de ser calculado; cálculo } \\
\text { centralizado - gargalo; cálculo } \\
\text { distribuído: sobrecarga de comunicação. }\end{array}$ \\
\hline Estados & $\begin{array}{l}\text { Consumo de memória moderado, } \\
\text { aceita modelos com espaços de } \\
\text { estado grandes. }\end{array}$ & $\begin{array}{l}\text { Melhor desempenho quando o espaço de } \\
\text { estados necessário a ser armazenado é } \\
\text { pequeno. }\end{array}$ \\
\hline Memória & Consumo de memória moderado. & $\begin{array}{l}\text { Consumo de memória dinâmico; } \\
\text { sobrecarga na gravação dos estados; fóssil } \\
\text { collection; cálculo freqüente do GVT; } \\
\text { gerenciamento de memória complexo. }\end{array}$ \\
\hline $\begin{array}{l}\text { Mensagens e } \\
\text { Comunicação }\end{array}$ & $\begin{array}{llr}\text { Obrigatória } & \text { a chegada } & \text { das } \\
\text { mensagens e processamento } & \text { dos } \\
\text { eventos em } & \text { ordem cronológica } & \text { do } \\
\text { timestamp; } & \text { topologia } & \text { de } \\
\text { comunicação estática. } & \\
\end{array}$ & $\begin{array}{l}\text { Mensagens podem chegar fora de ordem } \\
\text { cronológica - devem ser executadas pela } \\
\text { ordem do timestamp; única fila de } \\
\text { entrada; topologia de comunicação } \\
\text { dinâmica. }\end{array}$ \\
\hline Implementação & $\begin{array}{l}\text { Fácil para implementar; estruturas } \\
\text { de dados e controles simples. }\end{array}$ & $\begin{array}{l}\text { Difícil para implementar; estrutura de } \\
\text { dados simples, porém manipulação } \\
\text { complexa. }\end{array}$ \\
\hline
\end{tabular}

Tabela 1 Comparação das características dos protocolos Conservativos e Otimistas. 


\subsection{Protocolo Assíncrono}

A maior sobrecarga na simulação distribuída está relacionada à necessidade de sincronização dos eventos distribuídos. A abordagem conservativa introduz sobrecargas na simulação relacionadas aos mecanismos de detecção e recuperação de deadlocks e cálculo do lookahead. As sobrecargas da abordagem otimista estão ligadas à ocorrência de rollbacks, gravação das variáveis de estado e cálculo do GVT.

A questão é: a relação de causa e efeito precisa ser preservada em todos os tipos de simulação? [THO99]. Em [THO98] é investigada uma abordagem diferente das duas anteriormente vistas, adotando um comportamento, de certa forma, anarquista. Essa abordagem simplesmente ignora a ocorrência de erros de causa e efeito, eliminando a sobrecarga devida à necessidade de sincronização dos eventos. As vantagens encontradas foram ganhos significantes no tempo de execução da simulação e valores resultantes estatisticamente corretos, quando comparados com a execução de uma simulação sincronizada, para algumas aplicações.

A estratégia para diminuir a sobrecarga devido à sincronização segue duas linhas:

1. redução do número de vezes que a simulação necessita ser sincronizada;

2. eliminação da necessidade de sincronização ou manutenção da relação de causa e efeito.

Martini, Rümeskasten e Tölle em [MAR97] fizeram experiências com a idéia de relaxamento da relação de causa e efeito em suas simulações de redes de computadores. Em seus experimentos, a execução otimista é feita dentro de intervalos de uma simulação sincronizada conservativamente e nenhum esquema de recuperação é invocado quando uma violação de causa e efeito é encontrada.

Com relação a essa exposição do programa de simulação a computações potencialmente erradas, Martini et al argumentam que as vantagens de "tolerar ou relaxar" a sincronização superam as desvantagens de tal abordagem: o erro dos resultados da simulação é pequeno e freqüentemente dentro de um intervalo de limite de confiança e o tempo de execução da simulação pode ser significantemente reduzido. 
Em um outro trabalho [PHA00] foram desenvolvidas simulações de redes ATM sem nenhum sincronismo. Os resultados e as vantagens encontradas foram semelhantes aos verificados em [MAR97].

Nem todas as aplicações, porém, podem ser consideradas para a simulação que não obedece à restrição de causa e efeito. As aplicações que necessitam manutenção da relação de causa e efeito não são candidatas a essa abordagem, como a simulação de lógica digital. Porém, alguns sistemas, ou um grupo de sistemas, poderiam ser considerados e tirariam proveito das vantagens dessa abordagem.

Em [THO99]foi implementado um simulador, o NoTime, que não preserva a relação de causa e efeito dos eventos da simulação. O NoTime é um simulador que foi desenvolvido para se estudar os efeitos de se ignorar os erros de causa e efeito dentro da simulação distribuída. Da mesma forma que as abordagens otimista e conservativa, os processos físicos do sistema são representados neste simulador por processos lógicos. A interação entre os processos se dá através de troca de mensagens, no caso, implementada em MPI (Message Passing Interface) [GRO94].

Os objetos da simulação são agrupados e associados a cada LP. A arquitetura do NoTime é ilustrada na Figura 3-6. O ciclo de execução da simulação de cada processo segue da forma tradicional: o processo escalona um objeto de simulação, o evento disponível na lista de entrada é escalonado seguindo a ordem de chegada (FIFO), é processado o evento e a sua execução pode gerar ainda mensagens locais ou remotas. As mensagens locais são postas imediatamente na lista de entrada do objeto correspondente. As mensagens não locais são enviadas para o LP receptor através de troca de mensagem. 


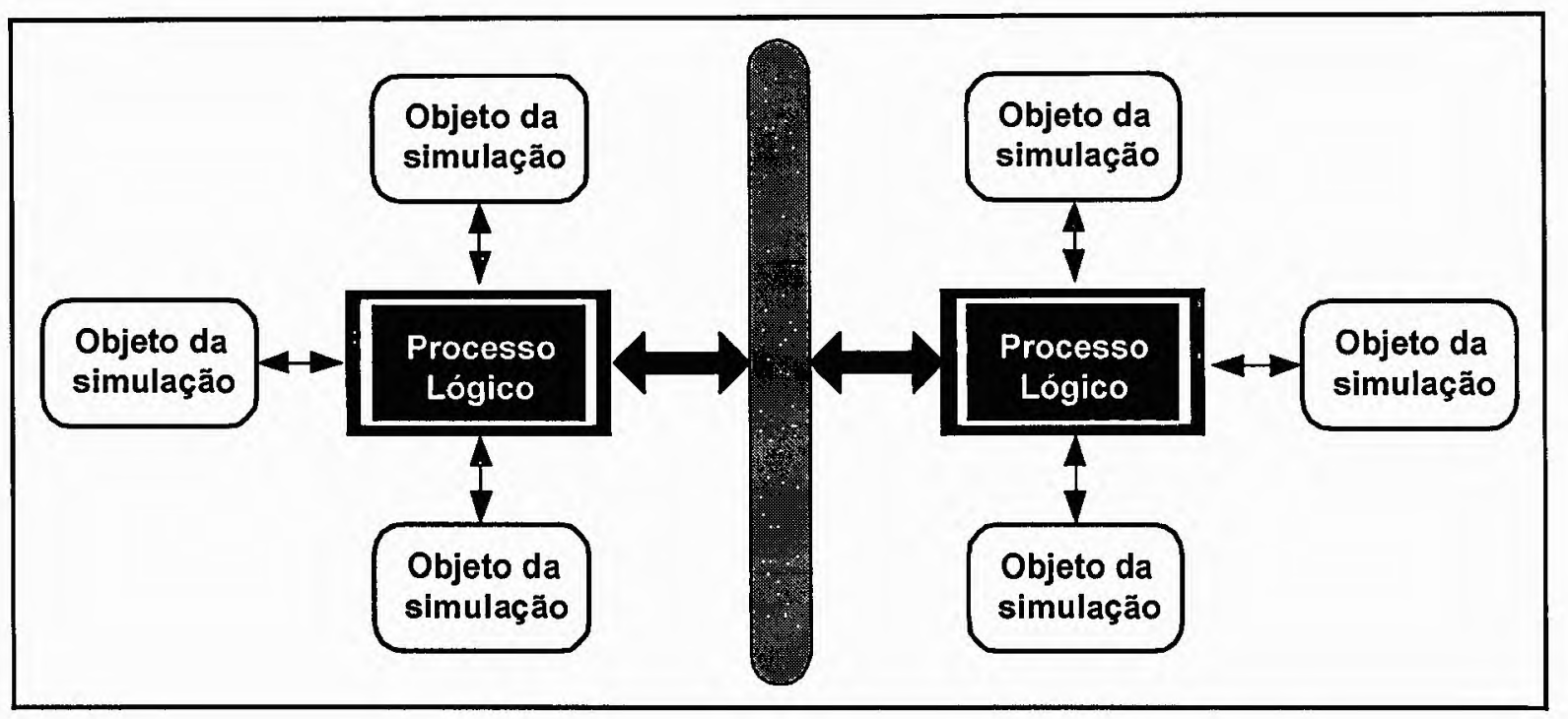

Figura 3-6 Arquitetura do NoTime.

A simulação que não utiliza nenhum mecanismo de sincronização introduz erros nos resultados da simulação. Porém, as experiências realizadas em trabalhos que abordam este mecanismo [MAR97] [THO99] [PHA00] mostram que esses erros podem ser pequenos e dentro de um intervalo de confiança. A grande vantagem prática de não se considerar a relação de causa e efeito é a redução do tempo execução da simulação. As experiências encontradas em trabalhos relacionados ao relaxamento da relação de causa e efeito serão citadas no próximo capítulo, onde também será feita uma comparação entre as três abordagens aqui apresentadas.

\subsection{Considerações Finais}

Neste capítulo foram apresentados três mecanismos para o tratamento da relação de causa e efeito dentro da simulação distribuída. Os mecanismos conservativos utilizam a técnica de bloquear os processos que não possuem eventos seguros para serem processados, o que pode levar a situação de deadlock dos processos. Alguns protocolos evitam a ocorrência de deadlocks [BRY77] [CHA79] [MIS86] [FUJ90a] e outros permitem que os processos entrem em situação de deadlock e então um mecanismos de recuperação é utilizado [CHA81] [FUJ90a]. 
Os mecanismos otimistas supõem que nenhum erro de causa e efeito irá ocorrer, assim não necessitam detectar quando é seguro processar um evento, apenas seguem a execução normal da simulação e quando um erro é detectado, um procedimento de recuperação chamado de rollback é ativado [FUJ90a] para voltar a simulação a um estado consistente. O protocolo otimista mais conhecido é o Time Warp [JEF85].

A abordagem assíncrona [THO99], aqui denominada de anarquista diminui a sobrecarga introduzida na simulação devido a necessidade de sincronização entre os eventos, simplesmente ignorando os erros de causa e efeito. Nem todas as aplicações podem ser modeladas por essa abordagem, mas alguns sistemas podem usufruir a sua principal vantagem: redução do tempo de execução da simulação.

Comparações entre os métodos otimistas e conservativos não podem ser facilmente caracterizadas devido às distinções das técnicas que cada um utilizam. Foi apresentado então uma comparação entre as principais características de cada método [FER94].

Não se pode concluir que os métodos conservativos são melhores ou piores que os otimistas. O desempenho do protocolo depende muito do comportamento da aplicação que vai ser simulada, podendo ser mais bem empregado um método otimista, conservativo ou assíncrono. 


\section{Capítulo 4}

WARPED

Neste capítulo será feita uma descrição do simulador WARPED, um kernel que implementa o protocolo otimista baseado no paradigma de tempo virtual definido por Jefferson [JEF85]. A biblioteca KUE também é descrita neste capítulo, bem como as modificações que foram feitas para a sua utilização.

\subsection{Introdução}

O WARPED é um simulador distribuído otimista que implementa o protocolo Time Warp. A interface de programação da aplicação no WARPED visa tornar fácil a modelagem de aplicações de eventos discretos, sem o conhecimento dos detalhes internos do núcleo do simulador [RAD98].

O sistema está implementado em $\mathrm{C}++$ usando o compilador GNU $\mathrm{C}++$ e utiliza as vantagens da programação orientada a objeto. Um dos benefícios é que a aplicação do programador pode redefinir e reconfigurar funções, sem a modificação direta do código do núcleo. As trocas de mensagens entre os objetos distribuídos são feitas através da biblioteca de passagem de mensagem MPICH [ARG98]. 
A Figura 4-1 apresenta a organização de um sistema modelado no WARPED [THO99]. Os objetos da simulação (SO) são agrupados em entidades chamadas de processos lógicos ou LPs. Os SO associados a um LP são processados em um único processador e o paralelismo ocorre em nível de LP.
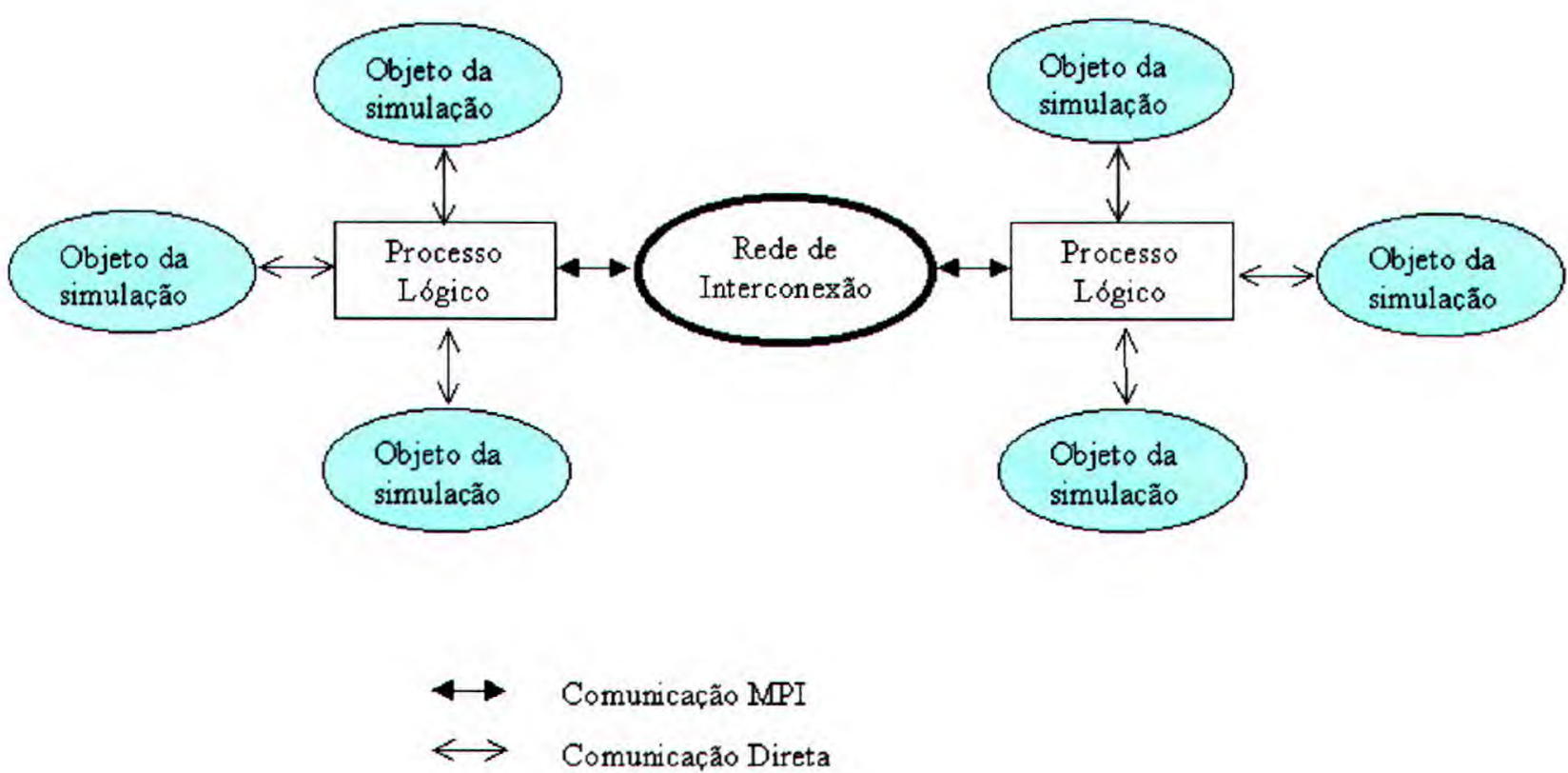

Figura 4-1 Organização de um sistema modelado no WARPED.

Por exemplo, se dois processadores estão disponíveis para a simulação distribuída, dois LPs podem ser definidos e os objetos da simulação podem ser agrupados nesses dois LPs, sendo então executados paralelamente.

A Figura 4-2 mostra a estrutura de um processo lógico (LP). As filas de entrada e saída armazenam os eventos que chegam e saem do LP respectivamente. A fila de estados armazena a história do LP. Cada LP também mantém um relógio chamado de Local Virtual Time (LVT), que representa o tempo da simulação naquele processo.

Cada LP é responsável pelo gerenciamento da comunicação e escalonamento para execução dos objetos da simulação associados a ele. Um objeto gerenciador da comunicação é associado a cada LP que é responsável por manipular e conduzir a comunicação dentro e entre LPs. 
A comunicação entre objetos da simulação de um mesmo LP é feita pela inserção direta do evento na fila de entrada do objeto destino, o que é muito mais rápido do que a comunicação entre SOs de diferentes LPs, que necessitam utilizar as rotinas de send/receive da biblioteca de passagem de mensagem, no caso MPICH. Dessa forma, os SOs que se interagem mais freqüentemente devem ser alocados no mesmo LP.

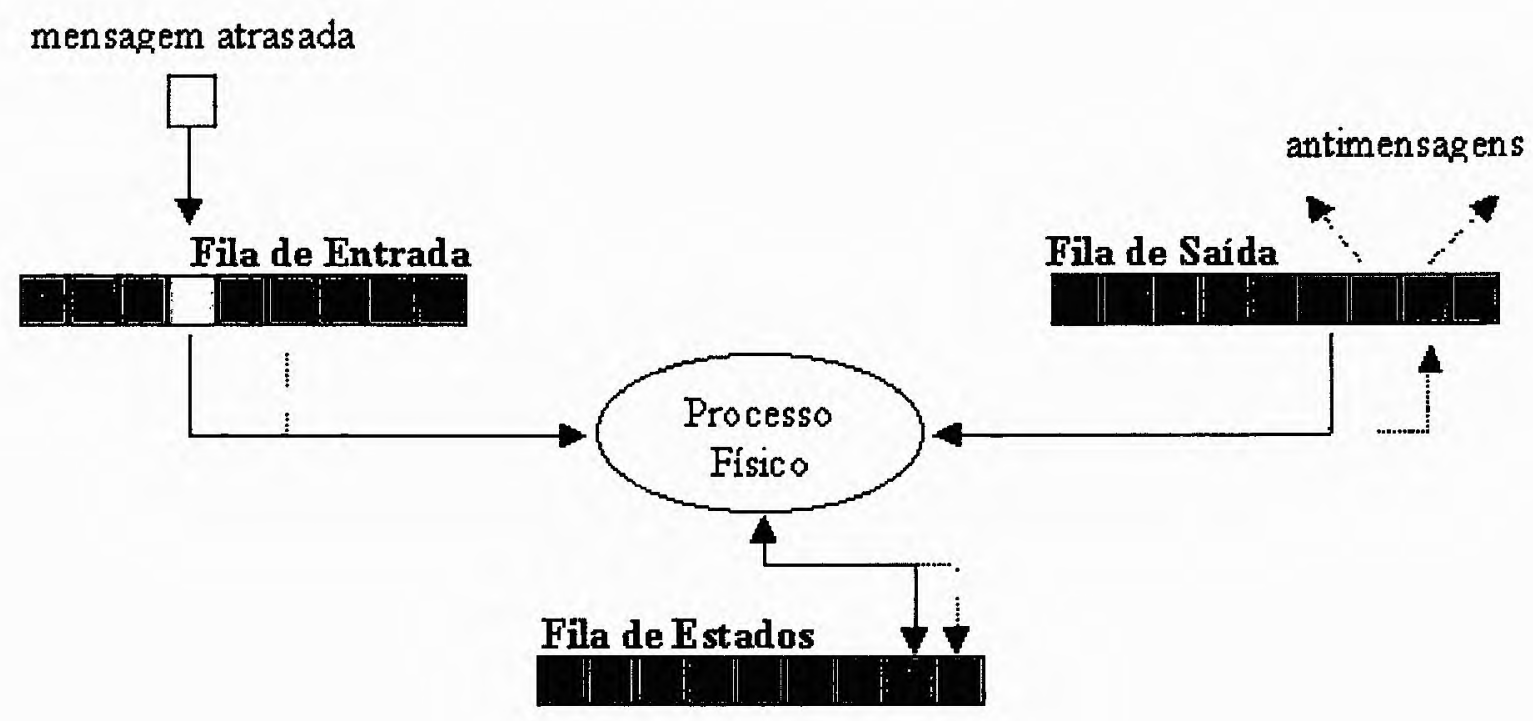

Figura 4-2 Processo Lógico.

O algoritmo usado para o cálculo do GVT (Global Virtual Time) é o pGVT [DSO94]. Esse algoritmo compreende dois elementos funcionais:

1. processo gerenciador do GVT: esse processo calcula, mantém e informa aos outros processos lógicos o valor do GVT. O valor de GVT é o menor valor de todos os LGVTs;

2. cálculo e distribuição do LGVT (local GVT): esse calculo é feito localmente a cada processo lógico. O LGVT é o menor valor de timestamp entre as mensagens que ainda não foram executadas (mensagens que estão ainda na fila de entrada ou em trânsito) em um determinado tempo t. 
Cada LP calcula o seu LGVT e este deve ser sempre informado para o gerenciador do GVT, para que seja calculado um novo valor de GVT. O valor de GVT pode ser configurado para ser calculado de acordo com um intervalo de tempo (tempo da simulação) fixo. Depois de calculado um novo valor de GVT, esse valor é passado para todos os LPs para que a coleta de lixo seja feita.

\subsection{Interface de Programação da Aplicação (API) do WARPED}

As funções básicas que o núcleo do WARPED fornece para a aplicação são métodos para o envio e recebimento de eventos entre SOs e a possibilidade de definir diferentes tipos de objetos e entidades (SO) [RAD98][THO99]. A interface da aplicação com o sistema é conseguida através das características de orientação a objetos da linguagem $\mathrm{C}++$. A modelagem de uma aplicação envolve a identificação dos objetos da simulação, suas variáveis de estado e os eventos que serão trocados entre eles. A aplicação do programador necessita então definir as seguintes classes:

1. Objetos da simulação (SO).

2. As variáveis de estado que devem ser armazenadas de acordo com cada objeto.

3. Eventos que serão trocados entre eles.

Um SO representa uma entidade que pode enviar/receber eventos de/para outro SO. Como resultado do processamento de eventos, as variáveis de estado de um SO são modificadas e outros eventos podem ser gerados. A Figura 4-3 ilustra as interfaces da aplicação presentes no WARPED.

A interface vista pelo SO do programador está representada pela definição da classe usersimulationobject. A definição desta classe é feita em duas partes. A primeira é um conjunto de métodos que o núcleo fornece para o SO. Esses métodos fornecidos pelo núcleo são para a comunicação (sendevent, getevent), verificação das informações do núcleo (havemoreevent, getsimulationtime) e acesso às variáveis de estado (getstate). 
A segunda parte consiste em um conjunto de métodos escritos pelo programador da aplicação, tendo cada método uma função específica. A função initialize é chamada em cada SO antes do inicio da simulação. Essa chamada é para que cada SO, se necessário, realize alguma ação de inicialização. Por exemplo, a inicialização pode incluir a abertura de arquivos, a configuração de variáveis de estado iniciais ou a transmissão de eventos de inicialização para os outros processos distribuídos da simulação. Analogamente, o método finalize é chamado no final da simulação. Dessa forma, o SO pode fazer uma "limpeza total", realizando ações como fechamento de arquivos, computação das estatísticas, produção de saídas.

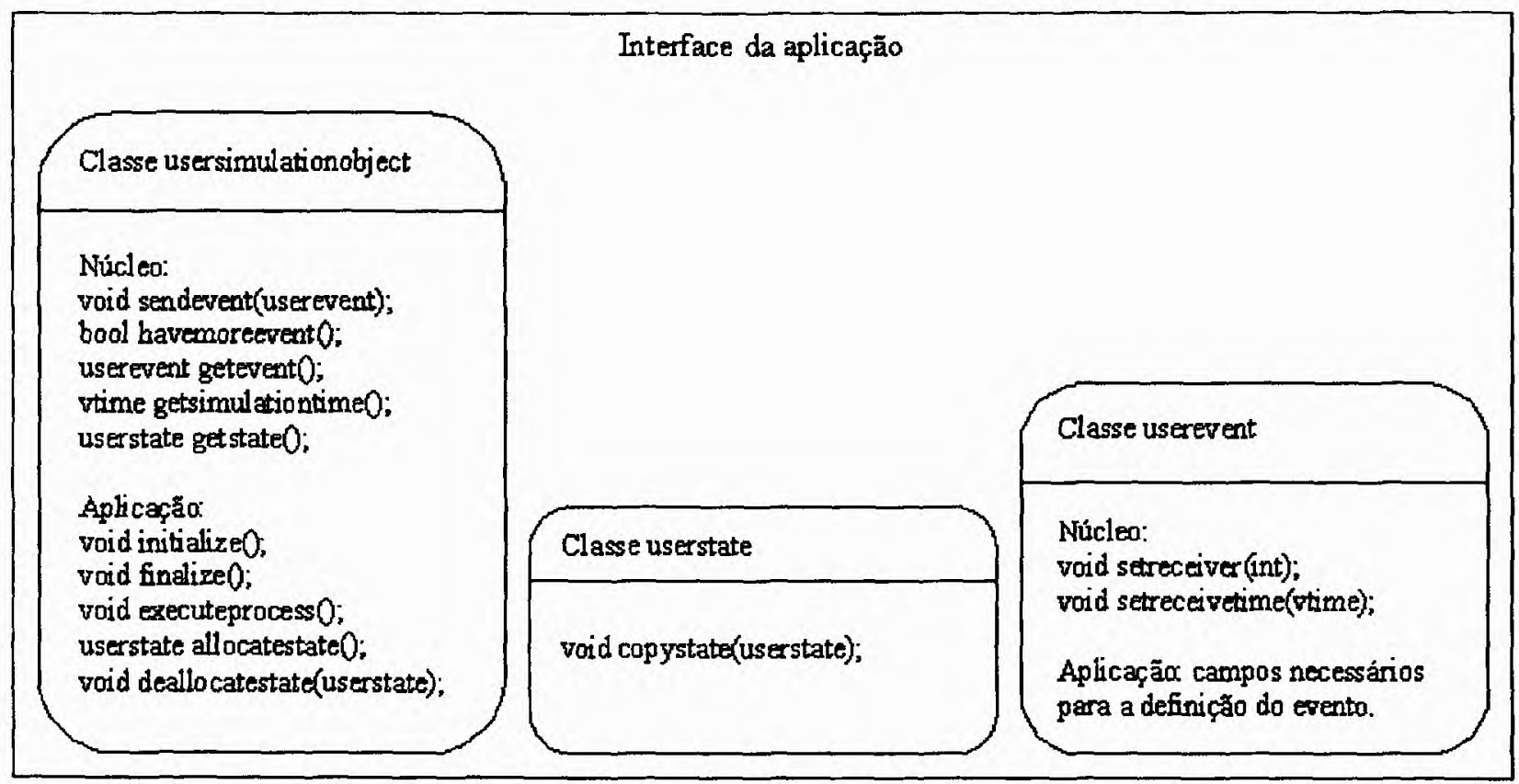

Figura 4-3 API do WARPED.

O método executeprocess de cada SO é chamado pelo núcleo sempre que o SO tem um evento para ser processado. O núcleo chama allocatestate dentro de cada SO quando é necessário alocar uma variável de estado e o deallocatestate é chamado para entregar de volta uma variável de estado para a aplicação quando necessário (rollback). 
Qualquer SO tem a necessidade de definir algumas variáveis de estado e essas variáveis são modificadas devido à execução dos vários eventos por ele recebido. Este comportamento é especifico para cada aplicação. O método copystate da Figura 4-3 é chamado pelo núcleo para copiar as variáveis de estados definidas pelo usuário para uma lista de estados que poderão ser usados no caso de rollback.

Os eventos representam a comunicação entre os objetos da simulação. A Figura 4-3 mostra a classe que define os eventos do programador (classe userevent). $\mathrm{O}$ método setreceiver permite que a aplicação fixe o id (identificação) do SO receptor da mensagem. O método setreceivertime permite que aplicação fixe o tempo (da simulação) em que o evento deverá ser recebido. $\mathrm{O}$ usuário deve fornecer os outros dados que serão enviados na mensagem.

Depois de definida as classes da Figura 4-3, o programador da aplicação precisa instanciar todos os SOs em um arquivo main.cc e associar um único id para cada SO. Dependendo do paralelismo da aplicação, os LPs devem ser criados através da classe logicalprocess (fornecida pelo núcleo), que necessita de três argumentos de entrada: o número total de objetos da simulação, o número de objetos dentro do LP local e o número total de LPs na simulação.

Para um melhor desempenho, a partição dos SOs deve ser feita de tal maneira que os SOs que interagem com mais freqüência entre si sejam alocados no mesmo LP. Os SOs são ligados a um LP através do método logicalprocess: :registerobject. Uma vez que todos os objetos da simulação foram associados a um LP, o método logicalprocess::allregistered é chamado. A simulação pode, então, ser inicializada através da chamada do método logicalprocess: :simulate em cada LP.

Na Tabela 2, é apresentado um exemplo de um arquivo main.cc. Neste arquivo são definidos quatro objetos: source, queue, server e sink. Esses objetos definem o modelo de Redes de Filas de uma MM1. 
\#include $<$ stdio.h $>$

\#include < sys/time.h>

\#include "LogicalProcess.hh"

\#include "CommMgrInterface.hh"

\#include "SimulationTime.hh"

\#include "Types.hh"

\#include "QueueObject.hh"

\#include "SourceObject.hh"

\#include "ServerObject.hh"

\#include "SinkObject.hh"

const VTime LogicalProcess::SIMUNTIL = PINFINITY;

int main(int argc, char *argv[]) \{

int id $=0$;

physicalCommInit ( \&argc, \&argv );

id = physicalCommGetId $($;

if(id $==0)\{$

LogicalProcess $\mathrm{lp}(4,4,1)$; // define um LP: número total de SOS,número de SOs locais e número de LPs na simulação

/objeto source tem o objetivo de gerar chegada de eventos no sistema(MM1)

SourceObject source0("source0",50000);//nome e n. de eventos

source 0. id $=0$; / identificação

source 0 .setDistribution(EXPONENTIAL, $0.0833,0$ );//istribuição que será

//usada para gerar as 50000 chegadas

source 0 dest $=1 ; / /$ para quem enviará mensagens

lp.registerObject(\&source 0$) ; /$ registra o objeto

/objeto queue tem o objetivo de armazenar os eventos que requisitam o

/servidor, mas este não pode atendê-los imediatamente

QueueObject queuel("queuel",1, 1);//nome, identificação e número de servidores

lp.registerObject(\&queue1);/registra objeto

/objeto server executa eventos

ServerObject server2("server2");//nome

server2.id $=2 ; /$ identificação

server2. setServerDistribution(EXPONENTIAL,0.04,0);//distribuição dos tempos de serviço

server2 dest $=3 ; / /$ destino

server2.qDest $=1 ; /$ identificação da fila

lp.registerObject(\&server2);//registra objeto

Tabela 2 Exemplo de um arquivo main.cc. 


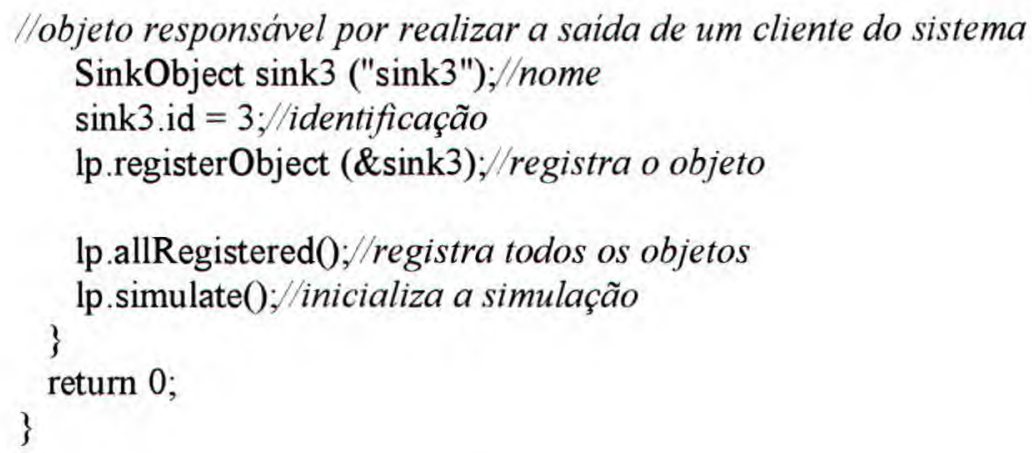

Tabela 2 Exemplo de um arquivo main.cc.

\subsubsection{Biblioteca Kue}

Juntamente com o WARPED versão 1.0.2, a biblioteca KUE [THO99] foi implementada com a finalidade de fornecer uma interface para a construção de modelos de Redes de Filas. A biblioteca fornece alguns objetos necessários para a criação de um modelo de Redes de Filas que pode então ser simulado sobre o núcleo do WARPED.

A biblioteca original implementa os seguintes objetos:

- Source: num modelo de redes de filas, o papel de um objeto source é produzir tokens ou eventos. Cada objeto source tem uma função de distribuição usada para distribuir os eventos.

- Fork: distribui os eventos recebidos para diversas saídas.

- Join: envia os eventos recebidos (de várias entradas) para uma única saída.

- Delay: implementa o "tempo de pensar".

- Queue: é definido como uma unidade de armazenamento e uma disciplina de fila (FIFO, LIFO). Pode ser uma fila de um único servidor ou de vários servidores. Armazena eventos recebidos em um buffer, e quando o servidor requisita um evento para processar, o evento da cabeça da fila é enviado. 
- Server: é uma entidade capaz de produzir a requisição de um serviço. Quando um servidor está ocupado atendendo a uma requisição, os eventos que chegam são armazenados na fila. Quando o servidor termina o processamento de um evento, ele manda uma mensagem para sua fila solicitando um novo evento para ser processado.

- Sink: é um objeto que "consome" os eventos de um modelo de redes de filas significando a saída de um cliente do sistema.

Vários problemas foram encontrados na utilização desta biblioteca, levando a uma série de modificações. Essas modificações estão descritas nos itens de 4.2.1.1 a 4.2.1.5.. Objetos como fork e join não foram mantidos na nova versão, já que não são objetos característicos de um modelo de Redes de Filas.

\subsubsection{Objeto Source}

Esse objeto tem como finalidade produzir eventos (chegada de clientes). Uma mudança feita neste objeto foi a troca do tipo da variável que representa o tempo da simulação (timestamp), que foi definida como do tipo inteira, mas na realidade essa variável pode e assume valores reais. Quando o tempo da próxima chegada era calculado através de alguma das funções de distribuição implementadas no WARPED, o valor retornado era um real, mas apenas a parte inteira era considerada na simulação. Por exemplo, se fosse gerado um tempo para a próxima chegada de 2.9 unidades de tempo, o valor considerado seria 2 . Esse arredondamento influenciava no cálculo das saídas da simulação.

Uma instância de um objeto source é criada através da definição de um objeto do tipo SourceObject. Para isso, é necessário que seja dado: um nome ao objeto (com o qual ele será tratado no sistema); uma identificação, que deve ser única para cada objeto; a função de distribuição; a semente para geração dos números aleatórios; quantos eventos esse objeto deverá gerar durante a simulação. Também deve ser especificado para onde os eventos gerados devem ser encaminhados.

Um exemplo de criação de um objeto source é o seguinte (Tabela 3): 
SourceObject source0("source0",50000);//cria o objeto source0 para gerar 50000 chegadas. source $0 . \mathrm{id}=0 ; / /$ identificação do objeto source 0 .setDistribution(EXPONENTIAL, 10.5,0); //a função de distriuição é exponencial com média igual a 10.5 segundos source 0 .dest $=1 ; / /$ destino dos eventos gerados

\section{Tabela 3 Criação de uma instancia do objeto source.}

\subsubsection{Objeto Queue}

O objetivo desse objeto é armazenar os eventos que chegam requisitando um servidor, mas não há servidor disponível para atendê-los naquele instante. Esse evento então entra numa "fila de espera" até que algum servidor possa servi-lo.

Na implementação original, o objeto queue, por erro de implementação, não possuía nenhum tipo de armazenamento, e assim, os eventos que eram recebidos e não podiam ser atendidos imediatamente pelo servido eram "perdidos", embora na documentação da biblioteca estivesse informado um dispositivo de armazenamento já estaria implementado.

O código do objeto queue da versão original é a seguinte, Tabela 4:

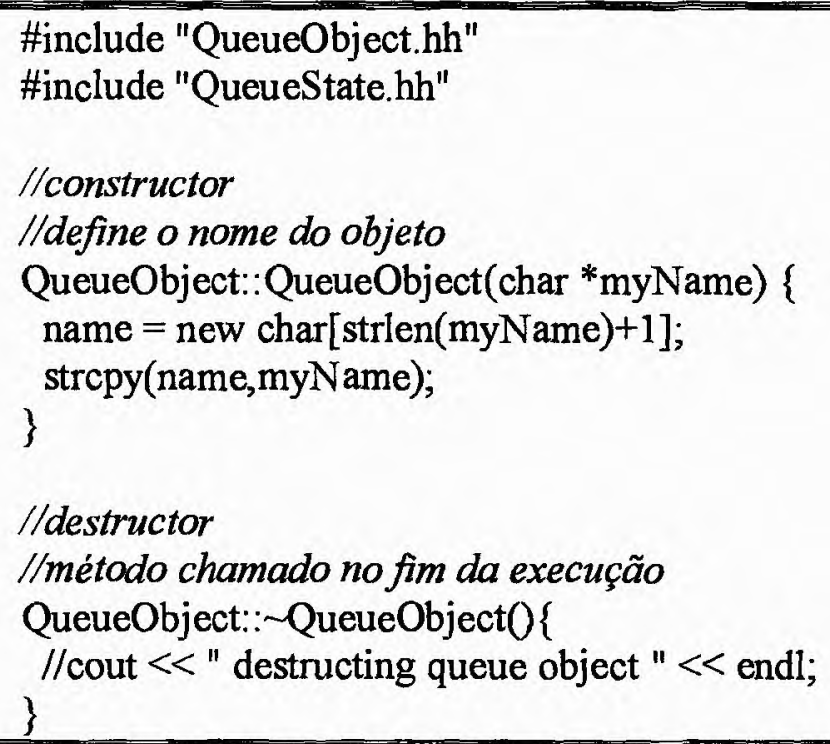

Tabela 4 Código do objeto queue versão original. 
//método executado quando existe um evento para o objeto

void QueueObject:: executeProcess 0\{

BasicEvent *recvEvent ;

recvEvent = getEvent(); //verifica se tem evento para executar

if ( recvEvent ==NULL) \{//se não existe evento finaliza o método

cerr $<<$ name $<<$ "scheduled for execution with no events " $<<$ endl;

//mensagem de erro

\}

else \{//se existe evento para processar, gera uma evento para o seu servidor

BasicEvent *newEvent $=($ BasicEvent $*$ )new char[recvEvent- $>$ size $]$;

memcpy (newEvent, recvEvent, recvEvent->size);

newEvent->dest $=$ serverID;

sendEvent ( newEvent);

\}

\}

//aloca variável de estado

BasicState* QueueObject::allocateState $($ \{

return (BasicState *) new QueueState 0 ;

\}

Tabela 4 Código do objeto queue versão original.

Após as modificações o código passou a ser (Tabela 5):

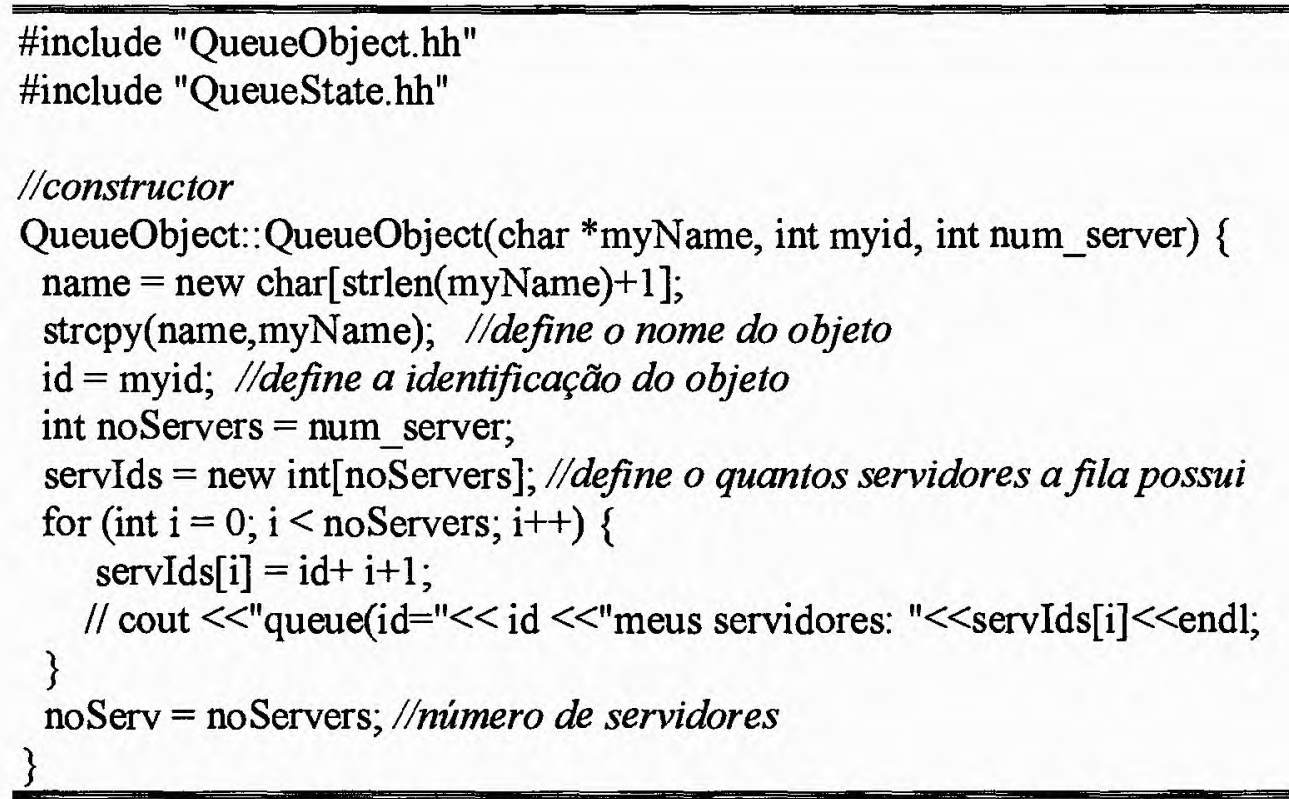

Tabela 5 Código do objeto queue da biblioteca KUE versão nova. 


\section{//destructor}

//imprimi a saída dos resultados da simulação: Tempo Médio de Espera na "Fila de Espera"; //Tamanho Médio da "Fila de Espera"

QueueObject:: QueueObject $)\{$

cout $\quad<<$ queue(id="<< id $\quad<<$ "espera $\quad="<<(($ QueueState* $)$ state- $>$ current $)-$ $>$ espera/((QueueState*)state->current)->totsistema $<<" \mid \mathrm{n}^{\prime \prime}<<$ "queue(id=" $<<$ id $<<$ " tamanho da fila $="<<\left(\left(\right.\right.$ QueueState $\left.{ }^{*}\right)$ state- $>$ current $)->$ tamfila $/\left(\left(\right.\right.$ QueueState $\left.{ }^{*}\right)$ state- $>$ current $)->$ cont $<<$ endl; delete [] servIds;

//método executado quando o evento é escalonado

void QueueObject::executeProcess 0 \{

BasicEvent *recvEvent;

recvEvent = getEvent $($;

if (recvEvent != NULL) \{

BasicEvent *newEvent $=\left(\right.$ BasicEvent $\left.{ }^{*}\right)$ new char[sizeof(BasicEvent $\left.)\right]$;

new (newEvent) BasicEvent();

$\operatorname{sim}=0$;

// verifica se o evento que chegou é de um dos servidores ou é uma requisão de serviço

// se sim $==1$, o evento é de um de seu servidores

// se sim $==0$, o evento é uma nova requisição de serviço

for (int $\mathrm{i}=0 ; \mathrm{i}<$ noServ; $\mathrm{i}++$ ) if (recvEvent->sender=-servIds[i]) $\operatorname{sim}=1$;

if $(\operatorname{sim}=1)\{$

// o evento recebido é de um dos servidores requisitando um novo evento para processar if (((QueueState*)state->current)->head != NULL) \{

//se a fila de espera não estiver vazia

//retira o evento da cabeça da fila e envia para o servidor

newEvent->entryTime $=\left(\left(\right.\right.$ QueueState $\left.{ }^{*}\right)$ state- $>$ current $)->$ head->entryTime;

Link $*$ tmpLink $=(($ QueueState $*)$ state->current $)->$ head;

((QueueState*)state->current)->head = tmpLink->next;

delete tmpLink;

((QueueState*)state->current)->tottamfila--; //estatística

newEvent->dest $=$ recvEvent->sender;

newEvent- $>$ size $=$ sizeof(BasicEvent $)$;

newEvent->recvTime $=$ getLVT ()$+0.000000001$;

$(($ QueueState* $)$ state->current $)->$ espera $=/ /$ estatística

((QueueState*)state->current)->espera + (getLVT0-newEvent->entryTime); sendEvent(newEvent);

Tabela 5 Código do objeto queue da biblioteca KUE versão nova. 
else \{

lla fila de espera está vazia

//coloca o servidor como desocupado - idle $==$ true

int $\mathrm{i}$;

for $(\mathrm{i}=0 ; \mathrm{i}<$ noServ; $\mathrm{i}++)$ if $($ servIds $[\mathrm{i}]=$ recvEvent->sender) break;

$(($ QueueState* $)$ state->current $)->$ serverIdle $[\mathrm{i}]=$ true;

\}

else if $(\operatorname{sim}=0)\{$

// o evento é uma nova requisição de serviço

((QueueState*)state->current)->totsistema++; //estatistica

$\left((\text { QueueState })^{*}\right.$ state- $>$ current $)->$ tamfila $=/ /$ estatistica

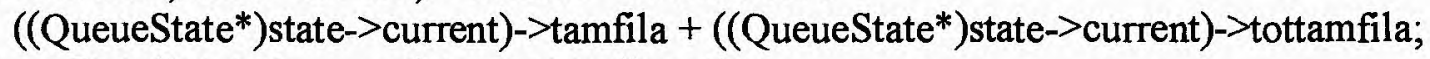

((QueueState*)state->current)->cont++; //estatística

//verifica se existe algum servidor desocupado

int $\mathrm{i}$;

for $(\mathrm{i}=0 ; \mathrm{i}<$ noServ; $\mathrm{i}++)$ if $((($ QueueState* $)$ state->current $)->$ serverIdle[i] $==$ true $)$ break;

if $(i<$ noServ $)\{$

//se existe servidor desocupado, verifica se tem evento esperando na "fila de espera"

if (((QueueState*)state->current)->head != NULL) \{

//se a "fila de espera" não estiver vazia

I/retira da fila o evento da cabeça da fila, envia este evento para ser atendido

newEvent->entryTime $=(($ QueueState* $)$ state->current $)->$ head->entryTime;

// move the head

Link *tmpLink;

tmpLink $=(($ QueueState $)$ state->current $)->$ head;

((QueueState*)state->current)->head $=$ tmpLink->next;

delete tmpLink;

((QueueState*)state->current)->tottamfila--://estatística

$(($ QueueState $)$ state->current $)->$ espera $=$

((QueueState*)state->current)->espera + (getLVT0-newEvent->entryTime); //coloca o evento recém chegado na fila

((QueueState*)state->current)->enQueue(recvEvent->recvTime);

((QueueState*)state->current)->totfila++; //estatística

\}

((QueueState*)state->current)->tottamfila++; //estatistica

I/se a "fila de espera" estiver vazia, envia o evento recem chegado para ser atendido else $\{$ newEvent->entryTime $=$ recvEvent->entryTime; $\}$

newEvent- $>$ dest $=$ servIds[i];

newEvent->size = sizeof(BasicEvent);

newEvent->recvTime $=$ getLVT $0+0.000000001$;

// coloco o servidor como ocupado

((QueueState*)state->current)->serverIdle[i] = false;

\} sendEvent(newEvent);

Tabela 5 Código do objeto queue da biblioteca KUE versão nova. 
I/se não existe servidor desocupado, entao coloco o evento na "fila de espera" else \{

((QueueState*)state->current)->enQueue(recvEvent->recvTime);

((QueueState*)state->current)->totfila++;//estatística

((QueueState*)state->current)->tottamfila++; //estatística

$$
\}^{3}
$$

\section{//aloca varióvel de estado}

BasicState* QueueObject::allocateState O \{

return new QueueState(noServ); \}

Tabela 5 Código do objeto queue da biblioteca KUE versão nova.

O objeto fila, quando recebe algum evento, verifica se o evento é uma nova requisição de serviço ou se é um evento de um de seus servidores. Cada servidor após executar um evento envia uma mensagem para sua fila, informado que ele está desocupado e pode então receber um novo evento para execução.

Quando a mensagem é de um dos servidores, a fila verifica se existem eventos esperando na "fila de espera". Se sim, envia o evento que está na cabeça da fila e enfileira o novo evento. Se a fila estiver vazia, coloca o servidor como desocupado.

Como antes a fila não possuía nenhum dispositivo de armazenamento, dados estatísticos da fila não podiam ser coletados, tais como tempo médio de espera na fila e o tamanho médio da "fila de espera".

Uma instância do objeto queue é criada pela definição de um objeto do tipo QueueObject. Devem ser especificados um nome para o objeto, uma identificação única e o número de servidores que estão associados a essa fila. Essa definição é a seguinte (Tabela 6):

QueueObject queue1("queue1",1, 1);//nome, identificação e número de servidores

Tabela 6 Criação de uma instância do objeto queue. 


\subsubsection{Objeto Server}

Esse objeto tem o objetivo de fornecer um serviço a um cliente (token ou evento). $O$ objeto definido na versão original da biblioteca possibilitava apenas a comunicação com um outro objeto. A versão atual possibilita que o servidor comunique-se com quantos objetos for necessário. O mesmo problema encontrado no objeto source em relação ao tipo da variável que representa o tempo da simulação (de inteiro em vez de real), foi encontrado e corrigido.

O código da versão original (Tabela 7) é o seguinte:

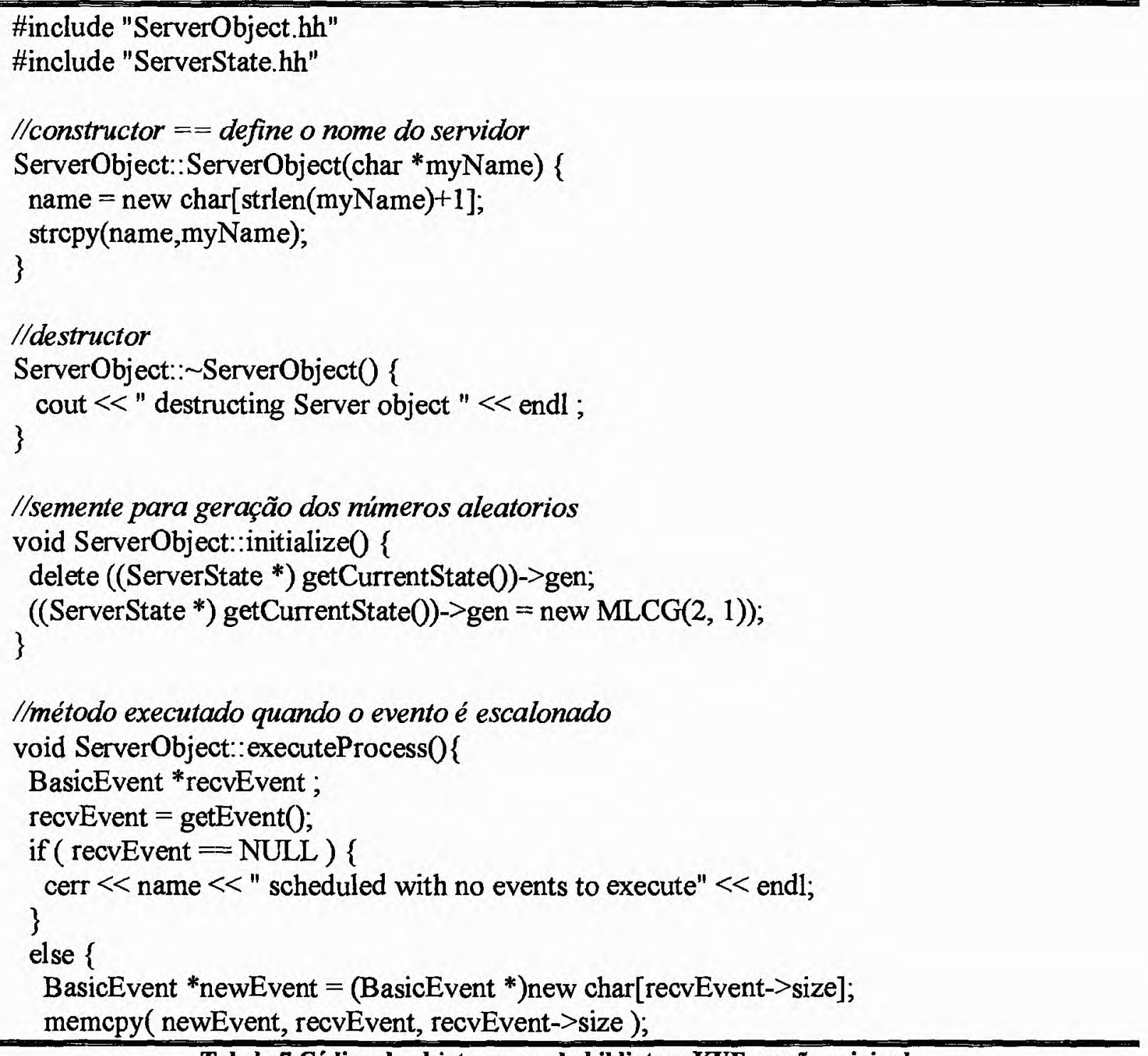

Tabela 7 Código do objeto server da biblioteca KUE versão original. 


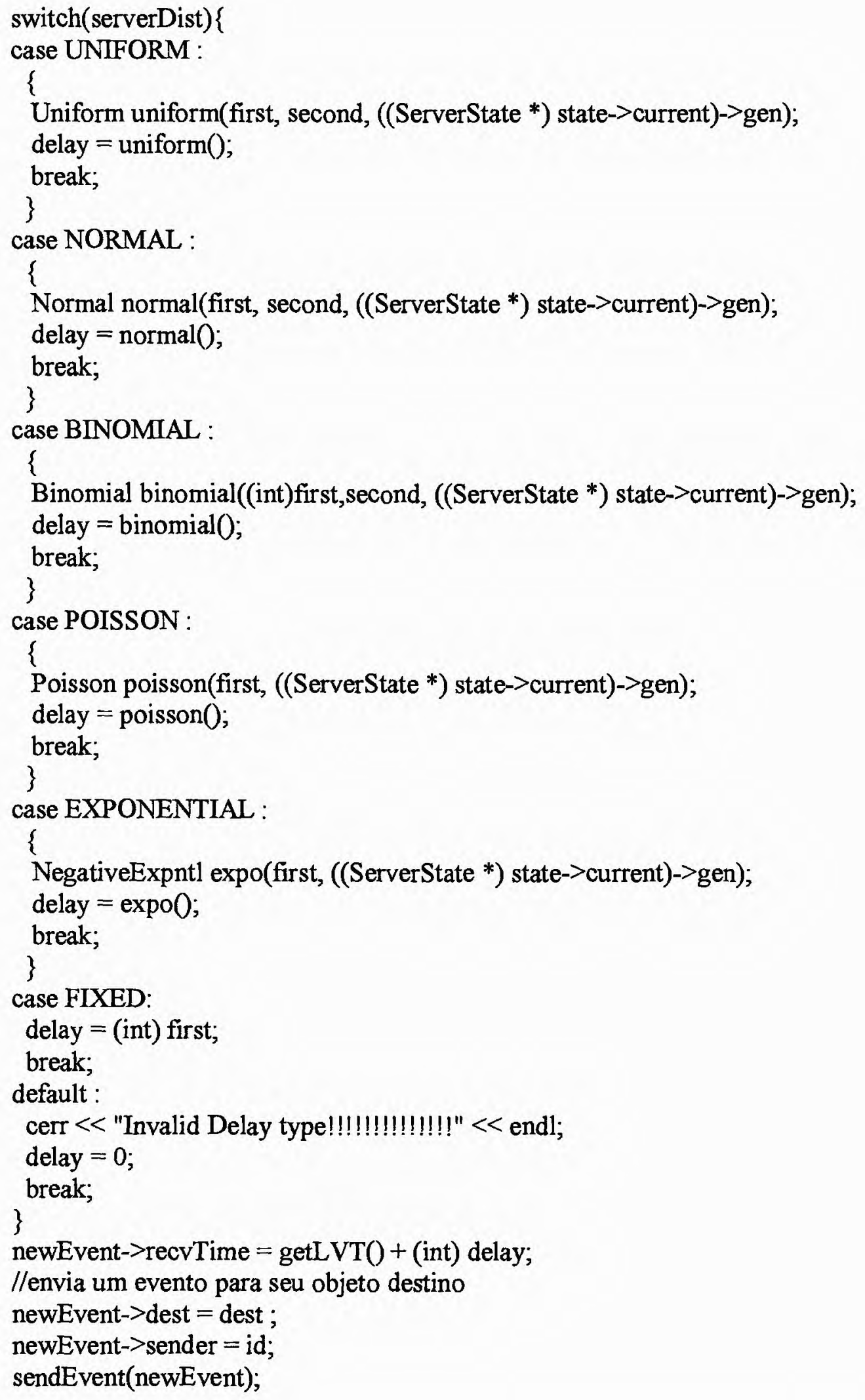




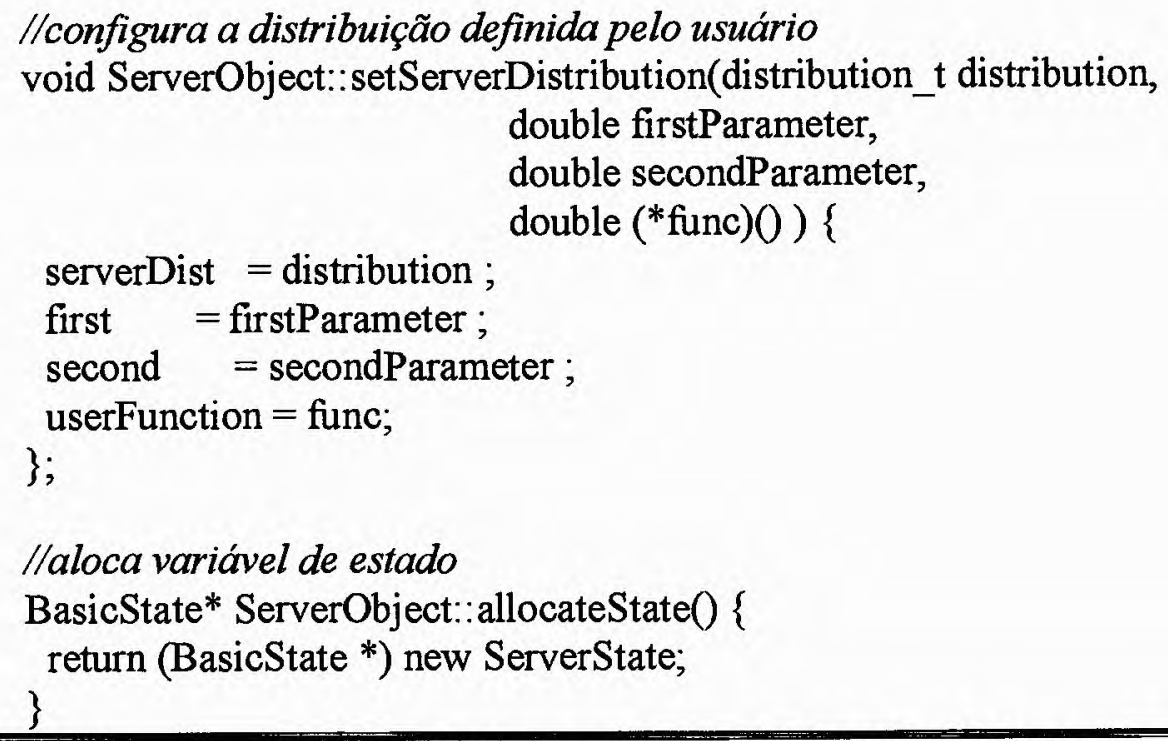

Tabela 7 Código do objeto server da biblioteca KUE versão original.

O código da versão nova é o seguinte (Tabela 8):

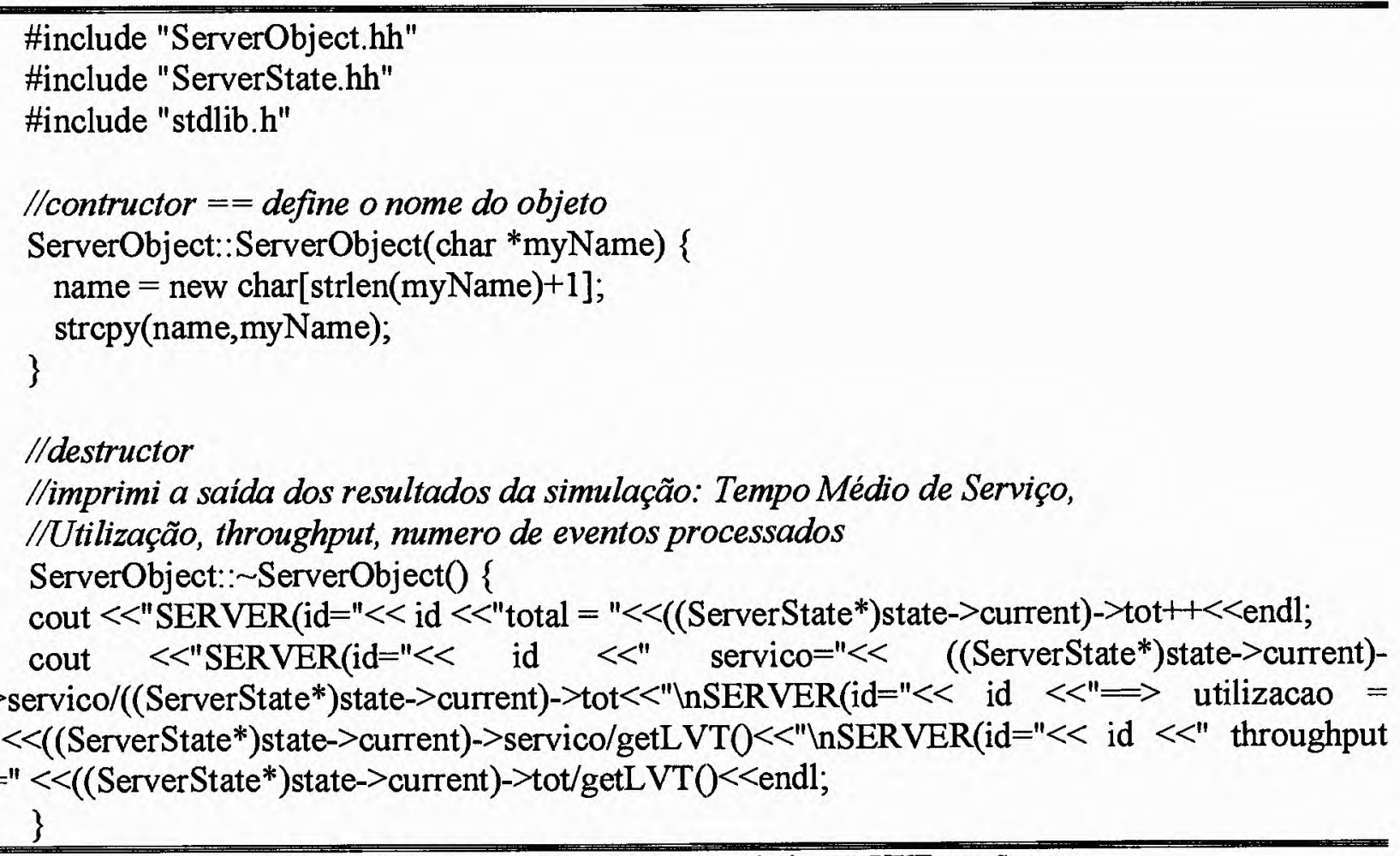

Tabela 8 Código do objeto server da biblioteca KUE versão nova. 


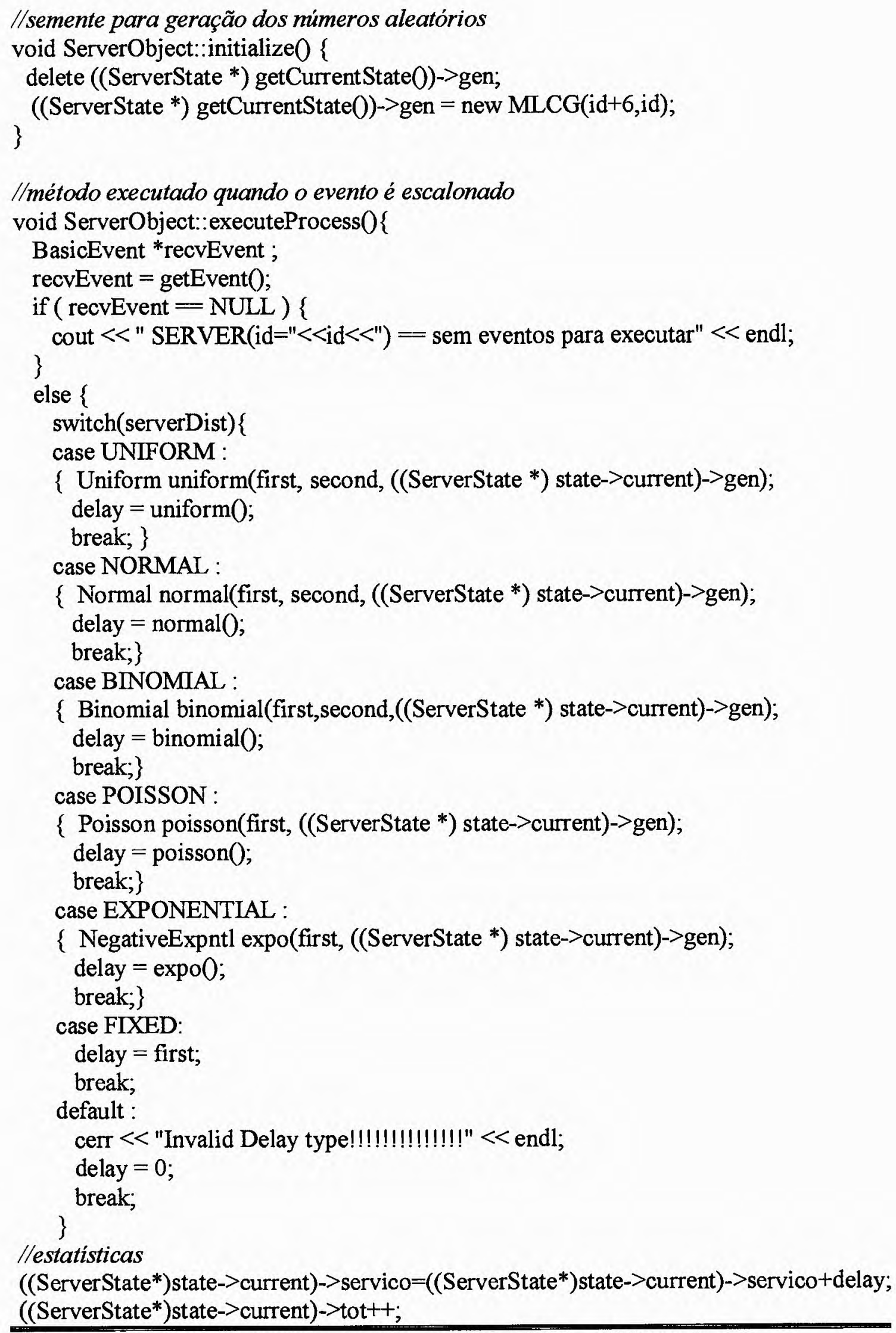

Tabela 8 Código do objeto server da biblioteca KUE versão nova. 
// Envia um evento para a fila "dizendo" que está desocupado

BasicEvent *idleEvent $=\left(\right.$ BasicEvent $\left.{ }^{*}\right)$ new char[sizeof(BasicEvent $\left.)\right]$;

new (idleEvent) BasicEvent 0 ;

idleEvent $->$ dest $=$ qDest;

idleEvent->recvTime $=$ getLVT( $)+$ delay;

idleEvent->size $=$ sizeof(BasicEvent);

idleEvent->entryTime $=0$;

sendEvent(idleEvent);

//gera uma evento para outro objeto

((ServerState*)state->current)->outro++;

BasicEvent *novoEvent $=($ BasicEvent* $)$ new char[sizeof(BasicEvent $)$; new (novoEvent) BasicEvent $($;

if (num_out $==1$ ) \{

\}

novo $\bar{E}$ vent- $>$ dest $=$ out ids $[0]$

else \{

if (num_out $=-=2)$ \{

$\mathrm{j}=$ randompar $(0,100)$;

if $(j<=$ chance $)$ novoEvent- $>$ dest $=$ out_ids $[0]$;

else novoEvent- $>$ dest $=$ out_ids $[1]$;

\}

if (num_out $>2$ ) \{

$\mathrm{tt}=$ randompar $(0$,num_out $)$;

novoEvent->dest $=$ out_ids $[\mathrm{tt}]$;

\}

\}

novoEvent->size $=$ sizeof $($ BasicEvent $)$;

novoEvent->entryTime $=$ recvEvent->entryTime;

novoEvent->recvTime $=$ novoEvent->entryTime;

sendEvent(novoEvent);

\}

\};

//configura a distribuição definida pelo usuário

void ServerObject::setServerDistribution(distribution_t distribution, double firstParameter, double secondParameter,

serverDist $=$ distribution; double $\left({ }^{*}\right.$ func $)(0)$ \{

first = firstParameter ;

second = secondParameter;

userFunction = func;

\};

Tabela 8 Código do objeto server da biblioteca KUE versão nova. 
/laloca variavel de estado

BasicState* ServerObject::allocateState() \{

// return (BasicState *) new ServerState;

return new ServerState;

\}

Tabela 8 Código do objeto server da biblioteca KUE versão nova.

Uma instância do objeto server é criada pela definição de um objeto do tipo ServerObject. Devem ser especificados nome para o objeto, uma identificação única e o objeto destino, ou conjunto de objetos destinos. Esta definição é a seguinte (Tabela 9):

ServerObject server2("server2");//nome do objeto

server2.id $=2$; / identificação do objeto

int out_ids $2[10]=\{1,13,25,37,49,61,73,85\} ; / /$ objetos destinos

server2.setServerDistribution(10,out_ids2,EXPONENTIAL, 5,0);

/la função de distriuição é exponencial com média igual a 10.5 segundos

server2.qDest $=1$; //identificação do objeto fila deste servidor

\section{Tabela 9 Criação de uma instância do objeto server.}

\subsubsection{Objeto Sink}

Esse objeto tem a finalidade de consumir eventos (os eventos que deixam o sistema, no caso de sistemas abertos, são enviados para este objeto). Não houve nenhuma modificação nesse objeto. Para a criação de uma instância desse objeto é necessário definir um objeto do tipo SinkObject. É preciso fornecer um nome e uma identificação única, por exemplo (Tabela 10):

SinkObject sink3 ("sink3");//nome do objeto sink3.id = 3;/identificação do objeto

Tabela 10 Criação de uma instância do objeto sink.

\subsubsection{Objeto Delay}

Esse objeto é muito usado em modelos de rede de computadores. Os eventos que passam por esse objeto sofrem um atraso de acordo com um intervalo que pode ser probabilístico ou fixo. 
Uma instância desse objeto é criada através da definição de um objeto do tipo DelayObject. É necessário especificar um nome para o objeto, uma identificação única, uma função para a determinação do tempo de atraso e o objeto destino (Tabela 11).

DelayObject delay1("delay1");//nome do objeto delay $1 . i d=1 ; / /$ identificação do objeto delay1.setDelayDistribution(FIXED, 1,0); //"tempo de demora" fixo delay1.dest $=2$; //identificação do objeto destino

Tabela 11 Criação de uma instância do objeto delay.

\subsubsection{Validação da Biblioteca}

Testes com modelos de Redes de Filas foram realizados após a correção da biblioteca para que esta pudesse ser validada. Esses modelos e os resultados obtidos através da solução analítica foram retirados do trabalho de [SIL00] e são descritos detalhadamente no próximo capitulo.

Foram comparados os resultados obtidos na simulação seqüencial, simulação distribuída e pela solução analítica. Os dados coletados foram: tempo médio de serviço, utilização do servidor, throughput, tempo médio de espera na "fila de espera", tamanho médio da "fila de espera". Os programas de simulação seqüencial foram escritos usando o SMPL (SiMulation Programming Language) [MAC87]. Os resultados obtidos são mostrados nas tabelas 12, 13 e 14.

\begin{tabular}{cccccc}
\hline Modelo I & $\begin{array}{c}\text { Tempo Médio } \\
\text { de Serviço }\end{array}$ & Utilização & Throughput & $\begin{array}{c}\text { Tempo Médio de } \\
\text { espera na "fila de } \\
\text { espera" }\end{array}$ & $\begin{array}{c}\text { Tamanho Médio } \\
\text { da "fila de } \\
\text { espera" }\end{array}$ \\
\hline $\begin{array}{c}\text { Solução } \\
\text { Analítica }\end{array}$ & 0.05 & 0.60 & 12 & 0.075 & 0.9 \\
$\begin{array}{c}\text { SMPL } \\
\text { WARPED }\end{array}$ & 0.05 & 0.6019 & 12.005 & 0.0751 & 0.902 \\
\hline
\end{tabular}

Tabela 12 Resultados obtidos com o modelo 1. 


\begin{tabular}{cccccc}
\hline Modelo 2 & $\begin{array}{c}\text { Tempo Médio } \\
\text { de Serviço } \\
\text { Servidor 1 }\end{array}$ & $\begin{array}{c}\text { Utilizaçũo } \\
\text { Servidor 1 }\end{array}$ & $\begin{array}{c}\text { Throughput } \\
\text { Servidor I }\end{array}$ & $\begin{array}{c}\text { Tempo Médio de } \\
\text { espera na "fila de } \\
\text { espera" } \\
\text { Servidor I }\end{array}$ & $\begin{array}{c}\text { Tamanho Médio } \\
\text { da "fila de } \\
\text { espera" } \\
\text { Servidor I }\end{array}$ \\
\hline $\begin{array}{c}\text { Solução } \\
\text { Analítica } \\
\text { SMPL }\end{array}$ & 0.04 & 0.80 & 20.0004 & 0.16 & 3.2 \\
WARPED & 0.0399 & 0.806 & 20.008 & 0.1602 & 3.199 \\
\hline
\end{tabular}

Tabela 13 Resultados obtidos com o modelo 2 (a).

\begin{tabular}{cccccc}
\hline Modelo 2 & $\begin{array}{c}\text { Tempo Médio } \\
\text { de Serviço } \\
\text { Servidor 2 }\end{array}$ & $\begin{array}{c}\text { Utilização } \\
\text { Servidor 2 }\end{array}$ & $\begin{array}{c}\text { Throughput } \\
\text { Servidor 2 }\end{array}$ & $\begin{array}{c}\text { Tempo Médio de } \\
\text { espera na "fila de } \\
\text { espera" } \\
\text { Servidor 2 }\end{array}$ & $\begin{array}{c}\text { Tamanho Médio } \\
\text { da "fila de } \\
\text { espera" } \\
\text { Servidor 2 }\end{array}$ \\
\hline $\begin{array}{c}\text { Solução } \\
\text { Analítica } \\
\text { SMPL }\end{array}$ & 0.05 & 0.4 & 8.0004 & 0.033 & 0.2667 \\
WARPED & 0.05003 & 0.408 & 8.003 & 0.0333 & 0.266 \\
\hline
\end{tabular}

Tabela 14 Resultados obtidos com o modelo 2 (b).

Com esses resultados, a validação da biblioteca foi concluída e sendo a biblioteca considerada confiável para a modelagem de sistemas.

\subsection{Considerações Finais}

O projeto WARPED tem como objetivo fornecer à comunidade de simulação uma ferramenta que facilitasse a programação e modelagem de programas de simulação distribuída. $\mathrm{O}$ WARPED implementa o protocolo otimista Time Warp definido por Jefferson [JEF85] e seu núcleo fornece as rotinas básicas para comunicação entre os processos lógicos e implementa todos os mecanismos necessários para a execução de uma simulação otimista (calculo de GVT, gerenciamento de memória, mecanismo de rollback).

Neste capítulo, o WARPED foi descrito, assim como a sua interface para a programação de aplicações. A biblioteca KUE foi modificada para que pudesse ser utilizada e também a interface para a criação dos seus objetos foi detalhada.

Os problemas encontrados no uso do WARPED foram bastante perturbadores, principalmente pelo fato da biblioteca apresentar problemas de implementação e ter sido publicada como operacional [RAD96][RAD96][RAD98]. 
Após as modificações da biblioteca, uma série de experimentos foi realizada para a validação da saída da simulação utilizando os objetos da KUE. A validação foi concluída com sucesso, sendo os resultados obtidos no WARPED comparados com os resultados oriundos de uma simulação seqüencial (SMPL), bem como da solução analítica.

No próximo capítulo, serão descritos alguns modelos de Redes de Filas e os experimentos realizados para a avaliação de desempenho desses modelos no WARPED. 


\section{Capítulo 5}

\section{Avaliação de desempenho de alguns modelos no WARPED}

Neste capitulo serão apresentados alguns modelos de Redes de Filas construídos usando a biblioteca KUE corrigida. Esses modelos são os mesmos do trabalho de [SIL00]. Experimentos foram realizados com esses modelos para a avaliação de desempenho do WARPED.

\subsection{Introdução}

Os modelos de Redes de Filas considerados foram retirados da dissertação de mestrado de [SIL00]. São três modelos que representam um servidor de arquivos de um ambiente distribuído, sendo o primeiro modelo uma representação macroscópica do servidor, enquanto os outros dois o representam de maneira mais detalhada.

O primeiro modelo, Figura 5-2, representa um servidor de arquivos com um único centro de serviço (uma fila e um servidor) constituindo um modelo padrão MM1. Considerando um nivel de abstração bem alto, esse modelo pode representar um servidor de arquivos, como mostra a Figura 5-1.

As solicitações são feitas ao servidor de arquivos podendo ser enfileiradas ou atendidas imediatamente. 


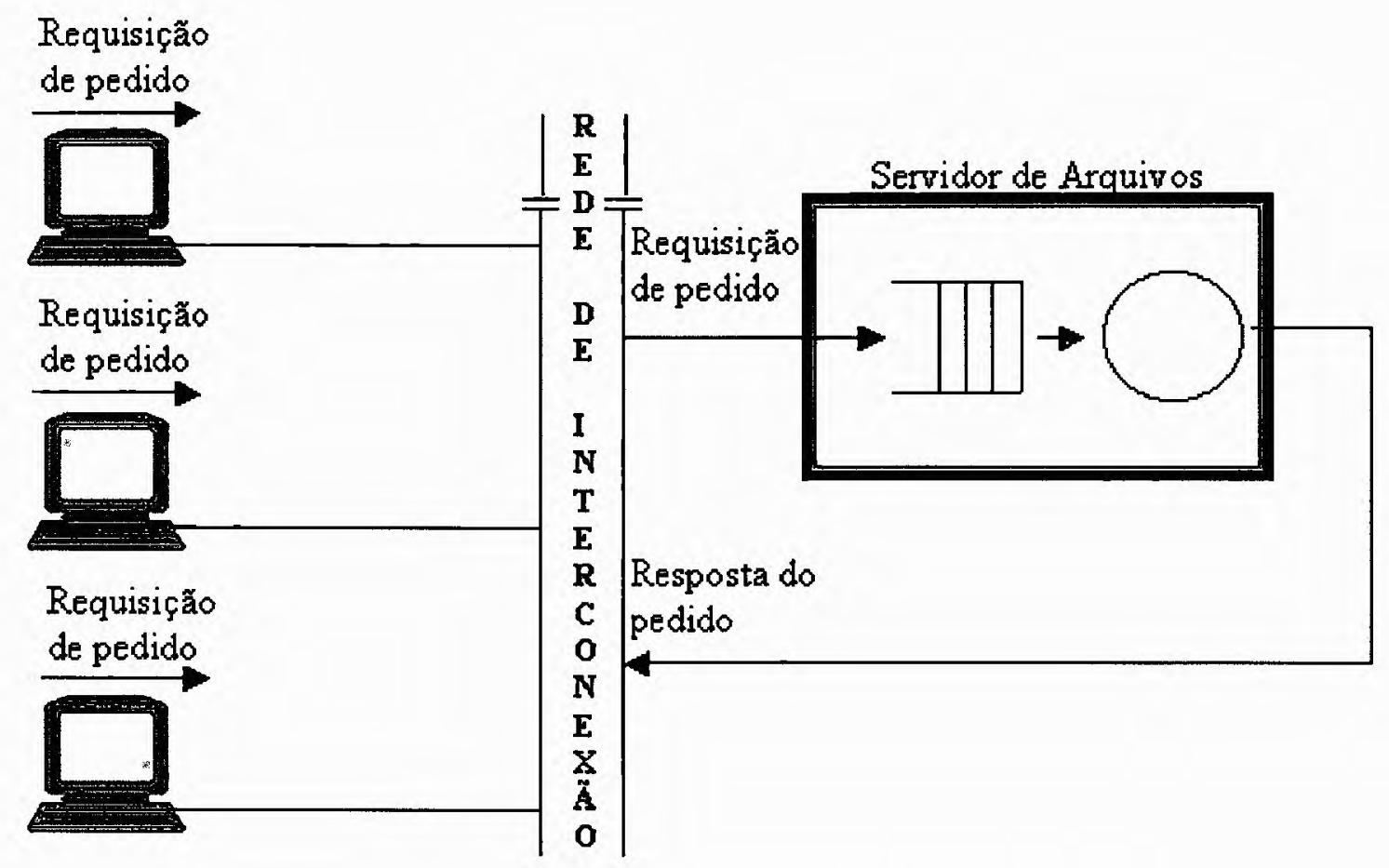

Figura 5-1 M/M/1 representando um Servidor de Arquivos

O segundo modelo, Figura 5-3, é composto por dois centros de serviço, cada um com uma fila e um único servidor. Nesse caso, quando uma requisição é feita ao servidor de arquivos pode-se utilizar o processador e também fazer acesso ao disco.

O terceiro modelo, Figura 5-4, é composto pelos mesmos elementos do segundo, porém com dois servidores que representam as funções de um PFE-In e PFE-out. O PFE faz a interface entre o sistema de rede e o servidor de arquivos. Assim, cada solicitação que chega é atendido pelo PFE-In e a resposta das requisições são passadas pelo PFE-out.

A chegada de clientes no sistema e os tempos de serviço de todos os modelos têm distribuições exponenciais.

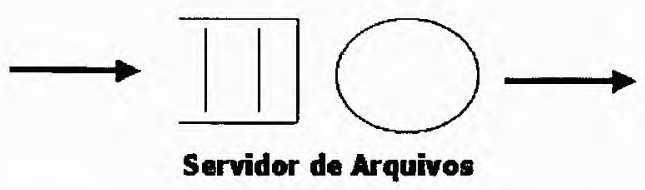

Figura 5-2 Modelo I : MM1. 


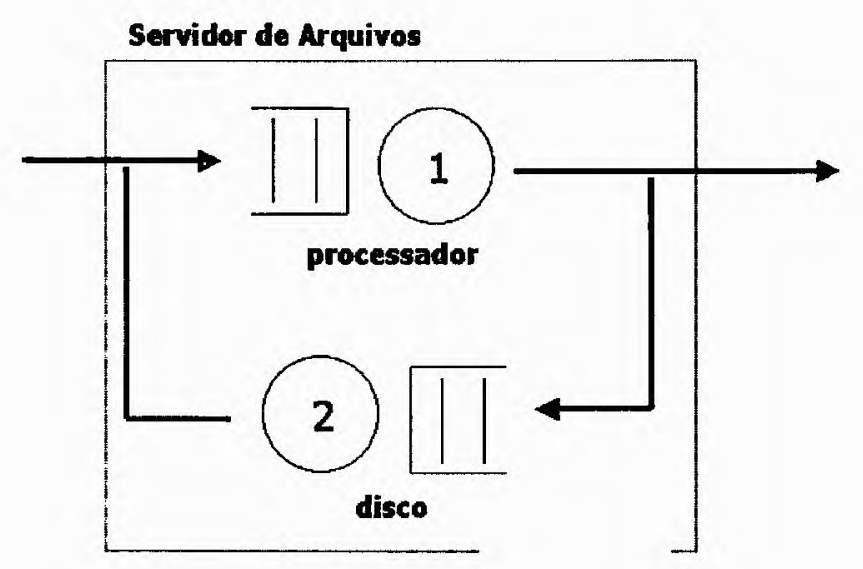

Figura 5-3 Modelo II: Servidor de Arquivos.

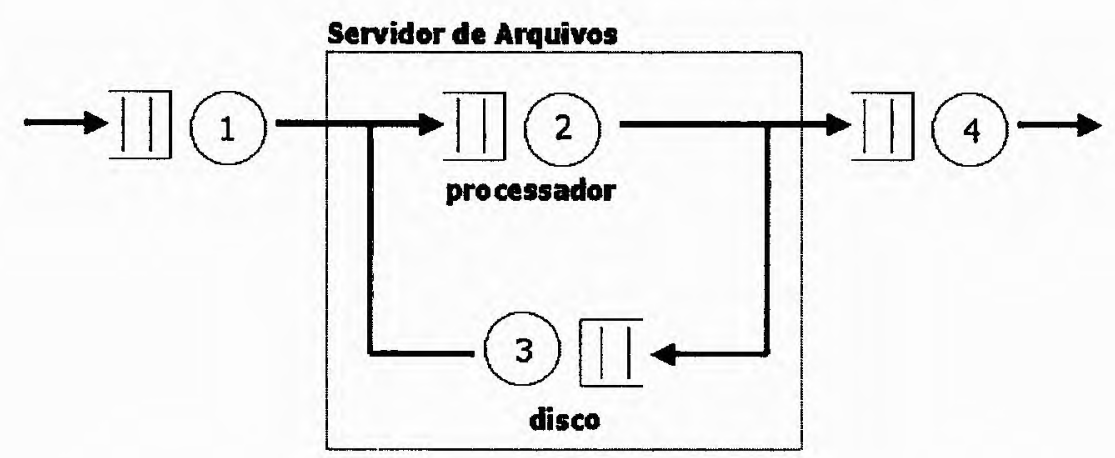

Figura 5-4 Modelo III: Servidor de Arquivos com PFE.

As métricas utilizadas para avaliação de desempenho da simulação distribuída foram as seguintes:

Tempo de Simulação Seqüencial: tempo (em segundos) de execução do programa de simulação em um único elemento de processamento, no WARPED.

Tempo de Simulação Distribuída: tempo (em segundos) de execução do programa de simulação no WARPED em uma máquina paralela ou sistema distribuído $\operatorname{com} n$ elementos de processamento.

Speedup: quociente entre os tempos da simulação seqüencial e da simulação distribuída. 
Todos esses modelos foram executados também seqüencialmente utilizando-se o SMPL. Assim, será comparado o desempenho da simulação seqüencial e da simulação distribuída.

\subsection{Plataformas Utilizadas}

Os experimentos foram executados em duas configurações de máquinas: (1) rede Ethernet 100Mbits/s com três máquinas (Pentium 100Mhz, Pentium 166MHz, Pentium MMX $200 \mathrm{MHz}$ ) com o sistema operacional Linux Red Hat versão 6.2; (2) máquina paralela SPP3 [CAR00], que é uma arquitetura paralela ( 8 nós de processamento, sendo cada nó um processador Pentium II Dual, $450 \mathrm{MHz}$, cache $512 \mathrm{~KB}$ ), desenvolvida pelo LCAD-USP (Laboratório de Computação de Alto Desempenho), executando o sistema operacional Linux Slackware.

\subsection{Experimentos realizados}

\subsubsection{Modelo I}

Para construir o Modelo I, é necessária a criação de quatro objetos: source, queue, server, sink. Uma requisição é gerada pelo objeto source e repassada para a fila (queue). Se o servidor não puder atendê-la, ela é enfileirada. O servidor (server) após atender a uma requisição envia a sua resposta para o objeto sink. A estrutura desse modelo no WARPED é apresentada na Figura 5-5:

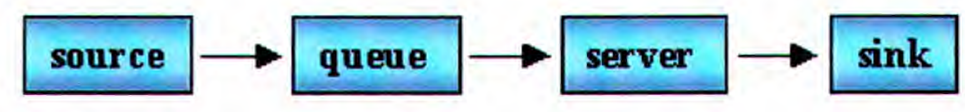

Figura 5-5 Organização do Modelo I no WARPED.

Duas configurações foram escolhidas para os experimentos com esse modelo:

Configuração 1: todos os objetos em um único LP; uma simulação seqüencial em cima do ambiente distribuído. 
* Configuração 2: dois LPs, um com o objeto source (LP 0) e outro com os objetos queue, server e sink (LP 1).

\begin{tabular}{|ll|lll|}
\hline & \multicolumn{2}{c}{ Ethernet } & \multicolumn{2}{c|}{ SPP3 } \\
\hline Modelo I & SMPL & WARPED & SMPL & WARPED \\
Configuração 1 & 0.7324701 & 12.29117 & 0.2208688 & 2.236899 \\
Configuração 2 & & 123.9904 & & $\mathbf{8 5 . 0 9 9 4 9}$
\end{tabular}

Tabela 15 Modelo I: tempos de execução.

Foram realizadas séries de dez execuções para cada configuração, cada execução com cinqüenta mil eventos gerados pelo objeto source. A Tabela 15 mostra os valores médios calculados de cada experimento.

A execução seqüencial mostra ser mais rápida que a distribuída. A explicação é que esse modelo é realmente muito simples e não apresenta nenhuma característica inerentemente paralela, ou seja, não há ganho de desempenho em se paralelizar um modelo tão simples. Mas esses modelos mais simplificados são importantes para se analisar o comportamento do ambiente.

Os tempos de simulação seqüencial e distribuída na configuração I mostram uma grande diferença numa configuração onde não há, no caso da simulação distribuída, comunicação entre processos separados fisicamente (existe apenas um processo lógico na simulação distribuída). Como todos os objetos estão sendo simulados em um único LP, a simulação é seqüencial no ambiente WARPED. Foi realizada a coleta dos tempos de cada passo do ciclo da simulação para se entender onde estaria sendo gasto mais tempo na execução do programa. A Tabela 16 mostra os dados coletados.

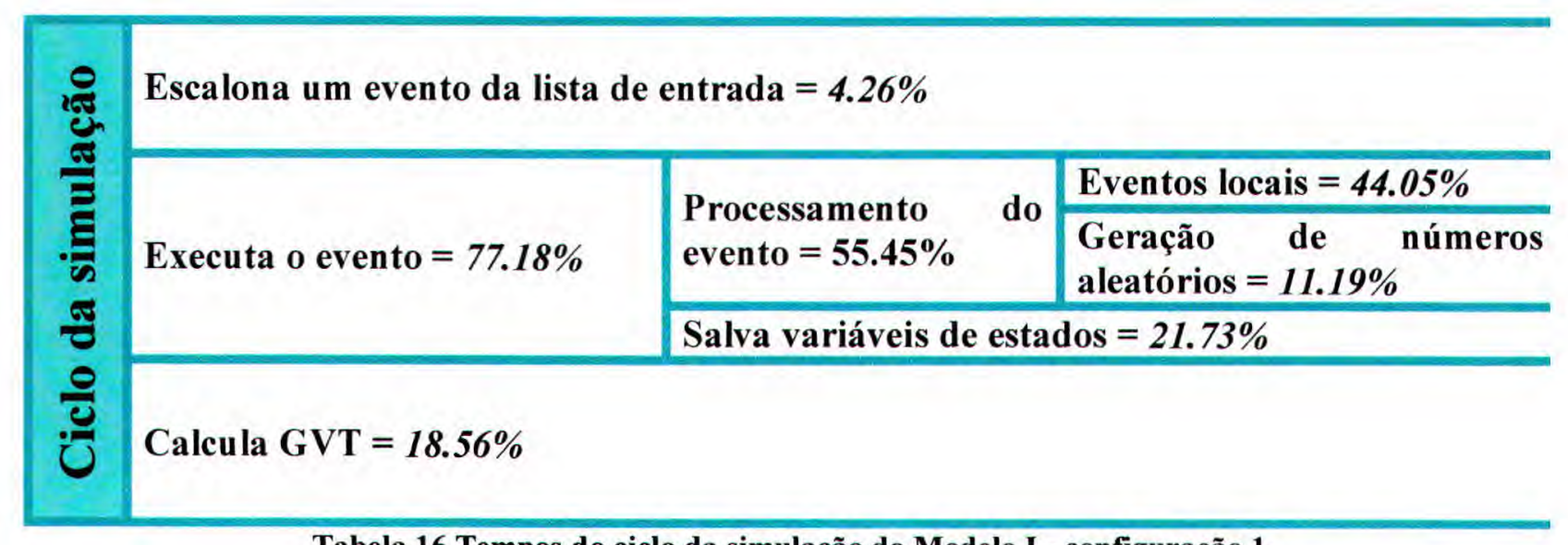

Tabela 16 Tempos do ciclo da simulação do Modelo I - configuração 1. 
O ciclo da simulação consiste em escalonar um evento da lista de entrada, executá-lo e quando for necessário calcular o valor de GVT. Escalonar um evento da lista de entrada significa retirar um evento da lista de eventos futuros para ser processado. Esse passo do ciclo da simulação gasta aproximadamente $4.26 \%$ do tempo total de execução do programa de simulação.

O cálculo do GVT é feito periodicamente, ou seja, de acordo com um intervalo de tempo determinado pelo programador. Logo em seguida ao cálculo do GVT é feita a "coleta de lixo", isto é, a liberação de espaço na memória. Na "coleta de lixo" são descartados todos os eventos da fila de saída com tempo menor que o valor do GVT. O tempo gasto para o cálculo do GVT e a "coleta de lixo" é de aproximadamente $18.56 \%$ do tempo total de execução do programa de simulação.

A execução do evento pode ser dividida em duas partes: processamento do evento e salvamento das variáveis de estado. O processamento do evento envolve a geração do número aleatório no caso dos objetos source e server, e o envio de eventos para outros objetos, sendo que nesse caso (configuração I) não há envio de mensagens remotas, apenas mensagens locais.

$\mathrm{O}$ envio de mensagens entre objetos de um mesmo processo lógico é feito através da inserção direta do evento na lista de eventos futuros do objeto. Os tempos gastos com as mensagens locais e a geração de números aleatórios são de aproximadamente $44.05 \%$ e $11.19 \%$ do tempo total de execução do programa de simulação, respectivamente. $O$ salvamento das variáveis de estado requer um tempo de aproximadamente $21.73 \%$ do tempo total. Assim, a maior parte do tempo é gasto no envio de eventos locais. Essa sobrecarga pode ser explicada devido à estrutura de dados da lista de eventos futuros.

No WARPED, cada objeto da simulação tem uma fila de eventos de entrada (chamada de "minilista" - minilist), uma fila das suas variáveis de estado e a fila de eventos de saída (Figura 5-6). 


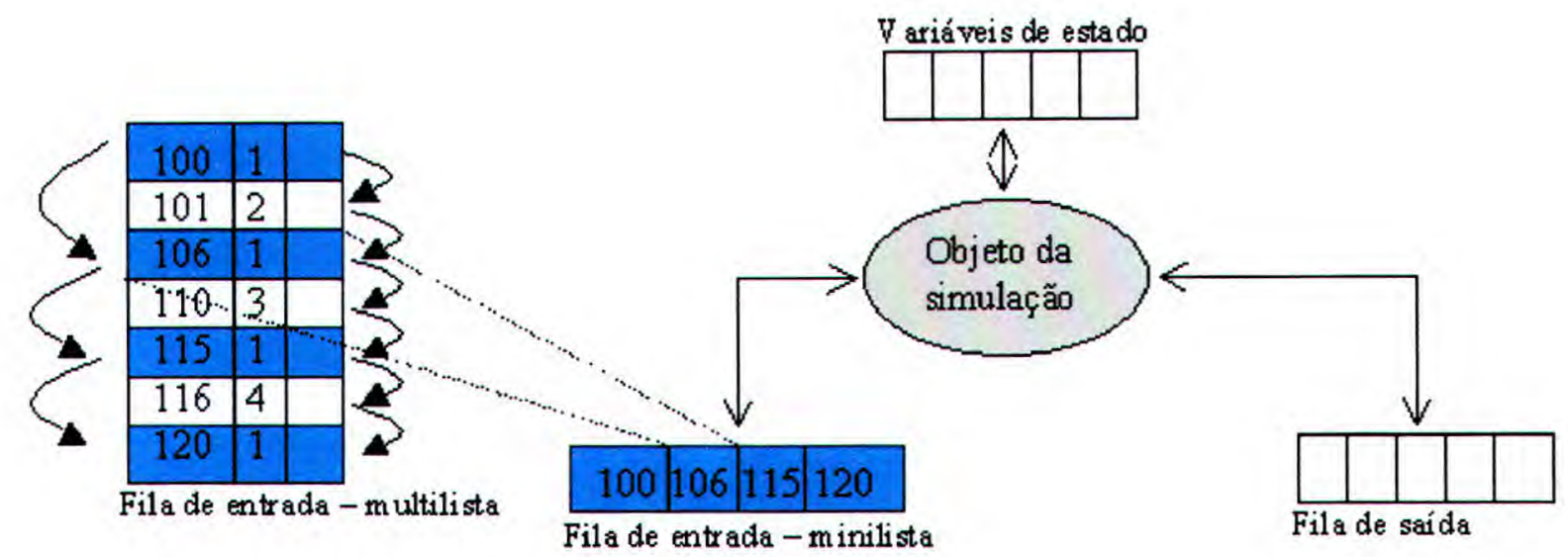

Figura 5-6 Estrutura de dados da multilista.

Um processo lógico engloba um número de objetos da simulação. As filas de eventos de entrada de todos os objetos de um mesmo LP são agrupadas em uma única fila chamada de "multilista" (multilist). Na verdade, não existe a estrutura minilista separada, pois cada objeto tem um ponteiro para a multilista de onde começa a sua minilista. Quando um objeto envia um evento para outro objeto local, o LP tem que inserir o evento na multilista e na minilista, atualizando os ponteiros das duas listas.

Inserir um evento na lista consiste em: inserir o evento na lista principal (multilista) e na minilista apropriada; verificar se a minilista precisa sofrer rollback. No caso da configuração I, não existe a ocorrência de rollback, já que os objetos executam seqüencialmente dentro do LP, mesmo assim a verificação é feita.

O tempo gasto em inserir na fila de eventos futuros mostrou tomar uma parte relativamente alta do tempo da simulação no WARPED (44.05\%), no caso da simulação seqüencial. Isso é devido às verificações que são necessárias para se inserir o evento no lugar correto, acertando os ponteiros das duas filas e verificar se é preciso executar rollback ou não. 
Em relação ao tempo no caso da simulação distribuída, o aumento notado da configuração 1 para a 2 (na simulação com WARPED) foi investigado para se determinar onde estaria a sobrecarga da simulação distribuída. Os testes realizados mostraram que a maior parte do tempo de execução da simulação é gasta no envio de mensagens remotas. Na configuração 2 , o LP 0 envia mensagens para o LP 1 e através da coleta do tempo de envio das mensagens remotas, foi constatado que aproximadamente $92 \%$ do tempo é gasto para o envio de mensagens remotas.

Assim, foi necessário investigar se essa sobrecarga era devida às rotinas de comunicação do MPI ou a se a maneira como foi implementado o uso das rotinas de comunicação no WARPED estava inadequada. Foi necessária a construção de um programa em MPI que utilizasse os mesmos modos e rotinas de comunicação, nesse caso "bufferizada", com os mesmos tamanhos de buffer e mensagem enviada.

Foram coletadas uma amostra com os valores do tempo de envio de mensagens com o MPI e outra amostra com os tempos de envio de mensagens remotas usando a rotina de envio de mensagem remota do WARPED, que é implementada em cima do MPI. Os resultados obtidis são os mostrados nas Tabela 17 e Tabela 18 :

\begin{tabular}{|c|c|c|}
\hline Ethernet & $\mathrm{MPI}$ & WARPED \\
\hline $\begin{array}{l}\text { Tempo médio de envio de } \\
\text { mensagens remotas } \\
\text { Variância }\end{array}$ & 0.00140959 & $\begin{array}{r}0.001172034 \\
0.0000146285\end{array}$ \\
\hline
\end{tabular}

Tabela 17 Tempo médio de envio de mensagens remotas - Ethernet.

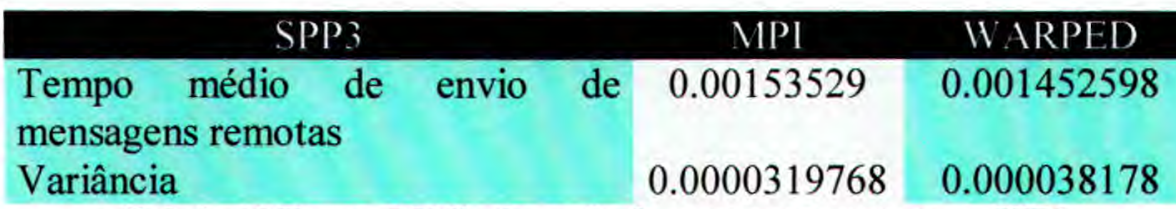

Tabela 18 Tempo Médio de envio de mensagens remotas - SPP3.

Com esse dados, foi realizada uma análise estatística com o objetivo de verificar se existe alguma diferença significativa entre os valores obtidos, ou seja, se o tempo gasto no programa MPI tem uma diferença estatisticamente significativa em relação ao tempo obtido no WARPED [ACH95][STE81]. Nesse teste de significância foi considerado o seguinte:

* $\mu_{\mathrm{WARPED}}=$ tempo médio de envio de mensagem remota no WARPED. 
* $\mu_{\mathrm{MPI}}=$ tempo médio de envio de mensagem remota no MPI.

* Hipótese nula $\left(\mathrm{H}_{0}\right): \mu_{\mathrm{WARPED}}=\mu_{\mathrm{MPI}}$

* Hipótese alternativa $\left(\mathrm{H}_{1}\right): \mu_{\mathrm{WARPED}} \neq \mu_{\mathrm{MPI}}$

Considerando as duas amostras de tamanho 500, a estatística dos testes de hipóteses é dada por:

$$
Z_{O B S}=\frac{\bar{X}_{M P I}-\bar{X}_{\text {WARPED }}}{\sqrt{\frac{s_{M P I}^{2}}{n_{M P I}}+\frac{s_{W A R P E D}^{2}}{n_{\text {WARPED }}}}}
$$

onde: $Z_{O B S}$ é o valor de $\mathrm{Z}$ obtido a partir dos valores amostrais;

$\bar{X}_{M P I}$ e $\bar{X}_{\text {WARPED }}$ são as médias amostrais dos tempos obtidos;

$s_{M P I}^{2}$ e $s_{W A R P E D}^{2}$ representam as variâncias amostrais;

$n_{M P I}$ e $n_{\text {WARPED }}$ representam o tamanho das amostras.

O nível de significância de um teste é a probabilidade da hipótese nula ser rejeitada, quando verdadeira. Nesse caso, será considerado um $\alpha$ (nível de significância) igual a 0.05 , conseqüentemente tem-se $\mathrm{Z}_{\alpha / 2}=\mathrm{Z}_{0.025}=1.96$ (teste bicaudal). Isso significa que existe a probabilidade de no máximo $5 \%$ de se errar ao se rejeitar a hipótese nula.

Substituindo os valores das Tabela 17 e Tabela 18 na equação acima, tem-se os seguintes valores de Z:

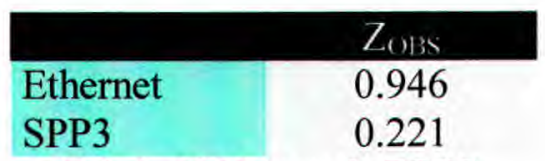

Tabela 19 Valores de ZOBS. 
Como os valores de $Z_{\mathrm{OBS}}$ em ambos os casos são menores que $\mathrm{Z}_{0.025}$, a hipótese nula não pode ser rejeitada, já que os valores de $\mathrm{Z}_{\mathrm{OBS}}$ pertencem à área de aceitação $(-1.96 \leq \mathrm{Z} \leq 1.96)$. Portanto, pode-se dizer que não existe uma diferença estatisticamente significativa entre os tempos médios das Tabela 17 e Tabela 18.

Como o tempo médio de envio de mensagens remotas no programa MPI não é significativamente diferente do tempo médio no WARPED, pode-se concluir que a sobrecarga do aumento do tempo de execução da simulação distribuída é devido à rotina de comunicação do MPI e não de como ela foi implementada (utilizada) no WARPED.

Uma forma de se melhorar o tempo da simulação distribuída está em particionar o modelo de simulação em uma forma adequada, agrupando-se os objetos que interagem com maior freqüência em um mesmo processo lógico.

Outro fator que pode influenciar também é a granulosidade dos LPs da simulação. Se a granulosidade for fina, a simulação sofrerá uma sobrecarga maior do que no caso de uma granulosidade média. $\mathrm{O}$ efeito da granulosidade será mais detalhado no item 5.4 .

\subsubsection{Modelo II}

A estrutura do modelo II mapeado no WARPED é mostrada na Figura 5-7. Uma requisição gerada pelo objeto source é enviada para fila do processador (queue1). Caso o servidor possa atendê-la, a requisição é enviada para o servidor (server 1); caso contrário, a requisição é enfileirada e fica esperando que o servidor fique desocupado. Após a requisição ser atendida pelo servidor (server1), a sua resposta é enviada para o objeto sink. Se for necessário o acesso a algum dado na unidade de disco, a requisição é passada para a fila do disco (queue2) e, após o acesso ao disco, ela retorna para a fila do processador. A probabilidade de uma requisição necessitar algum acesso ao disco foi considerada nesse caso igual a 40\% [SIL00]. Foram feitas três configurações diferentes:

* Configuração 1: todos os objetos em um único LP.

Configuração 2: o objeto source foi associado a um LP e os outros objetos foram colocados em outro LP (Figura 5-8). 
Configuração 3: os objetos source, queue1, server1 (processador) são associados a um LP e os objetos queue2, server2 (disco) e sink são associados a outro LP (Figura 5-9). Os objetos, dessa forma, foram divididos em números iguais e foi aumentada a interatividade entre os LPs.

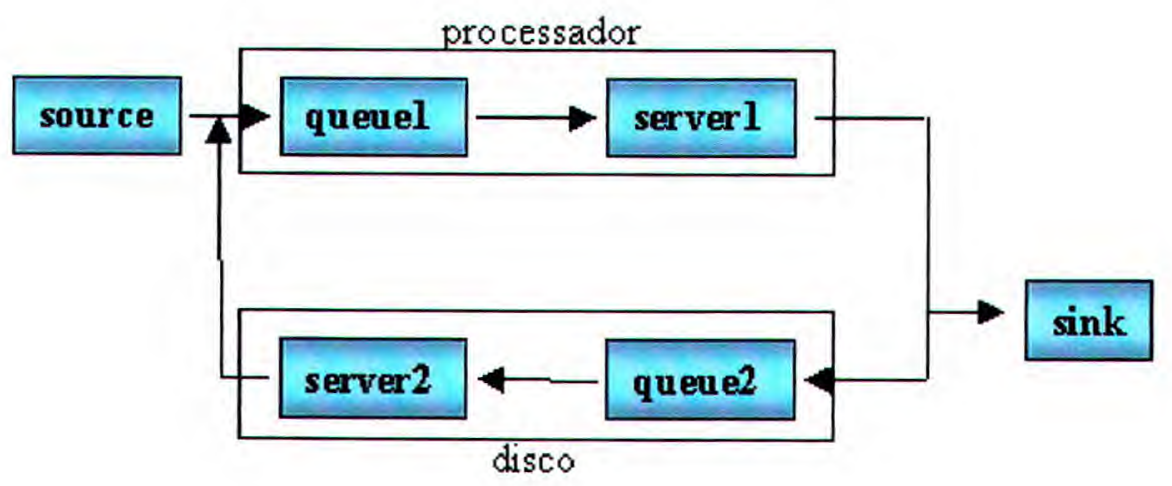

Figura 5-7 Organização do Modelo II no WARPED.

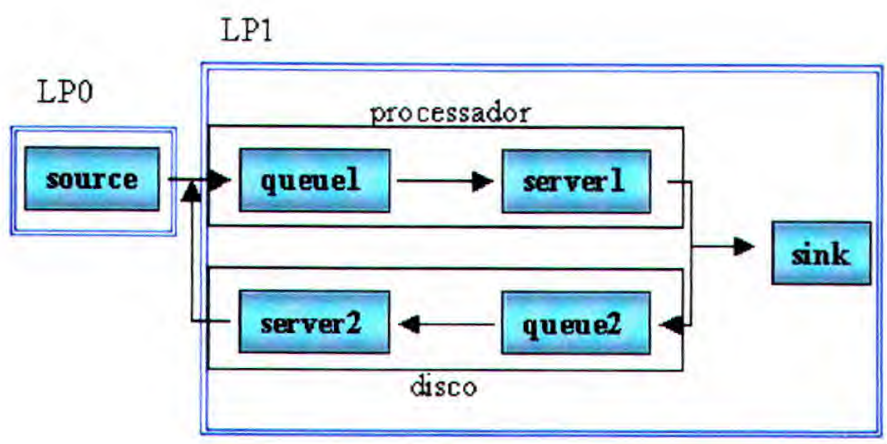

Figura 5-8 Modelo II - configuração 2.

LP0

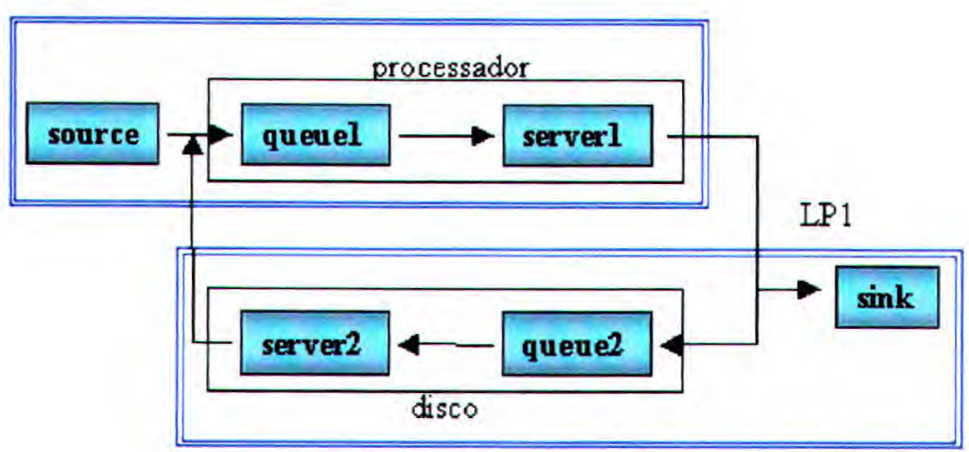

Figura 5-9 Modelo II - configuração 3. 
Da mesma forma que no modelo I, foram realizadas séries de dez execuções para cada configuração, cada execução com cinqüenta mil eventos gerados pelo objeto source. A Tabela 20 mostra os valores médios calculados de cada experimento.

\begin{tabular}{|lllll|}
\hline & \multicolumn{2}{c}{ Ethernet } & \multicolumn{2}{c|}{ SPP3 } \\
\hline Modelo II & SMPL & WARPED & SMPL & WARPED \\
Configuração 1 & 1.678154 & 22.27921667 & 0.5371337 & 4.578037 \\
Configuração 2 & & 168.97317 & & 81.95698 \\
Configuração 3 & & 214.068 & & 102.361
\end{tabular}

Tabela 20 Modelo II - tempos de execução.

O tempo da simulação seqüencial também é menor do que o da simulação distribuída, também pelo fato desse modelo não ser complexo. É interessante notar como a forma da partição do modelo pode influenciar na execução da simulação. Isso pode ser observado nas configurações 2 e 3. Quando se aumenta o grau de interatividade dos processos lógicos, o tempo de execução da simulação também aumenta consideravelmente devido ao aumento da necessidade de comunicação entre os processos lógicos.

\subsubsection{Modelo III}

A organização do Modelo III no WARPED é mostrada na Figura 5-10. O funcionamento é como no modelo II com a diferença de que antes de uma requisição chegar ao processador, ou uma resposta ser enviada, passam antes pelos processadores Front-End-In e Front-End-Out respectivamente.

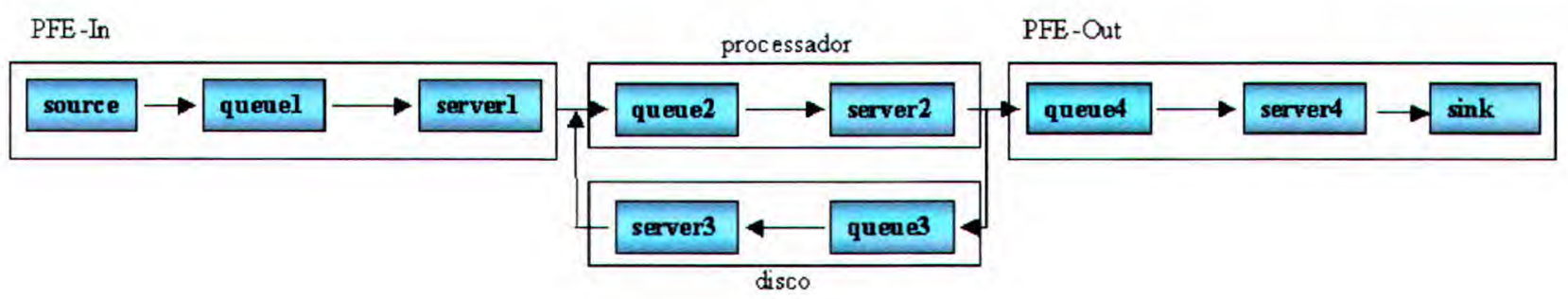

Figura 5-10 Organização do Modelo III no WARPED.

Foram feitas quatro configurações:

* Configuração 1: todos os objetos em um único LP. 
* Configuração 2: o PFE-In foi associado a um LP e os outros objetos em um outro LP (Figura 5-11).

* Configuração 3: os PFE-In e PFE-Out foram associados num LP e os outros objetos em um outro LP (Figura 5-12).

* Configuração 4: o PFE-In e o processador foram associados a um LP e o $P F E$ Out e o disco foram associados a outro LP (Figura 5-13).

Configuração 5: três LPs - o PFE-In num LP; processador e disco em um LP; PFE-Out em um LP (Figura 5-14).

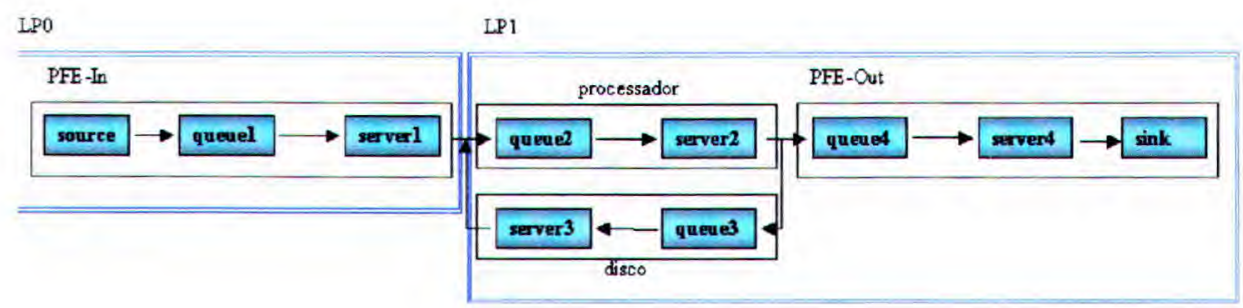

Figura 5-11 Modelo III - configuração 2.

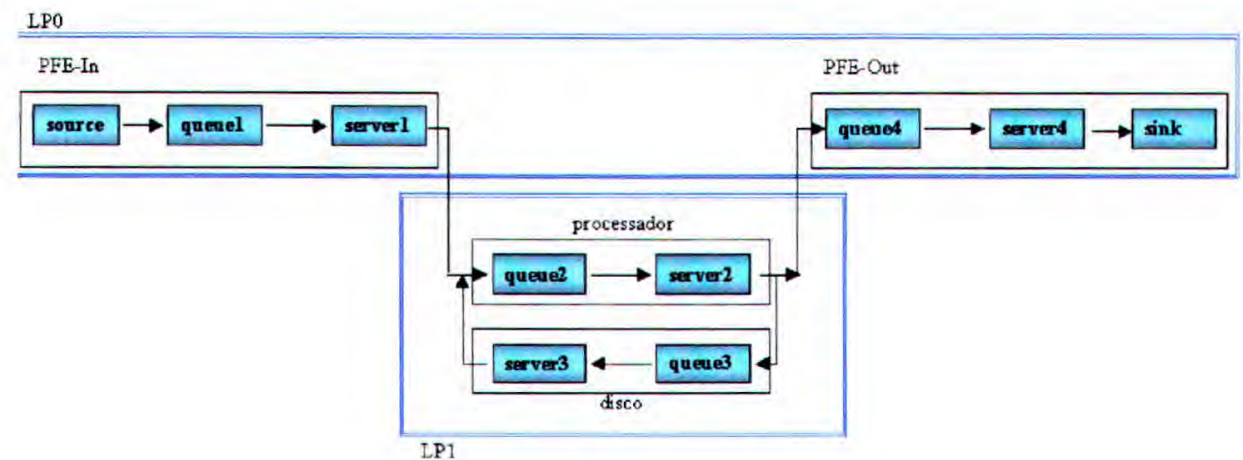

Figura 5-12 Modelo III - configuração 3. 


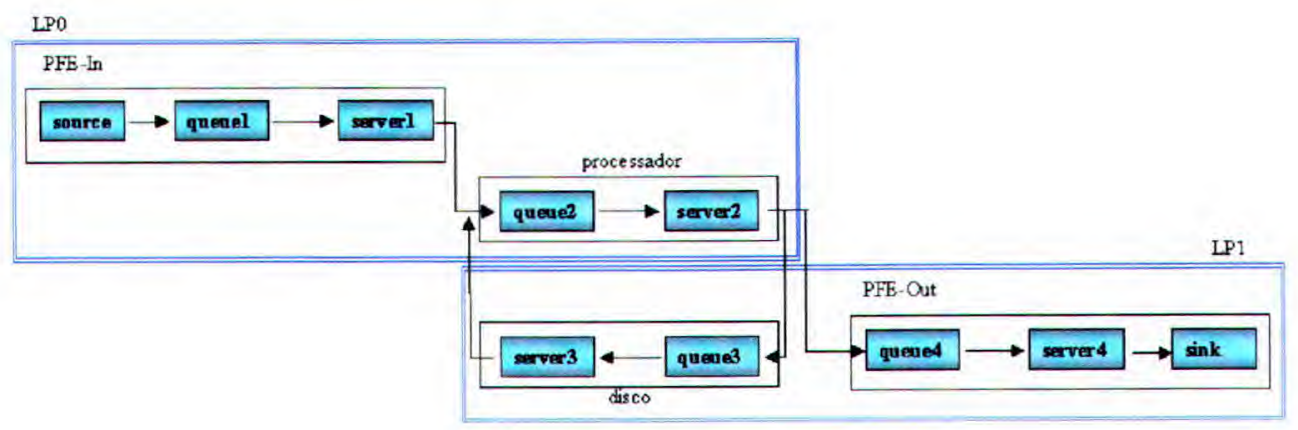

Figura 5-13 Modelo III - configuração 4.

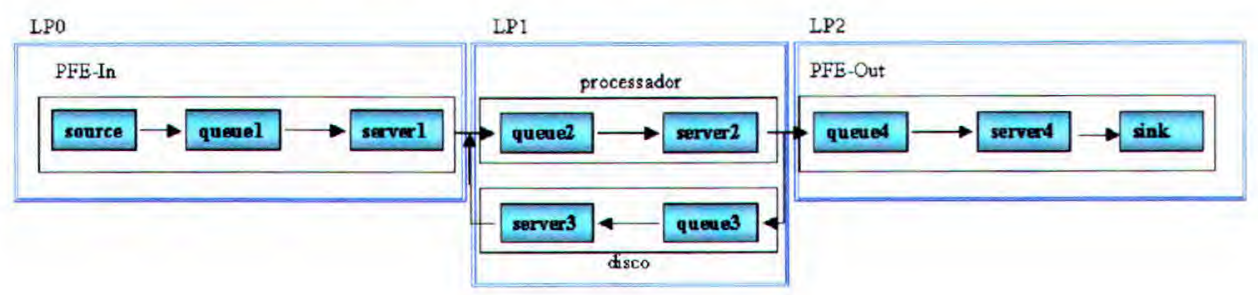

Figura 5-14 Modelo III - configuração 5.

Assim como nos modelos anteriores, foram realizadas séries de dez execuções para cada configuração, cada execução com cinqüenta mil eventos gerados pelo objeto source. A Tabela 21 mostra os valores médios calculados de cada experimento.

\begin{tabular}{|l|l|lll|}
\hline & \multicolumn{2}{c}{ Ethernet } & \multicolumn{2}{c|}{ SPP3 } \\
\hline Modelo III & SMPL & WARPED & SMPL & WARPED \\
Configuração 1 & 2.9049878 & 43.26203 & 0.8956926 & 7.755992 \\
Configuração 2 & & 115.4167 & & 72.07362 \\
Configuração 3 & & 105.1137 & & 43.57343 \\
Configuração 4 & 106.7489 & & 47.55187 \\
Configuração 5 & & 197.5629 & & 176.3229 \\
\hline
\end{tabular}

Tabela 21 Modelo III - tempos de execução.

Também pela simplicidade do modelo, a simulação seqüencial foi mais rápida do que a distribuída. A diferença de tempo entre as configurações 1 (1 LP) e 2 da simulação distribuída se deve à sobrecarga da comunicação entre os processos lógicos. Essa sobrecarga foi mais sentida na configuração 5 com 3 processos lógicos. 


\subsection{Efeitos da Granulosidade e da Comunicação entre Processos Lógicos}

Uma outra experiência realizada foi aumentar a granulosidade dos processos lógicos de um modelo, ou seja, aumentar o tamanho das unidades de trabalho que são submetidas a cada elemento de processamento. Também houve a variação de interatividade entre os LPs. Para isso foi construído o modelo da Figura 5-15.

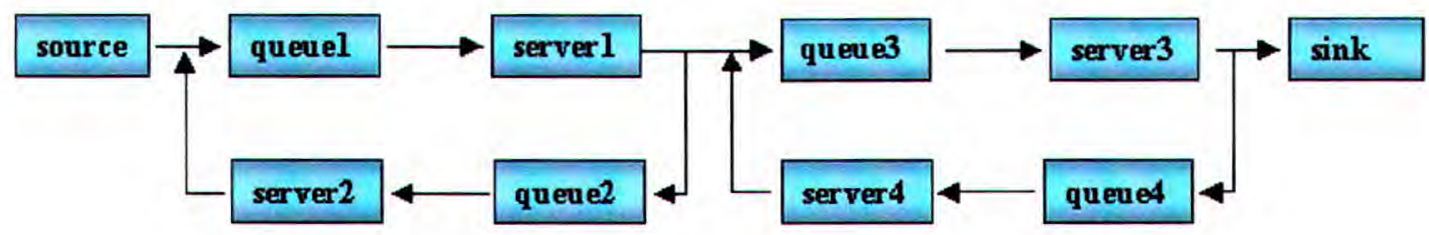

Figura 5-15 Modelo Experimental.

O modelo foi configurado em dois LPs: (1) objetos source, queue1, server1, queue2, server2; (2) objetos server3, queue3, queue4, server4 e sink. Um evento, depois de ser processado pelo serverl, tem uma probabilidade $p$ de ser enviado para a queue3. Dessa forma, variando-se essa probabilidade pode-se aumentar ou diminuir a interatividade entre os processos lógicos. A granulosidade também foi variada em dois tamanhos, sendo a granulosidade 1 a maior.

O primeiro experimento foi o seguinte: com a configuração acima, a probabilidade $p$ foi variada para que fosse analisado o impacto do aumento da comunicação entre os LPs. Um comando de laço foi inserido no código de execução de cada objeto para que a granulosidade fosse aumentada (granulosidade 1). Da mesma forma, foi aumentada a granulosidade no programa de simulação seqüencial. As Tabelas 22 e 23 mostram os tempos médios de execução da simulação e o valor de Speedup respectivamente. 


\begin{tabular}{|llllll}
\hline & \multicolumn{2}{c}{ Ethernet } & \multicolumn{2}{c}{ SPP3 } \\
\hline Probabilidade & SMPL & WARPED & SMPL & WARPED \\
$60 \%$ & 735.076477 & 462.7188 & 207.8321 & 155.9438 \\
$70 \%$ & 582.0142214 & 406.1432 & 163.291 & 135.9482 \\
$80 \%$ & 472.6479738 & 375.2872 & 132.8186 & 122.7068 \\
$90 \%$ & 403.2288818 & 345.7866 & 109.82924 & 114.9352
\end{tabular}

Tabela 22 Modelo Experimental - Granulosidade 1 - tempos de execução.

\begin{tabular}{lll} 
& \multicolumn{1}{c}{ Ethernet } & \multicolumn{1}{c}{ SPP3 } \\
\hline Probabilidade & Speedup & Speedup \\
$60 \%$ & 1.5886 & 1.3327 \\
$70 \%$ & 1.433 & 1.2011 \\
$80 \%$ & 1.2594 & 1.0824 \\
$90 \%$ & 1.1661 & 0.9556
\end{tabular}

Tabela 23 Modelo Experimental - Granulosidade 1 - Speedup.

Um segundo experimento com o mesmo modelo e configuração, variando a probabilidade $p$ e considerando uma granulosidade menor (2) do que a da experiência anterior foi realizado e os dados são os mostrados nas Tabelas 24 e 25.

\begin{tabular}{|ll|lll|}
\hline & \multicolumn{2}{c}{ Ethernet } & \multicolumn{2}{c|}{ SPP3 } \\
\hline Probabilidade & SMPL & WARPED & SMPL & WARPED \\
$60 \%$ & 380.20398 & 299.47 & 104.4714 & 111.985 \\
$70 \%$ & 290.5381 & 253.0138 & 82.045068 & 107.0048 \\
$80 \%$ & 236.3149 & 225.5556 & 66.748526 & 104.7068 \\
$90 \%$ & 99.9104 & 209.0782 & 55.18275 & 101.2188
\end{tabular}

Tabela 24 Modelo Experimental - Granulosidade 2 - tempo de execução.

\begin{tabular}{lll}
\hline & \multicolumn{1}{c}{ Ethernet } & \multicolumn{1}{c}{ SPP3 } \\
\hline Probabilidade & Speedup & Speedup \\
$60 \%$ & 1.2696 & 0.9329 \\
$70 \%$ & 1.1483 & 0.7667 \\
$80 \%$ & 1.0477 & 0.6375 \\
$90 \%$ & 0.4779 & 0.5452
\end{tabular}

Tabela 25 Modelo Experimental - Granulosidade 2 - Speedup.

A Figura 5-16 representa graficamente os valores de speedup dos dois experimentos.

O experimento com a granulosidade 1 mostra que melhores desempenhos foram alcançados com a probabilidade de $80 \%$ de comunicação no caso da SPP3 e com a probabilidade de $90 \%$ no caso da rede ethernet. 


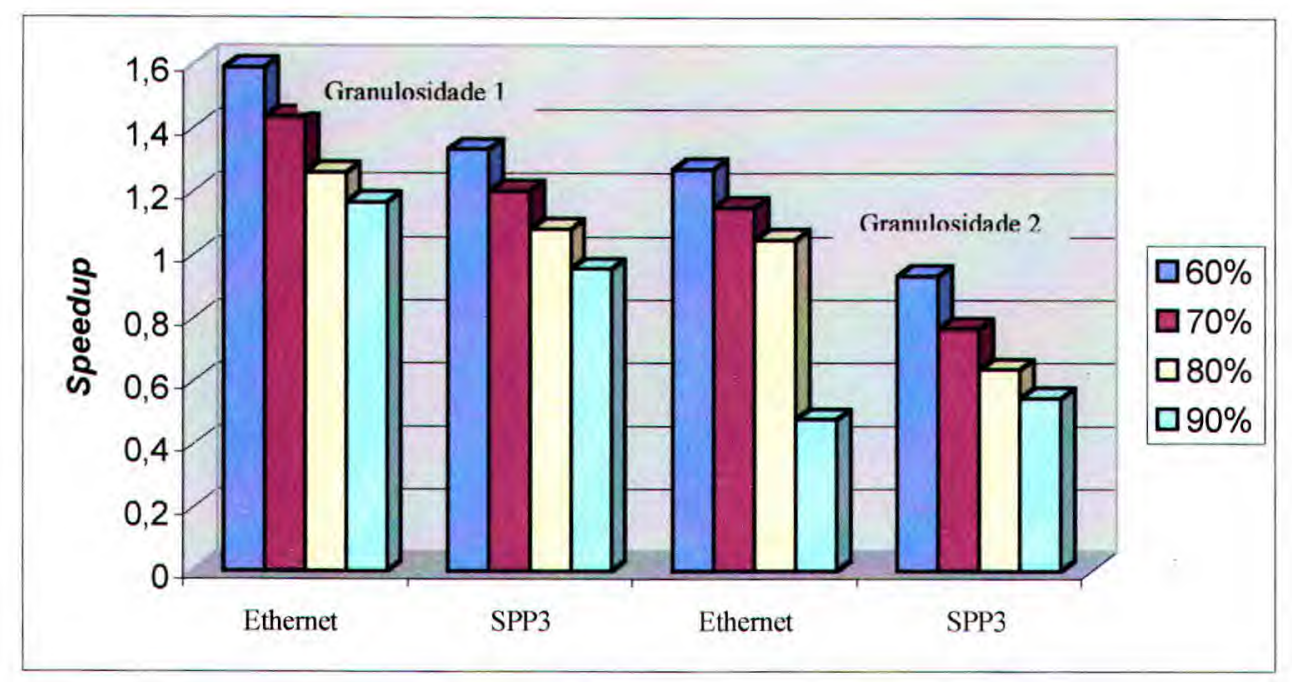

Figura 5-16 Gráfico com os valores de speedup.

O experimento com a granulosidade 2 mostra que melhores desempenhos foram alcançados com a probabilidade de $60 \%$ de comunicação no caso da SPP3 e com a probabilidade de $80 \%$ no caso da rede ethernet. Isso não significa que a rede ethernet é a melhor opção, mas que houve um maior ganho na simulação distribuída em relação à seqüencial nesse caso da ethernet. Porém, verificando-se os valores de tempo médio de execução na Tabela 24 , nota-se que a execução da simulação distribuída na SPP3 foi mais rápida.

O objetivo desses experimentos é demonstrar que o desempenho da simulação depende da granulosidade e do grau de interatividade entre os processo lógicos. Assim, para modelos que tenham uma granulosidade média, com os processos lógicos sendo particionados de forma a minimizar a comunicação (diminuir a sobrecarga da troca de mensagens), a simulação distribuída se torna viável, sendo uma opção atrativa, diminuindo o tempo de execução em relação a simulação seqüencial. A simulação seqüencial de uma rede PCS (Personal Communication Service) - telefonia móvel, com mil células por exemplo pode levar mais de 20 horas enquanto que a correspondente simulação distribuída pode ser executada em menos de 3 horas, usando-se oito processadores [CAR94][FIS95]. 
Em [ULS99], foi concluído que a forma de partição dos processos lógicos na simulação distribuída deve ser realizada em função das características da plataforma de hardware/software utilizada: "... a partição deve buscar reduzir a comunicação para plataformas com meio de comunicação de baixo desempenho e maximizar o balanceamento para plataforma paralela, com meio de comunicação de alto desempenho."

É importante sempre analisar o modelo para se decidir se a granulosidade do modelo possibilitará um melhor desempenho da simulação quando executada em paralelo. Além da granulosidade, a sobrecarga da comunicação entre os processos lógicos deve ser bem considerada, pois o tempo de entrega de uma mensagem através da rede de interconexão pode ser bastante variado e influenciado por fatores não controláveis, tal como a latência de comunicação.

Em [FUJ94], foi estudado o efeito da comunicação no desempenho da simulação com Time Warp. Foi verificado que aumentando-se o tempo de comunicação, o desempenho reduz-se significativamente. A degradação do desempenho aumenta mais ainda quando a granulosidade da aplicação é fina, como é o caso dos modelos I, II e III apresentados anteriormente. O atraso na comunicação tem um efeito maior nas aplicações de simulação distribuída otimista do que em outras devido aos erros de sincronização e geração de antimensagens para anular as computações incorretas [FUJ94].

\subsection{Considerações Finais}

Alguns modelos de Redes de Filas foram construídos não somente para validar a biblioteca KUE, como também para avaliar o desempenho da simulação distribuída no WARPED.

Foi observado que o ganho em desempenho pode ser conseguido para modelos complexos e grandes. A forma como os objetos do modelo são particionados influencia no desempenho da simulação distribuída e por isso deve-se levar em conta esse fator. O grau de interatividade entre os processos lógicos também pode inviabilizar a simulação distribuída e deve-se considerar a forma de partição dos processos lógicos na simulação distribuída em função das características da plataforma de hardware/software utilizada [ULS99]. 
Considerando-se esses fatores, a simulação distribuída pode substituir a simulação seqüencial visando diminuir tanto o esforço computacional, como o tempo de execução do programa.

O atraso na comunicação tem um efeito maior nas aplicações de simulação distribuída otimista do que em outras, devido aos erros de sincronização e geração de antimensagens para anular as computações incorretas [FUJ94]. 


\section{Capítulo 6}

Conclusões

\subsection{Introdução}

A avaliação de desempenho de sistemas computacionais pode ser feita com a utilização da simulação, que se destaca entre as diversas ferramentas existentes pela sua flexibilidade e custo relativamente baixo.

A simulação seqüencial pode ser empregada em várias situações, porém, ela tende a ser mais lenta e inadequada para modelos detalhados (complexos). Nesses casos, a simulação distribuída pode substituir com sucesso a simulação sequiencial, não somente diminuindo o tempo de execução do programa de simulação, mas também podendo dividir o esforço computacional entre os diversos processadores disponíveis na plataforma paralela.

O problema central da simulação distribuída está na sincronização entre os processos que estão separados. Por isso, deve-se fazer a partição dos objetos da simulação de forma a minimizar a necessidade de sincronização e comunicação entre esses processos. 


\subsection{Conclusões}

O WARPED implementa a simulação distribuída utilizando o protocolo de sincronização otimista Time Warp sobre plataformas distribuídas. A biblioteca MPICH é a base para a comunicação entre os processos lógicos.

A comunicação entre processos fisicamente separados pode sobrecarregar a execução da símulação distribuída, podendo mesmo inviabilizar sua utilização. Por isso, a partição do modelo de simulação deve ser feita considerando-se as características do modelo e da arquitetura de hardware que será usada. Em geral, deve-se tentar minimizar a necessidade de comunicação e submeter aos processadores uma carga de trabalho de tamanho adequado, explorando granulosidades de média a grossa.

Nos experimentos realizados neste trabalho, foi observado que aumentando-se a granulosidade dos modelos, um speedup pode ser alcançado com a simulação distribuída. Observa-se da literatura que a simulação distribuída tem sido bastante utilizada em aplicações tais como redes de computadores, sistemas wireless e redes PCS (Personal Communication Service), pois essas aplicações resultam em modelos grandes e complexos, onde a simulação seqüencial pode levar horas ou mesmo dias para ser executada. Utilizando-se uma plataforma paralela ou um sistema distribuído (o que torna-se cada vez mais popular e adequado), pode-se dividir o programa de simulação em vários processos lógicos e, com isso, obter-se uma diminuição do tempo de execução. Como esses modelos tendem a gerar uma partição dos objetos com granulosidade média, melhor desempenho pode ser conseguido [CAR94]. 
Os experimentos realizados nesta dissertação mostram que nem sempre é fácil obter-se speedup com as simulações distribuídas. No caso observado (usando o Time Warp) e também no que se encontra nas publicações da área (por exemplo, utilizando o CMB [ULS99][BRY77][CHA79] [ULS97]), para ter-se ganho de desempenho deve-se ter um planejamento cuidadoso e crítico do experimento de simulação. Modelos simples, por exemplo, dificilmente levarão a ganho de desempenho, sendo preferido o uso da simulação seqüencial. Modelos de complexidade média podem obter ganhos de desempenho desde que haja um balanceamento cauteloso entre a granulosidade dos processos lógicos e a necessidade de comunicação entre processos alocados em máquinas distintas. Adotando-se plataformas distribuídas, toda comunicação entre máquinas ocorre via rede de interconexão, o que traz sobrecargas consideravelmente altas.

No caso estudado, o próprio sistema de passagem de mensagens (biblioteca MPICH) introduz sobrecargas difíceis de serem contornadas. Mas, obtendo-se a granulosidade adequada e minimizando-se a comunicação, bons resultados são sempre esperados.

\subsection{Contribuições}

Esta dissertação contribui de diversas formas para a área de simulação distribuída, destacando-se:

- Revisão bibliográfica cobrindo não apenas o Time Warp (que foi objeto principal da parte prática do trabalho), mas também o CMB e a abordagem assíncrona.

- Apresentação de uma compilação de resultados publicados em outros trabalhos, comparando-se as abordagens adotadas para o sincronismo de programas de simulação distribuída.

- Detalhamento de um sistema para simulação distribuída, WARPED [RAD98], de código aberto, que pode ser útil a muitas aplicações praticas.

- Identificação de problemas que inviabilizaram a utilização do WARPED na implementação de modelos de redes de filas, fato não relatado na literatura. 
- Um novo projeto para as rotinas que compõem a biblioteca KUE do WARPED (que cuida da simulação de modelos de redes de filas) corrigindo e obtendo suas funcionalidades, onde necessário.

- Um estudo detalhado do funcionamento do WARPED quando simulando redes de filas, visando a identificação dos tempos gastos em cada etapa.

- Avaliação de desempenho de simulações de modelos de redes de filas implementados no WARPED, com comparação com os resultados obtidos seqüencialmente (definição de speedup).

- Correção de uma falha na literatura da área, uma vez que o WARPED e sua biblioteca KUE, como disponibilizados, não eram operacionais.

- Domínio sobre os procedimentos que compõe o WARPED/KUE, facilitando futuras implementações de simulações baseadas no Time Warp.

\subsection{Dificuldades Encontradas}

A maior dificuldade encontrada foi em relação à instalação e configuração do WARPED. Além de pouca informação disponível na documentação de como instalar e configurar, foram necessárias várias modificações nos arquivos de compilação.

O WARPED foi implementado utilizando-se o paradigma de programação orientada a objeto. Linguagens orientadas a objeto [ARN01] visam, entre outros objetivos, tornar o código produzido facilmente modificável sem, na realidade, alterar fisicamente esse código. Esse é um conceito único e muito poderoso, porque à primeira vista parece não ser possível modificar alguma coisa sem de fato alterá-la. Entretanto, é plenamente possível fazer-se isso usando-se os conceitos de herança e polimorfismo.

Porém, mesmo nos casos de sistemas orientados a objetos, uma boa documentação do programa deve ser feita para que o código possa ser realmente alterado e compreendido para que as vantagens do paradigma de programação orientada a objeto possam ser realmente utilizadas. 
A pouca documentação dos programas que implementam as funcionalidades do núcleo do WARPED foi dificuldade à parte, requerendo um tempo considerável para o entendimento de como foram implementados todos os objetos e métodos. Esse entendimento era necessário para que a avaliação de desempenho pudesse ser plenamente realizada. A falta de uma boa documentação certamente tornou a correção da biblioteca KUE muito mais difícil.

\subsection{Propostas para Trabalhos Futuros}

Com a realização desta dissertação pôde-se identificar vários trabalhos para realização futura, destacando-se:

- Migração do WARPED para outro ambiente de comunicação, como PVM (Parallel Virtual Machine) ou outra implementação do padrão MPI. Com isso, poderá ser analisado o desempenho do ambiente WARPED em diferentes plataformas, identificando, assim, quais são as melhores implementações e em que condições devem ser utilizadas.

- Implementação de outras variações do protocolo otimista Time Warp, analisandose também, qual seria o desempenho da simulação. Também seria possível a identificação de grupos de aplicações que alcançariam melhor desempenho de acordo com uma determinada estratégia de cancelamento, cálculo do GVT, "coleta de lixo", gravação das variáveis de estado etc.

- Desenvolvimento de uma interface gráfica amigável para facilitar a construção dos programas de simulação no WARPED.

- Avaliação do desempenho da ferramenta WARPED em relação a outras ferramentas para simulação distribuída que implementam a mesma categoria de protocolo de sincronização ou diferente.

- Implementação de um novo ambiente de simulação distribuída baseada no Time Warp, removendo algumas das excentricidades identificadas no WARPED que o distanciam da realidade dos modelos de Redes de Filas, como por exemplo o modo como filas são implementadas. 


\section{Referência Bibliográfica}

[ACH95] Achcar, J. A, Rodrigues, J., Introdução à Estatística para Ciências e Tecnologia. Instituto de Ciências Matemática e Computação, USP, São Carlos, 1995.

[ARG98] Argonne National Laboratory. www.mcs.anl.gov/mpi/mpich, 1998.

[ARN01] Arnaut, D. H.., Entendendo C++: uma introdução acelerada, www.arnaut.eti.br/, 2001.

[BEG83] Beguelin, A. PVM: Parallel Virtual Machine. A User's Guide and Tutorial for Networked Parallel Computing Survey, v. 15, 1983, 3-43.

[BRU97] Bruschi, S. M., Projeto de Implementação de um Ambiente de Simulação Distribuído Automático (ASDA). Monografia (Qualificação de Doutorado), Instituto de Ciências Matemática e Computação - USP, São Carlos, 1997.

[BRY77] Bryant, R. E. Simulation of packet communications architecture computer systems. MIT-LCS-TR-188, Massachusetts Institute of Technology, 1977.

[CAR00] Carmo, Maxwell S. Mirador II - Uma extensão da Ferramenta Mirador para o monitoramento e gerenciamento da maquina paralela SPP3. Dissertação de Mestrado, Instituto de Ciências Matemática e Computação de São Carlos - USP, São Carlos, 2000.

[CAR94] Carothers, C., Fujimoto, R. M., Lin, Y., Distributed Simulation of PCS Networks Using TimeWarp. Proceedings International Workshop on Modeling, Analysis and Simulation of Computers and Telecommunications Systems, pp. 2-7, 1994.

[CHA79] Chandy, K. M.; Misra, J. Distributed Simulation: a case study in design and verification of distributed programs. IEEE Transactions on Software Engineering, SE-5, 5, 1979, 440-452.

[CHA81] Chandy, M.; Misra, J. Assynchronous Distributed Simulation Via a Sequence of Parallel Computations. Communications of the ACM, v. 24, n. 4. 1981, 198-205.

[DSO94] D'Souza, L. M., Fan, X., Wilsey, P. A., pGVT: an algorithm for accurate GVT estimation. Proceedings of the $8^{\text {th }}$ Workshop on Parallel and Distributed Simulation (PADS94), Society of Computer Simulation, pp. 102-109, 1994.

[FER94] Ferscha, A.; Tripathi, S. K. Parallel and Distributed Simulation of Discrete Event Systems. Computer Simulation - Technical Report - 3336, Dept. of Computer Science, University of Maryland, College Park, MD, 1994.

[FIS95] Fishwick, P.A.; Lin, Y. B. Asynchronous Parallel Discrete Event Simulation. IEEE Transactions on Systems, Man and Cybernetics, v. 20, 1995. 
[FUJ90] Fujimoto, R. M. Parallel Discrete Event Simulation. Communications of the ACM, v. 33 , n. 10, 1990, 31-53.

[FUJ90a] Fujimoto, R. Performance of Time Warp under synthetic workloads. In

Proceedings of the SCS Multiconference on Distributed Simulation, v. 22, Society for Computer Simulation, 1990, 23-28.

[FUJ94] Fujimoto, R. M., Carothers, C. D., England, P., Effect of communication overheads on Time Warp performance: an experimental study. Proceedings of the $8^{\text {th }}$ Workshop on Parallel and Distributed Simulation, pp. 118-125, 1994.

[GRỌ94] Gropp, W.; Lusk, E.; Skjellum, A. Using MPI: Portable Parallel Programming with the Message-Passing Interface. MIT Press, Cambridge, MA, 1994.

[HAO96] Hão, F., Wilson, K., Fujimoto, R., Zegura, E., Logial Process Size in Parallel Simulations. In Proceedings of the 1996 Winter Simulation Conference, 645-652, 1996

[JEF85] Jefferson, D. R. Virtual Time. ACM Transaction Programming Language and System, v. 7, n. 3, 1985, 404-425.

[JHA94] Jha, V., Bagrodia, R., A Unified Framework for Conservative e Otimistic Distributed Simulation. Proceedings $8^{\text {th }}$ Workshop on Parallel Distributed Simulation, IEEE Computer Society, 1994, 12-15.

[KAL97] Kalantery, N.; Lengauer, C; Guebl, M.; Godatch, S. Tentative Time Warp. In lecture Notes in Computer Science L300, Springer-Verlag, 1997, 458-468.

[MAC87] MaCDougall, M. H., Simulating Computing Systems - Techniques and Tools. The MIT Press, 1987.

[MAR97] Martini, P.; Rümekasten, M.; Tölle, J. Tolerant Synchronization for distributed simulations of interconnected computer networks. In Proc of the $11^{\text {th }}$ Workshop on parallel and distributed simulation, Society for Computer Simulation, 1997, 138141.

[MIS86] Misra, J. Distributed Discrete-Event Simulation. ACM Computing Surveys, v. 18, n. $1,1986$.

[MOR00] Morselli, J. C. de M.Jr., Um Mecanismo para Troca de Protocolos de Sincronização de Simulação Distribuída em Tempos de Execução. Tese de Doutorado, Instituto de Física de São Carlos - USP, São Carlos, 2000.

[NIC93] Nicol, D.; Fujimoto, R. Parallel Simulation Today. Technical Report, College of William and Mary, 1993.

[OVE91] Overeinder, B.; Hertzberger, B.; Sloot, P. Parallel Discrete Event Simulation. 1991. 
[PHA00]

Pham, C. D.; Fdida, S. Relaxation of Synchronization Constraints in Parallel Simulation of ATM Network. [on line: http://citeseer.nj.nec.com/contextsummary/18068/0], Fevereiro, 2000.

[RAD96] Radhakrisnan, R., McBrayer, T. J., Subramani, K., Chetlur, M., Balakrishnan, V., Wilsey, P. A Comparative Analysis of Various Time Warp Algorithms Implemented in the WARPED Simulation Kernel. Proceeding of the Annual Simulation Symposium, ASS - 1996.

[RAD98] Radhaknshnan, R.; Martin, D. E.; Lur, M. C.; Rao, D. M.; Wilsey, P. A. An objectoriented time warp simulation kernel. In Proceedings of the International Symposium on computing in Object-Oriented Parallel Environments (ISCOPE'98), 1998.

[RAO98] Rao, D. M.; Thondugulam, N. V.; Radhaknshnan, R.; Wilsey, P. Unsynchronized Parallel Discrete Event Simulation. In Proceedings of the 1998 Winter Simulation Conference, 1998, 1563-1570.

[RIG89] Righter, R., Walrand, J. C., Distributed Simulation of Discrete event Systems. Proceedings of the IEEE, 99-113, 1989.

[SIL00]

[SPO01]

Silva, A. R. F., Modelos de Redes de Filas para Sistemas Computacionais Distribuídos: Simulação e Métodos Analíticos. Dissertação de Mestrado, Instituto de Ciências Matemática e Computação de São Carlos - USP, São Carlos, 2000.

Spolon, R., Um Método para Avaliação de Desempenho de Protocolos de Sincronização Otimistas para a Simulação Distribuída. Tese de Doutorado, Instituto de Física de São Carlos - USP, São Carlos, 2001.

[SPO99] Spolon, R., Santana, M. J., Santana, R. H. C. Distributed Simulation, Time Warp and its Variations: Taxonomy and Performance Evaluation Issues. Proceedings of the 13th European Simulation Multiconferece, Warsaw - Poland, 1999, 220-227.

[STE81] Stevenson, W. J., Estatística Aplicada à Administração. Editora HARBRA ltda, São Paulo, 1981.

[THÖ98] Thondugulam, N. V. Unsynchronized Parallel Discrete Event Simulation. Division of Research and Advanced Studies of the University of Cincinnati, 1998.

[THO99] Thondugulam, N. V.; Rao, D. M.; Radhaknshnan, R.; Wilsey, P. Relaxing casual constraints in PDES. In Proceedings of the $13^{\text {th }}$ International Parallel Processing Symposium, 1999, 696-700.

[ULS97] Ulson, Roberta S., Santana, Regina H. C., Santana, Marcos J., A Distributed Simulation Environment for Computing Systems Performance Evaluation. The Proceedings of the 1997 Summer Computer Simulation Conference, Arlington, Virginia, 1997. 
[ULS99] Ulson, R. S.. $\underline{\text { Simulação Distribuída em plataformas de portabilidade: viabilidade }}$ de uso e comportamento do protocolo CMB. Tese de Doutorádo, Instituto de Física de São Carlos - USP, São Carlos, 1999.

[VEE99] Vee, V.-Y., Hsu, W.-J., Parallel Discrete Event Simulation: A Survey. Center for Advanced Information Systems, SAS - Nanyang Technological University, 1999. 